\title{
WestVirginiaUniversity
}

THE RESEARCH REPOSITORY @ WVU

Graduate Theses, Dissertations, and Problem Reports

2021

\section{Modeling Gas Migration During a Gas Kick}

\author{
Ali Zankawi \\ alzankawi@mix.wvu.edu
}

Follow this and additional works at: https://researchrepository.wvu.edu/etd

Part of the Other Engineering Commons

\section{Recommended Citation}

Zankawi, Ali, "Modeling Gas Migration During a Gas Kick" (2021). Graduate Theses, Dissertations, and Problem Reports. 10344.

https://researchrepository.wvu.edu/etd/10344

This Thesis is protected by copyright and/or related rights. It has been brought to you by the The Research Repository @ WVU with permission from the rights-holder(s). You are free to use this Thesis in any way that is permitted by the copyright and related rights legislation that applies to your use. For other uses you must obtain permission from the rights-holder(s) directly, unless additional rights are indicated by a Creative Commons license in the record and/ or on the work itself. This Thesis has been accepted for inclusion in WVU Graduate Theses, Dissertations, and Problem Reports collection by an authorized administrator of The Research Repository @ WVU. For more information, please contact researchrepository@mail.wvu.edu. 
Graduate Theses, Dissertations, and Problem Reports

2021

Modeling Gas Migration During a Gas Kick

Ali Zankawi

Follow this and additional works at: https://researchrepository.wvu.edu/etd

Part of the Other Engineering Commons 
Modeling Gas Migration During a Gas Kick

Ali Zankawi

A thesis submitted to the

Benjamin M. Statler College of Engineering and Mineral Resources at

West Virginia University

In partial fulfillment of requirements for the degree of

Master of Science

In

Petroleum and Natural Gas Engineering

Mohamed El Sgher, Ph.D., Chair

Samuel Ameri, M.S.

Kashy Aminian, Ph.D.

Department of Petroleum and Natural Gas Engineering

Morgantown, West Virginia

2021

Keywords: Modeling Gas Migration During a Gas Kick

Copyright 2021 Ali Zankawi 


\title{
Abstract \\ Modeling Gas Migration During a Gas Kick
}

\begin{abstract}
Ali Zankawi
Gas kick is an undesirable problem in the oil and gas industry, which can potentially interfere with the production process and damage drilling equipment. The primary intent of this study is to highlight gas migration and its effect on gas kick mitigation approaches that would benefit the petroleum industry. The integrated analysis provides valuable insight regarding parameters promoting efficient drilling and production processes, Minimizing the risk of gas kicks. This study aimed to investigate the impact of critical parameters on gas migration during the gas kick in both water- and oil-based mud and promote the understanding of the dynamics of the choke pressure, gas velocity, and bottom-hole pressure based on completion and reservoir parameters.

This study reveals various factors affecting gas migration during gas kicks, characterized by different interactive parameters. These parameters include casing size, open hole size, drill-pipe size, drill collar size, kick volume, mud density, reservoir temperature, and circulation rate. This study used two base-models: Oil-Based mud and Water-Based mud. The models were used to perform several parametric studies to investigate the impact of critical parameters on gas migration during the gas kick. A commercial multiphase dynamic well control simulator was used in this study. Each type of mud acted differently and affected the gas migration discussed explicitly in this study. The study explicitly illustrates the different outcomes for each model during gas migration.
\end{abstract}

The parameters that range from most effective to least effective on gas migration are casing size, kick volume, drill-pipe size, mud density, and reservoir temperature, while in the OBM the parameters that range from most effective to least effective are casing size, kick volume, drill-pipe size, oil-water ratio, mud density, and reservoir temperature. However, the main differences are the gas rise velocity and time in the base models. In water-based mud, the Average gas velocity is $97.8 \mathrm{ft} / \mathrm{Min}$, while the average gas velocity in the oil-based mud is $75.6 \mathrm{ft} / \mathrm{Min}$. Thus, the waterbased mud is faster than the oil-based mud by 58\%. The gas is discharged from the well within 48.2 Minutes in the water-based mud, while the oil-based mud takes 115.7 Minutes. 


\section{DEDICATION}

"To my mother, my father, my 6rothers, my sister and my friends" 


\section{ACKNOWLEDGMENT}

First of All, I want to thank Dr. Mohamed El Sgher who supported and motivated me to continue working hard in order to accomplish this research. I would also like to thank Dr. Samuel Ameri for all his assistance and comfort not only to myself, but to all his students as well. Finally, I am extremely thankful for Dr. Kashy Aminian for his constant advice and aspiration to succeed.

Moreover, I want to personally thank my family for all their ongoing support, specifically my mother for always believing in me. She is the reason I am pursuing high academic goals, the least I could do is make her happy and a proud mother. In addition, I cannot forget about all the friends who motivated me to finish my research. A special thanks and appreciation go to Ibrahim Albuainain who helped me in times of need. Also, I want to thank Hamad Alsenan who supported and motivated me to do my best. 


\section{Table of Contents}

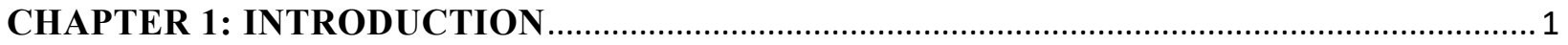

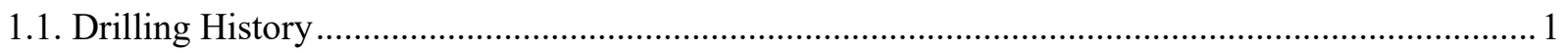

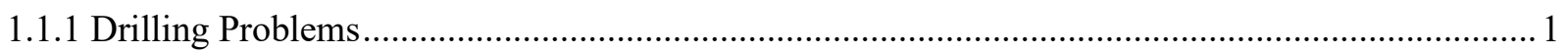

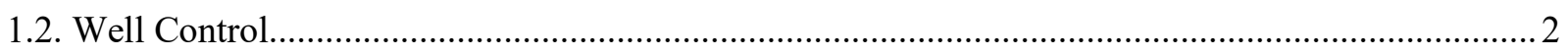

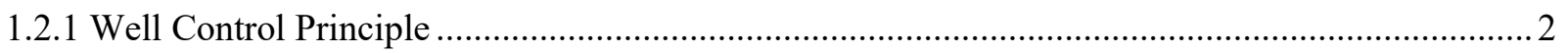

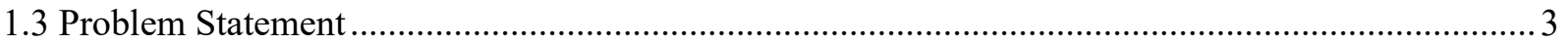

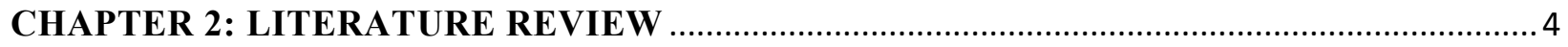

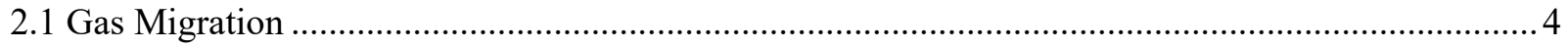

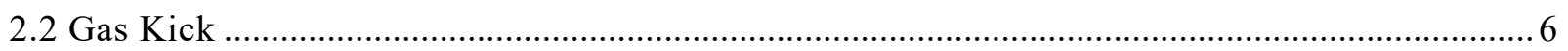

2.3 Well Control Methods …………………………………………………………………. 8

2.4 Previous Studies about Well Control …………………………………………….................

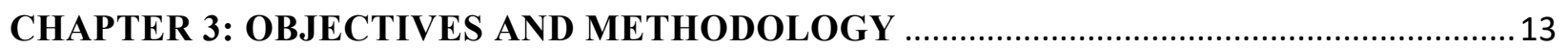

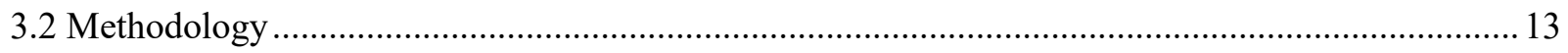

3.2.1 Model Development.......................................................................................................

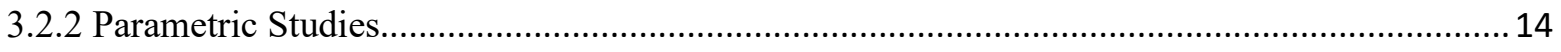

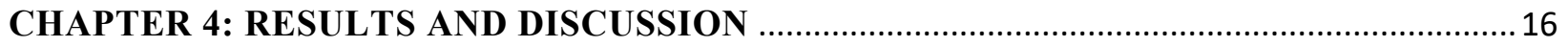

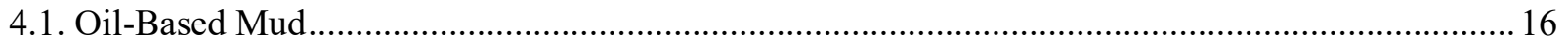

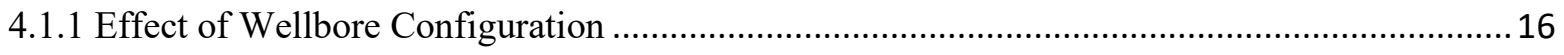

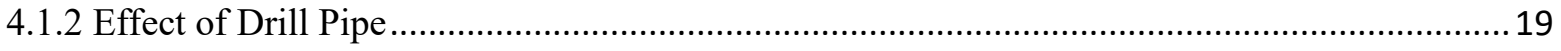

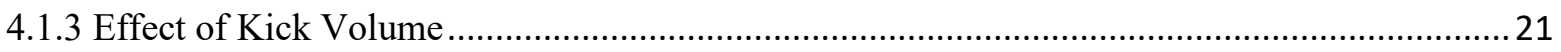

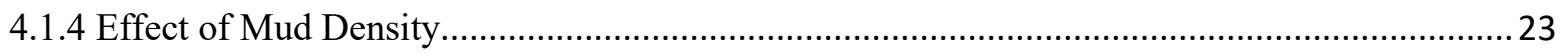

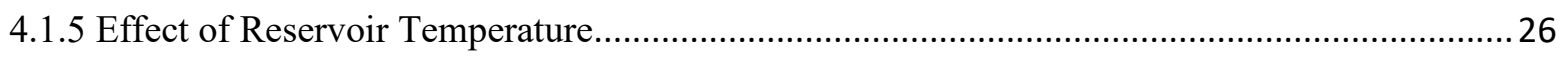

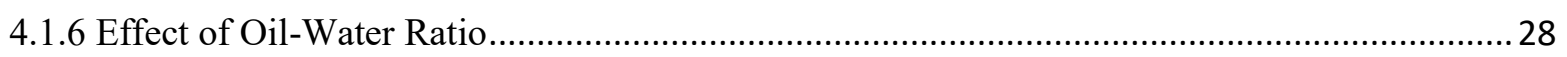

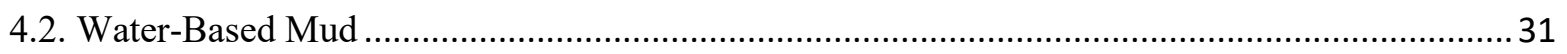

4.2.1 Impact of Wellbore Configuration ................................................................................... 31

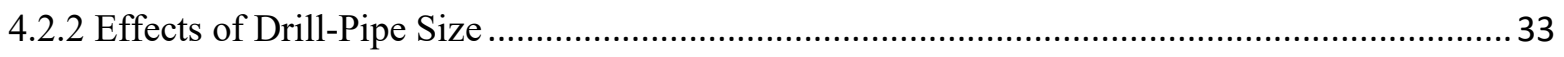

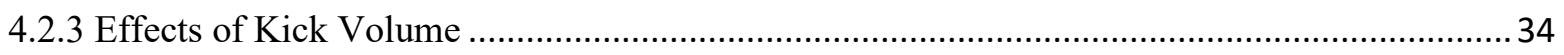

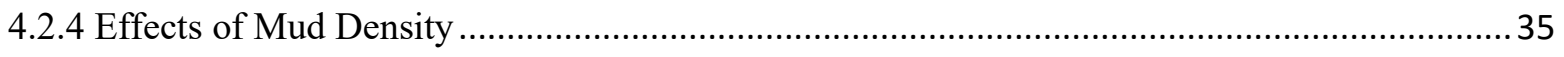

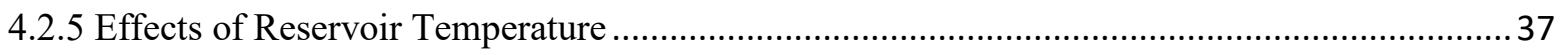

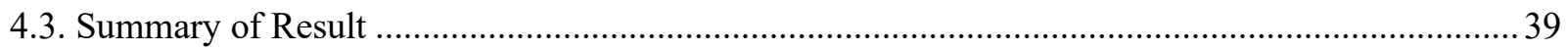




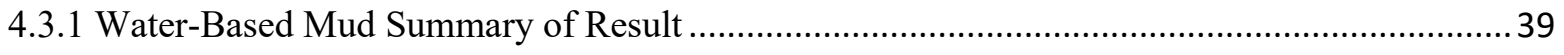

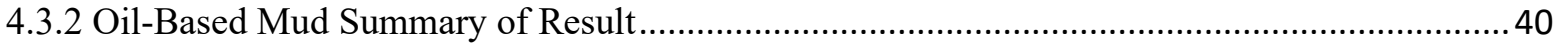

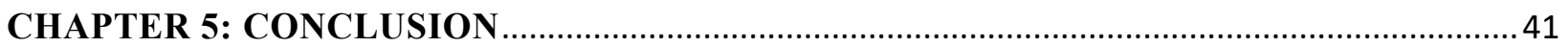

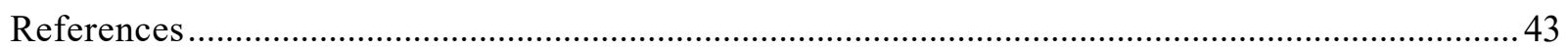




\section{List of Figures}

Figure 4. 1: Choke Pressure and BHP when the Gas Influx Reaches the Surface for Different Casing Sizes

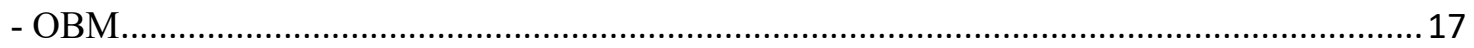

Figure 4. 2: Choke Pressure and BHP VS. Time for Different Casing Sizes - OBM .............................. 17

Figure 4. 3: Gas Velocity when the Gas Influx Reaches the Surface for Different Casing Sizes - OBM .. 18

Figure 4. 4: Gas Flow Rate for Different Casing Sizes - OBM ......................................................... 18

Figure 4. 5: Choke Pressure and BHP when the Gas Influx Reaches the Surface for Different Drill Pipe

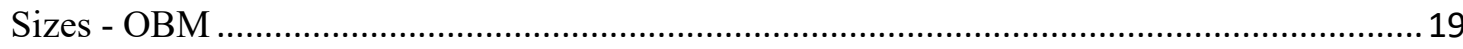

Figure 4. 6: Gas Velocity when the Gas Influx Reaches the Surface for Different Drill Pipe Sizes - OBM

Figure 4. 7: Choke Pressure and BHP VS. Time for Different Drill Pipe Sizes - OBM .........................20

Figure 4. 8: Choke Pressure and BHP when the Gas Influx Reaches the Surface for Different Kick

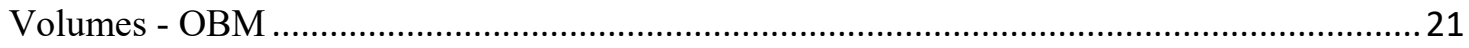

Figure 4. 9: Gas Velocity when the Gas Influx Reaches the Surface for Different Kick Volumes - OBM22

Figure 4. 11: Gas Flow Rate for Different Kick Volumes - OBM ..........................................................22

Figure 4. 10: Choke Pressure and BHP VS. Time for Different Kick Volumes - OBM ..........................23

Figure 4. 12: Choke Pressure and BHP when the Gas Influx Reaches the Surface for Different Mud

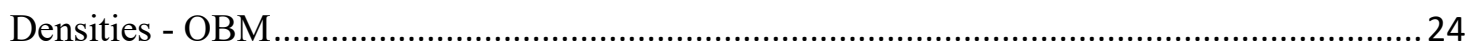

Figure 4. 13: Gas Velocity when the Gas Influx Reaches the Surface for Different Mud Densities - OBM

(a)

Figure 4. 14: Gas Flow Rate for Different Mud Densities - OBM ....................................................25

Figure 4. 15: Choke Pressure and BHP VS. Time for Different Mud Densities - OBM ...........................2 25

Figure 4. 16: Choke Pressure and BHP when the Gas Influx Reaches the Surface for Different Reservoir

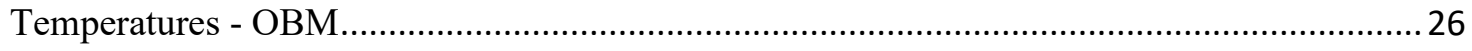

Figure 4. 17 Choke Pressure and BHP VS. Time for Different Reservoir Temperatures - OBM ............ 27

Figure 4. 18: Gas Velocity when the Kick Reaches the Surface for Different Reservoir Temperatures.... 27

Figure 4. 19: Gas Flow Rate for Different Reservoir Temperatures - OBM ......................................... 28

Figure 4. 20: Choke Pressure and BHP when the Gas Influx Reaches the Surface for Different Oil-Water

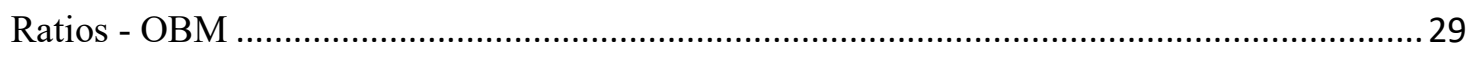

Figure 4. 21: Gas Flow Rate for Different Oil-Water Ratios - OBM ..................................................29

Figure 4. 22: Choke Pressure and BHP VS. Time for Different Oil-Water Ratios - OBM ........................ 30

Figure 4. 23: Solubility VS. Pressure (Monteiro. 2005) ..................................................................... 30

Figure 4. 24: Choke Pressure and BHP Pressure when the Gas Influx Reaches the Surface for Different

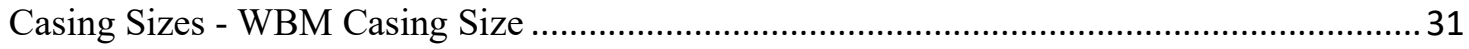

Figure 4. 25: Gas Velocity when the Gas Influx Reaches the Surface for Different Casing Sizes

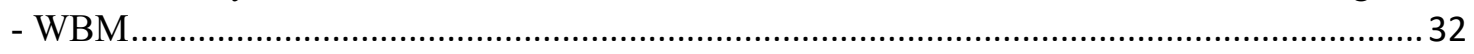

Figure 4. 26: Choke Pressure and BHP when the Gas Influx Reaches the Surface for Different Drill Pipe

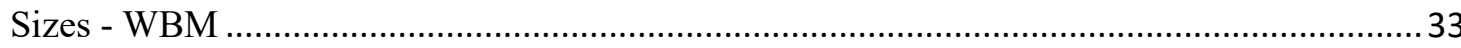

Figure 4. 27: Gas Velocity when the Gas Influx Reaches the Surface for different Drill Pipe

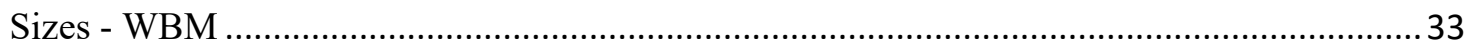

Figure 4. 28: Choke Pressure and BHP when the Gas Influx Reaches the Surface for Different Kick

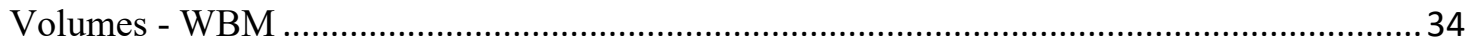

Figure 4. 29: Gas Velocity when the Gas Influx Reaches the Surface for Different Kick Volumes - WBM 
Figure 4. 30: Choke Pressure and BHP when the Gas Influx Reaches the Surface for Different Mud

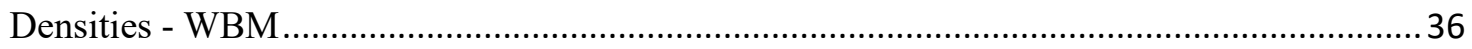

Figure 4. 31: Gas Velocity when the Gas Influx Reaches the Surface for Different Mud Densities -WBM

Figure 4. 32: Choke Pressure and BHP when the Gas Influx Reaches the Surface for Different Reservoir

Temperatures - WBM ...................................................................................................... 38

Figure 4. 33: Gas Velocity when the Gas Influx Reaches the Surface for Different Reservoir

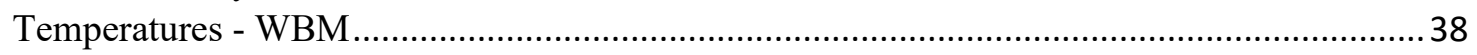

Figure 4. 34: Gas Velocity all Parameters when the Gas Influx Reaches the Surface - WBM..................39

Figure 4. 35: Time of Gas Migrates to the Surface All Parameters - WBM............................................ 39

Figure 4. 36: Gas Velocity all Parameters when the Gas Influx Reaches the Surface - OBM.................. 40

Figure 4. 37: Time of Gas Migrates to the Surface All Parameters - OBM.............................................40

Figure A 1: Gas flow rate for Different Drill Pipe Sizes - WBM..........................45

Figure A 2: Choke Pressure VS. Time for Different Drill Pipe Sizes - WBM......................... 45

Figure A 3: BHP VS. Time for Different Drill Pipe Sizes - WBM ..................................... 46

Figure A 4: BHP VS. Time for Different Kick Volumes - WBM ......................................... 46

Figure A 5: Gas Flow Rate for Different Kick Volumes - WBM ........................................... 46

Figure A 6: Choke Pressure VS. Time for Different Kick Volumes - WBM............................ 47

Figure A 7: BHP VS. Time for Different Mud Densities - WBM......................................... 47

Figure A 8: Choke Pressure VS. Time for Different Mud densities - WBM ........................... 48

Figure A 9: Gas Flow Rate for Different Mud Densities WBM............................................ 48

Figure A 10: Choke Pressure VS. Time for Different Reservoir Temperatures - WBM........... 49

Figure A 11: Gas Flow Rate for Different Reservoir Temperatures - WBM ........................... 49

Figure A 12: BHP VS. Time for Different Reservoir Temperatures - WBM........................... 50

Figure B1: Summary Page..................................................... 51

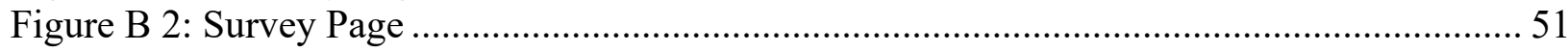

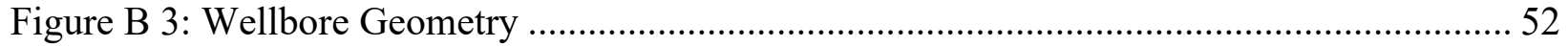

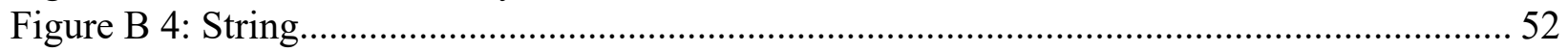

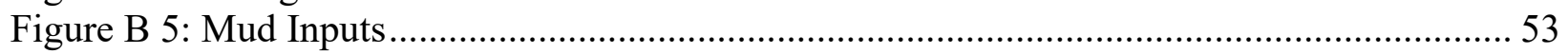

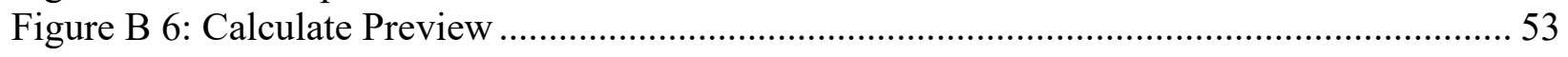

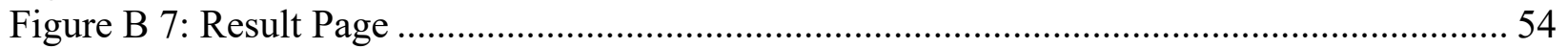




\section{List of Table}

Table 1: Base Model Parameters …………………...................................................................................................... 14

Table 2: Parameters and Their Values Used for Parametric Studies ...................................... 14

Table 3 Wellbore Configurations......................................................................................... 15

Table 4: Based-Model Results when the Gas Influx Reaches the Surface - OBM.................... 16

Table 5: Results of Different Casing Sizes when the Gas Influx Reaches the Surface - OBM.... 19

Table 6: Results of Different Drill Pipe Sizes when the Gas Influx Reaches the Surface -

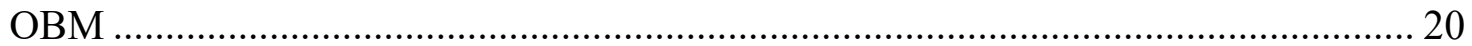

Table 7: Results of Different Kick Volumes when the Gas Influx Reaches the Surface OBM ... 23

Table 8: Results of Different Mud Densities when the Gas Influx Reaches the Surface - OBM. 26

Table 9: Results of Different Reservoir Temperatures when the Gas Influx Reaches the Surface -

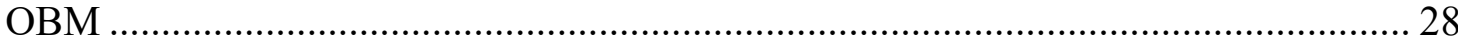

Table 10: Results of Different Oil-Water Ratios when the Gas Influx Reaches the Surface ....... 30

Table 11: Base-Model Results when the Gas Influx Reaches the Surface - WBM.................... 31

Table 12: Results of Casing Size when Gas Influx reaches the surface - WBM........................ 32

Table 13: Results of Different Drill Pipe Sizes when Gas Influx reaches the surface - WBM ... 34

Table 14: Results of Different Kick Volumes when Gas Influx Reaches the Surface - WBM .... 35

Table 15: Results of Different Mud Density when the Gas Influx Reaches the Surface - WBM 37

Table 16: Results of Different Reservoir Temperature when the Gas Influx Reaches the Surface WBM 


$\begin{array}{ll}\text { List of Symbols/ Nomenclature } \\ \text { BHA } & \text { Bottom-Hole Assembly } \\ \text { BHP } & \text { Bottom-Hole Pressure, psi } \\ \text { DC } & \text { Drill Collar, in. } \\ \text { DP } & \text { Drill Pipe, in. } \\ \text { MW } & \text { Mud Weight, ppg } \\ \text { OBM } & \text { Oil-Based Mud } \\ \text { SP } & \text { Surface Pressure, psi } \\ \text { WBM } & \text { Water-Based Mud }\end{array}$




\section{CHAPTER 1: INTRODUCTION}

\subsection{Drilling History}

Oil drilling began in the mid-19 century as mining companies sought to exploit underground hydrocarbon deposits. Consequently, oil drilling technology has evolved throughout the years with the increased need for efficiency in pumping petroleum from underground wells. In 1859, the first commercial production happened in Titusville, Pennsylvania, with the discovery of oil 70 feet below ground. At the time, oil rigs were wooden and easy to construct; however, they were significantly hazardous due to high blowout risks, and easy combustion. Throughout this period, drilling rigs evolved, and the rotary drill bit promptly developed as they drilled deeper and faster than the cable tools used in 1859. From 1900 to 1950, the oil industry experienced numerous blowouts, adversely affecting many companies. Consequently, in 1924, the first blowout preventer (BOP) was invented and considered a prominent innovation due to its efficiency. This period was a major milestone in the oil industry, which is particularly depicted through the improvement in the horizontal drilling process. In 1947, the first offshore rig was constructed, highlighting another milestone in the oil industry. In the 1950s, mechanical power was combined with the drilling rigs, thus increasing efficiency. Later in the 70 s, advanced control mechanisms emerged through the introduction of on-site generators into rig power components, promoting safety and productivity. Furthermore, technology advanced into the mid-90s with the development of precision

mechanisms that allowed directing drilling while maintaining rotation. The oil and gas industry technology has improved since the turn of the $21^{\text {st }}$ century, improving safety in high-risk environments and productivity. In 2006 in particular, horizontal pad drilling led to greater efficiency due to the full automation of rigs.

\subsubsection{Drilling Problems}

Oil and gas drilling are a significantly expensive venture, with workers citing the challenges of onshore and offshore drilling. Thus, petroleum drilling companies consider efficiency a fundamental issue, seeking Minimum risks and cost. Notably, the major well control problems experienced by companies include gas migration, gas kick, high formation pressure, a rapid increase in ROP, loss circulation, and blowout. 
To achieve the companies' economic and production targets, efficient well control is significantly emphasized. Having well control while drilling improves the outcomes for the companies. The well control measures significantly help in the development of appropriate reactionary approaches. Well control is a significant aspect of the oil industry given the cost of production, personnel safety, and uniform exploitation of natural resources.

\subsection{Well Control}

Well control is a technique used in oil and gas operations such as drilling, well workover, and well completion. Well control involves maintaining the hydrostatic pressure and formation pressure to avoid an influx into the wellbore. In addition, the approach involves estimating fluid formation pressure, the subsurface formation's strength, and the use of casing and mud density to predictably offset pressure. The main objective of well control is to efficiently and safely complete a well without any environmental effects or errors.

The well control or blowout prevention system (BOP) on a drilling rig is the system that prevents the uncontrolled catastrophic release of high-pressure fluids from the subsurface formation. BOP is the principal method in a well control system and is operated hydraulically; pressurized fluids are used to operate pistons and cylinders to open and close valves on the BOP; accumulators are used to stop the pressurized hydraulic fluid from running the hydraulics system on the rig. Accumulators store enough compressed energy to operate the blowout preventer even if the rig's power system is not operating.

\subsubsection{Well Control Principle}

The principle of well control, promotes efficient control of well control systems, guaranteeing accurate and safe working environments. The most common problems facing companies in the oil industry are blowouts and kicks. Kicks occur frequently while drilling. Multiple and Minute kicks can grow into big blowouts due to improper handling of well controls. 


\subsection{Problem Statement}

The main idea of this study is that when the driller begins the drilling process, in any well in the industry, with the bottom-hole pressure being less than the pore pressure, a kick starts to enter the wellbore. The impact of casing size, hole size, mud density, reservoir temperature, drill-pipe size, and kick volume on gas migration during a gas kick is explored in this study. In addition, the study examines the differential outcomes of bottom-hole pressure, chock pressure, and casing shoe pressure when the gas influx enters the well bore while using oil-based or water-based mud. 


\section{CHAPTER 2: LITERATURE REVIEW}

\subsection{Gas Migration}

Different authors have discussed gas production and migration, such as Nastev et al. (2001) According to the authors, landfill gas is produced due to the "micro-bialy mediated degradation of the organic portion of waste." This means that after the waste disposition, aerobic conditions cause decomposition in a process that generates heat and carbon dioxide. The resulting gas comprises organic compounds, primarily methane and carbon dioxide. In addition, the authors indicate that composition and pressure variations exist in the produced gas throughout its active lifecycle - the generation of carbon dioxide and methane results in increased pressure as well as corresponding partial pressures. The pressure gradient changes cause gas advection, while the concentration differences result in gas diffusion. It is also essential to understand that the generation of heat might also result in gas migration, considering the impacts of heat on the gas's thermodynamic properties.

Tissot and Welte (1978) explored the process of gas migration. According to the authors, it is common to find petroleum accumulations in regions with relatively coarse-grained permeable and porous rocks, where there is no organic matter. This means that the petroleum did not originate from these rocks, which means they have no organic matter. The authors state that "fluid petroleum compounds are generated in appreciable quantities only through geothermal action on high molecular weight organic kerogen usually found in abundance only in fine-grained sedimentary rocks and that usually, some insoluble organic residue remains in the rock at least through the oilgenerating stage." Therefore, the authors conclude that the place of origin of petroleum is not the same place where it is found in economically producible regions. Overall, the idea of gas migration refers to the movement of petroleum gas from the place of origin to the place of generation as a result of numerous factors (Nastev et al., 2001; Tissot \& Welte, 1978).

In the study of gas migration, it is essential to understand other aspects, such as the sources of gas migration, the implications of the process, and the various ways and measures for preventing the migration. Numerous sources and causes of gas migration have been explored. For example, Chafin (1994) mentioned that amongst the significant gas migration sources natural fractures are to be included. Natural fractures such as joints and faults are potential natural gas pathways migrating from deep gas-bearing formations in substantial quantities. Artificial conduits represent another cause and source of gas migration. This is because most near-surface natural gas migration 
is associated with conditions linked to the gas well. Chafin concluded that "man-made migration conduits introduce most near-surface gas." This means that these human-made conduits are mainly responsible for the migration of gas near the wells' surface.

Reservoir permeability is another factor that causes gas migration. Lin et al. (2020) mentioned that "reservoir permeability affects reservoir gas distribution in low-permeability reservoirs." These reservoirs contain highly permeable sandstone, which has pores that allow the movement of gas molecules from one region to the other. The authors conclude that gas migration is characterized by factors such as permeability. In addition to permeability, other factors include gas flow and migration force. Therefore, a reservoir's permeability can be another significant factor that contributes to gas migration.

Gas migration can have several effects. Guner, Elshehabi, and Bilgesu (2017) mentioned that it remains critical to have a deeper understanding of the dynamic behavior of undesired reservoir influxes, as well as the consequences that might result in well control emergencies. An example of an event that might result in an influx in a reservoir is gas migration. As mentioned, gas migration refers to gas movement from the place of production to where it can be commercially accessed and extracted (Nastev et al., 2001; Tissot \& Welte, 1978). This movement can result in reservoir influxes triggering emergencies. Pennoyer (2013) also explored the issue of gas migration as the movement of stray gas and how it affects the environment. According to the author, stray gas is the "subsurface sourced gas that shows up where you don't want it." The author explores several impacts of stray gas migration, mentioning that it might undermine the well integrity, such as its cement job or casing.

The implications of stray gas migration can be divided into several categories. For instance, there are subsurface impacts of the migration to the environment and resources. Among the impacts are fluid spills, habitat fragmentation, and air emissions (Pennoyer, 2013). There are also potential effects of gas migration of subsurface resources. According to Penoyer, the subsurface impacts can be realized through hydraulic fracturing processes. This results from the induced fractures or pathways made by the migrating gas. Stray gas migration also affects wellbore design and construction. As mentioned, migration can undermine wellbore integrity by resulting in barrier failures such as cement and casting. It might also result in missed isolation zones such as nuisance gas and show intervals. Overall, gas migration can affect the wellbore as well as the resources around it. It might also induce hydraulic fracturing, which can contaminate freshwater sources. 
There are various ways of preventing gas migration as well as the resulting negative implications. In an article aimed at improving cementing practices to prevent and control gas migration, Pour and Moghadasi (2007) started by mentioning that within the oil and gas industry, the migration of gas through cement columns has been a major problem. Gas migration undermines the integrity of a well, and as a result, it increases the likelihood of primary cement job failures. Taking the case of the Iranian South Pars Field, the authors mention that gas migration happens when the Kangan and Dalan formations are being drilled. It is a common practice that cement densities used in controlling gas influx are typically 120 PCF. However, the previous methods have been ineffective, and the authors have proposed a specially formulated cement that has a higher rate of static gel strength.

Crook and Heathman (1998) have also proposed several gas migration control systems. The authors start by proposing "a hands-on, interactive analysis system [which] can model downhole conditions." According to the authors, such a program remains useful in any gas flow situation since it allows for practical evaluation of gas migration control techniques through the help of the gas flow potential factor. Through such simple design factors, companies and stakeholders within the oil and gas sector can effectively reduce gas-flow potentials at reduced prices. The authors have further described how to control Minor, moderate, and extreme gas-flow potential conditions. In the case of Minor conditions, fluid-loss control additives, coupled with changing some elements of the job design, can help. In the case of moderate gas-flow potential conditions, exceptional fluid-loss control measures should be adopted. This means supplementing standard cement slurry with additives to slow the slurry's static gel strength development. As compared to traditional designs, this design results in a slower transmission of hydrostatic pressure. This means that as the cement starts to gel, the rate of filtrate loss reduces.

\subsection{Gas Kick}

In addition to gas migration, another phenomenon evident within the oil and gas industry is a gas kick. Different authors have attempted to define the process or concept of gas kick. For instance, Yin et al. (2019) noted that a gas kick refers to "the uncontrolled influx of formation fluid or gas into the wellbore, which occurs when the wellbore pressure at a certain location is less than the formation pressure and requires a well control emergency plan." A gas kick can also be defined as the influx of gas from drilled formations into the wellbore, resulting in an interruption in the 
drilling operations (Guner et al., 2017). An influx in liquids often increases pressure. Therefore, it remains essential to understand that a gas kick can result in much more adverse impacts than a liquid kick. This can mainly be attributed to the fact that gas tends to expand, and as a result, there is a higher variation in pressure (Yin et al., 2019).

Guner et al. (2017) mentioned that numerous factors can contribute to a gas kick, and key among these factors is the pressure underbalanced between the dynamic bottom hole pressure and the drilled formation pressure. As the gas expands, the bottom hole pressure reduces, resulting in more gas invasion. Additional factors that might contribute to gas kicks include a lack of awareness from the crew, improper or delayed actions, and equipment failure, which can trigger uncontrolled underground and surface blowouts. Such blowouts can pose significant threats to the safety of the drilling crew and the entire process. Therefore, it remains essential to detect gas kicks to prevent any negative implications that might result.

Detecting gas kicks means that relevant stakeholders within the oil and gas industry should implement different kick detection methods and systems. Yin et al. (2019) mentioned that there have been numerous and significant efforts that have been devoted to detecting kicks in the new oil and gas sector. In this sector, gas kick detection methods have evolved from simple methods to more intelligent and complex ones, owing to growth in technology such as machine learning. Many kick detection methods and systems in the modern oil and gas sector include an "integrated patternrecognition model consisting of a dynamic multiphase wellbore flow model and improved piecewise approximation and similarity measure algorithms for kick diagnosis". There can also be a cyber-physical approach towards detecting gas kicks, as it involves a combination of Bayesian mathematics and physics-based modeling. The Bayesian probabilistic framework can also be adapted to detect gas kicks in earlier stages depending on noisy drilling data. Modern machine learning techniques can also be used in reducing kick alarm rates while at the same time increasing the probability of kick detection. It is also possible to apply new noise reduction and pattern recognition signal processing to produce more informative and earlier notifications on kick detection. All those mentioned above are among how gas kicks can be detected at earlier periods to allow room for adopting approaches to reduce the impacts of the kicks.

Zhou Q et al. (2017) also proposed a kick detection method based on continuous Doppler ultrasonic waves. The authors have divided gas kick detection methods into intervention and nonintervention detection. The intervention method involves destroying the annulus structure, making 
it highly risky and costly. Non-intervention methods include ray imaging detection, pressure detection, and ultrasonic detection. The authors conclude that out of the approaches, the ultrasonic method has several advantages since it is a "non-intervention, low cost, mature technology, and [offers] environmental protection." This means that it can be more useful for detecting gas kicks to prevent the adverse effects that might otherwise result.

Because gas kicks can have adverse environmental and economic impacts, it remains essential to stakeholders in the oil and gas sector to understand the various ways of controlling gas kicks. Jahanpeyma and Jamshidi (2018) mentioned that there can be different gas kick control methods that are useful. Among them are the driller's method, the wait and weight method, and the concurrent method. These methods allow drilling crews to effectively remove the kick fluid from the well, filling the well with a heavier mud proportional to the developing pressure gradient instead. It is also important to understand that when using the methods as mentioned earlier, the "bottom-hole pressure should remain constant during the operation utilizing alternating pump speed and choke opening and closing. Additionally, the methods allow the crew a chance to close the choke and analyze the well's conditions at any step of the overall operation. When new mud reaches the drill bit at the bottom hole, the resulting pressure should be constant. Jahanpeyma and Jamshidi also cited several kick controls measures proposed by different authors. According to the authors, the primary methods include a "control process applying mass and momentum balance and auxiliary equations for liquid and gas phases to calculate density and gas speed values in any region of the well." A simulated well control process can also be used, where the mass and momentum balance and auxiliary equations can be used in simulating water-based mud and gas kick type. Another method involves using an advanced simulator that allows the prediction of standpipe and choking pressure. This can be used in deep-water horizontal wells that are typically based on dynamic bottom-hole pressure.

\subsection{Well Control Methods}

When a kick arises, the well should be shut-in (close the well), using one of the three methods to circulate the kick out of the wellbore and to keep the well under control. In the beginning, the shut-in happens in two ways. The two approaches are soft shut-in and hardshut-in. The soft shut-in procedure is the remote choke, which must be in an open position, while the blowout preventer is closed. The high closing reaction valve should be opened, and the remote choke closed, followed by recording pressures. The other method is hard shut-in, 
which starts with the closed remote choke and the blowout preventer shut-in, while the high closing reaction valve is opened and followed by recording the pressures (Watson et al., 2003). The hard shut-in is the fastest way to shut-in the well.

The two methods used to circulate the kick out of the wellbore are the driller's method and the wait and weight method. The driller's method procedure is used to shut in the well, obtain record casing and drill pipe pressure, calculate the kill mud weight, start up the pump by holding casing pressure constant, and pump old mud and circulate the kick out of the hole while keeping drill pipe pressure constant. After a kick circulated out of a wellbore, then the casing shut-in pressure try to stabilize. Then, the pressure is switched to constant drill pipe pressure and circulates the kill mud until it flows out of the choke, shutting down pumps by holding casing pressure constant, and checking casing pressure and drill pipe pressure to make sure both are zero psi. If both pressures are zero psi, this method completes the circulation kick out of the well (Zheng Shen., 2015). The procedure of the wait and weight method is to shut-in the well and get casing pressure and drill pipe pressure, calculate the kill mud weight, and mix the kill mud, then start up the pump by holding casing pressure constant and pump the kill mud and circulating the kick out of the hole, while keeping bottom-hole pressure constant, manipulating the choke to make sure drill pipe pressure to remain constant, and to follow the pressure reduction schedule.

\subsection{Previous Studies about Well Control}

Mohammad Rahman (2019) modeled four situations for both aqueous and oil-based drilling fluid. The model includes a situation where there is single gas bubble kick migration with circulation in the annulus and another with no circulation in the annulus; the other two situations are kick migration with a constant gas influx with circulation in the annulus and no circulation in the annulus. While modeling the single bubble kick migration with no mud circulation in the annulus, the gas bubble starts rising in the annulus, and the hydrostatic pressure starts decreasing, which causes the bubble to expand; however, the presence of drilling mud both above and below the gas bubble restricts its expansion. As a result of this situation, the gas expands five times its initial volume and produces a total pit gain of 25.6 bbl. This also increased the WHP from 532 psi to 614 psi. In the second situation, the same procedure was taken except for the friction added because of the circulation. The second 
situation is the kick reaching the wellhead after 35 Minutes, and the gas expanding more than five times the initial volume. The total pit gain volume was 26.5 bbl., and the WHP increased from 515 psi to 596 psi. Modeling the third situation, which is constant gas influx kick migration with no mud circulation, Mohammad Rahman uses the Hassan-Kabir model (Hassan \& Kabir, 2018) to simulate two-phase flow in the annulus. In this model, the influx of gas affects gas expansion and migration because the new incoming bubbles increase the pressure above them. As a result, for this situation, the first gas bubble reaches the wellhead after 4.45 hours, the gas volume fraction goes up to 0.045 near the wellhead, the wellhead pressure went up to $72 \mathrm{psi}$, from 514 to $586 \mathrm{psi}$, and the pit gain in this situation increases exponentially. The last situation is the constant gas influx kick migration with mud circulation. This situation's procedure is like the previous situation; the only difference is that the mud circulation cannot ignore the frictional pressure drop from the drilling mud. As a result, the gas bubble reached the wellhead in 52 Minutes, with a total pit gain of $3.8 \mathrm{bbl}$. and the wellhead pressure went up to $14 \mathrm{psi}$, from 506 psi to 520 psi.

Raheel Zubairy (2014) studied the increase of the wellbore pressure during a gas kick while assuming the bottom-hole pressure constant. This study's model calculated the pressure drop in the two-phase annulus using the mechanistic method provided by Hasan and Kabir (2002). The annulus pressure after the gas kick increases as the gas migrates up to the annulus; as the kick migrates up, the two-phase fluid density decreases because of the expansion due to lower pressures on the mixture gas as it approaches the surface. Since the gas migrates, the annulus's temperature keeps increasing from the initial temperature because of the mixture's density changing. The pit gain in this model was around 84 bbl.

Bjorn Gjorv (2003) performed an extensive simulation study of vertical, directional, horizontal, and ERD wells by using the two-phase well control simulator developed by Choe and Juvkam-Wold. The model is based on unsteady-state two-phase flow, water-based mud, one-dimensional flow along the flow path, kick occurring at the bottom of the well while drilling, and gas influx rates calculated from the formation assuming an infinite acting reservoir. As a result of this model, the kick size causes an increase in the maximum choke pressure with the TVD of the well. The kick size was around $10 \mathrm{bbl}$. in a deep well, with maximum choke pressure of kick sizes of 100 and $200 \mathrm{bbl}$. The kick size increases from 10 
to 50 barrels which the gas and mud are mixed through the choke, and for a more considerable amount of gas kick, only dry gas is circulated through the choke when higher pressure is observed. Increasing the bottom-hole pressure must stop the gas influx, which causes an increase in the choke pressure.

Fjelde et al. (2016) studied gas kick migration velocities and uncertainty. This study aimed to discuss the accuracy of the gas kick slippage model used in the transient flow. Three cases were studied in this model. A vertical well is considered in both cases 1 and 2, which is assumed to be 4000 meters deep while case 3 is 2000 meter less depth. The annulus outer diameter is assumed to be 0.331 meters and an inner diameter of 0.127 meters, which gives an annular flow area equal to 0.0634 -meter square and well volume of a 253 -meter cube. Water with compressibility that is related to sonic velocity is used as drilling fluid, which is equal to 1500-meters per second. The kick influx is assumed to be an ideal gas with a sonic velocity of 316-meters per second. The initial kick volume is a 4.1 -meters cube for both case 1 and case 2; the kick volume for case 3 is an 8.2-meter cube. The kick was introduced by using the gas mass rate of 16-kilograms per second. For 10 seconds, the well-kept static, then the gas mass rate was ramped up during a 10 second period. The well closed in 130 seconds, and the kick started migrating to the surface, leading to the pressure build-up, which continued until the kick reached the wellhead.

In case 1, there are two orders. The number of cells used in both methods varies between 25 to 100 cells. A slug flow model had considered, using $\mathrm{K}=1.2$ and $\mathrm{S}=0.55$-meters per seconds. The gas kick expands a little when migrating towards the wellhead because the liquid is slightly compressible. The pressure would stabilize after around 7300 seconds; however, when using 100 cells, it seems that the kick migrates faster than expected. The kick would need around 7300 seconds to reach the surface; that is the first-order method. In the second-order method, the results were obtained for 25 to 50 cells, and for the case with 50 cells, it seems that the pressure stabilized at a time similar to the first-order method, which is 7300 seconds. Also, the second-order method seems to reduce the negative liquid velocity. Comparing the higher cells method to the lower cells method guarantees an accurate result without introducing too many cells. 
In case 2, the main objective is to compare the difference in simulation results when considering bubble flow vs. slug flow. The simulation data, in this case, is similar to the previous case. For bubble flow, the $\mathrm{S}=0.23$ meters per second and $\mathrm{L}$ are varied between 1.0 to 1.2. For slug flow $K=0.55$ meters per second and $K=1.2$. For bubble flow, the kick is expected to reach the wellhead at 17,390 seconds, and the slug flow should reach the wellhead at 7270 seconds. Since the $\mathrm{S}$ value is too large, the 50 cells are used in this case. In the first order, the liquid velocity is negative because it almost balances with the gas velocity $\mathrm{S}$, which the gas velocity is almost zero, and it cannot be responsible for the transportation of the kick. After running the second-order method with only 25 cells, the predicted time for gas to reach the surface complements the expected numbers. However, using the first order with 25 cells in combination with the bubble model, it can also be concluded that the final pressure cannot be reached because the small amount of gas seems to be trapped in the well, which causes an error in the velocity field. In conclusion, in the first order, the result is quite unrealistic; however, when using the second-order method for bubble flow while using a $\mathrm{k}$ value equal to 1.0 or 1.2 , it gives the same result for a closed well.

In case 3, an 8.2-meters cube kick introduces a 2000 meter well, the well shut-in, and the gas migrates upward to the surface. For this case to suspend a smaller amount of gas in the well, the slip relation is modified to a no-slip condition where the $\mathrm{K}=1.0$ and $\mathrm{S}=0$; however, for the bubble model flow, the $\mathrm{K}=1.0$ and $\mathrm{S}=0.23$-meters per second. The pressure builds up and the gradient lowers when the gas trapped percentage increases, which also leads to the reduction of the final pressure. There are four different answers emerging by deducting the $\mathrm{S}$ value; however, only one is accurate and realistic. The real solution for this case is revealed when the gas value increment is specified in the model where slip relation is equal to 0.23 -meters per second. Fjeldeet al. (2016) concluded that using transient flow models can give valuable insight into the dynamics of kick migration; however, an error that occurs is potential in this case. In addition, while using the numerical method for multiphase flow, it is essential to understand the potential error. 


\section{CHAPTER 3: OBJECTIVES AND METHODOLOGY}

\subsection{Objectives}

This study aimed to investigate the impact of critical parameters on gas migration during gas kick situations in both water-based mud and oil-based mud and promote an understanding of the dynamics of the choke pressure, gas velocity, and bottom-hole pressure regarding different completion and reservoir parameters.

\subsection{Methodology}

To accomplish the objective of this study, a methodology consisting of the following steps was implemented:

1. Model development in commercial multiphase dynamic well control simulator

2. Sensitivity analysis to investigate the impact of casing size, hole size, mud density, kick volume, drill-pipe size, solubility, and reservoir temperature on gas migration during the gas kick

\subsubsection{Model Development}

In this study, a commercial multiphase dynamic well control simulator was used to investigate the impact of each parameter on the gas migration during a gas kick in both waterand oil-based mud. The well control method is identified as the driller method (twocirculation method). A literature review has been done, determining the parameter for the base model. This study establishes the water-based and oil-based mud models. The difference between the two base models is the type of drilling mud. The base model parameters are shown in Table-1. 
Table 1: Base Model Parameters

\begin{tabular}{|c|c|c|}
\hline Base Model Parameter & Values & Units \\
\hline Casing Size & $85 / 8^{\prime \prime}$ & \\
\hline Hole Size & $61 / 2^{\prime \prime}$ & \\
\hline Drill Collar & 4" & \\
\hline Drill Pipe & 3 1/2" & \\
\hline Depth & 7000 & ft. \\
\hline Reservoir Pressure & 5360 & Psi \\
\hline Reservoir Temperature & 200 & ${ }^{\circ} \mathbf{F}$ \\
\hline Kick Volume & 15 & Bbl \\
\hline Mud Weight & 12 & ppg \\
\hline
\end{tabular}

\subsubsection{Parametric Studies}

A sensitivity analysis was done to associate the impact of each parameter on the gas migration during the gas kick. Each run for the sensitivity analysis contains three different values for each parameter. Table 2 shows all ranges for each parameter. Furthermore, the oilwater $(\mathrm{O} / \mathrm{W})$ ratio for oil-based $(\mathrm{OBM})$ was changed to investigate its impact on the gas migration during the gas kick. Each casing size require a specific hole size. Table 3 shows the wellbore configuration for each run.

Table 2: Parameters and Their Values Used for Parametric Studies

\begin{tabular}{|c|c|c|c|}
\hline Base Model Parameters & Value & Range & Units \\
\hline Casing Size & $85 / 8 "$ & 8 5/8" - 7" & \\
\hline Hole Size & $61 / 2 "$ & $61 / 2 "$ - $57 / 8 "$ & \\
\hline Drill Pipe & 3 1/2" & 3 1/2" - 2 3/8" & \\
\hline Reservoir Temperature & 200 & $300-350$ & ${ }^{\circ} \mathbf{F}$ \\
\hline Kick Volume & 15 & $15-30$ & Bbl \\
\hline Mud Weight & $12(5360 \mathrm{psi})$ & $\begin{array}{c}10.33 \text { (5360 psi) -12 } \\
(4760 \mathrm{psi})\end{array}$ & ppg \\
\hline OWR & $80 / 20$ & $50 / 50-80 / 20$ & \\
\hline
\end{tabular}


Table 3 Wellbore Configurations

\begin{tabular}{|c|c|c|}
\hline \multicolumn{3}{|c|}{ Base Model } \\
\hline Casing & Casing (OD) & Casing (ID) \\
\hline Conductor & $16 "$ & $151 / 4^{\prime \prime}$ \\
\hline Surface & $10^{3 / 4 "}$ & $93 / 4 "$ \\
\hline Intermediate & $85 / 8^{\prime \prime}$ & 8" \\
\hline Hole Size & \multicolumn{2}{|c|}{ 6.5" } \\
\hline Drill Collar & \multicolumn{2}{|c|}{ 4" } \\
\hline Drill Pipe & \multicolumn{2}{|c|}{$31 / 2^{\prime \prime}$} \\
\hline \multicolumn{3}{|c|}{ Run 1} \\
\hline Casing & Casing (OD) & Casing (ID) \\
\hline Conductor & 16" & $151 / 4^{\prime \prime}$ \\
\hline Surface & $10^{3 / 4 "}$ & $93 / 4 "$ \\
\hline Intermediate & $75 / 8 "$ & $67 / 8^{\prime \prime}$ \\
\hline Hole Size & \multicolumn{2}{|c|}{$61 / 8^{\prime \prime}$} \\
\hline Drill Collar & \multicolumn{2}{|c|}{ 4" } \\
\hline Drill Pipe & \multicolumn{2}{|c|}{3 1/2" } \\
\hline \multicolumn{3}{|c|}{ Run 2} \\
\hline Casing & Casing (OD) & Casing (ID) \\
\hline Conductor & $16 "$ & $151 / 4 "$ \\
\hline Surface & 10 3/4" & $93 / 4 "$ \\
\hline Intermediate & 7" & $61 / 5^{\prime \prime}$ \\
\hline Hole Size & \multicolumn{2}{|c|}{$57 / 8^{\prime \prime}$} \\
\hline Drill Collar & \multicolumn{2}{|c|}{ 4" } \\
\hline Drill Pipe & \multicolumn{2}{|c|}{3 1/2" } \\
\hline
\end{tabular}




\section{CHAPTER 4: RESULTS AND DISCUSSION}

The results were obtained using a commercial multiphase dynamic well control simulator to understand and investigate the impact of parameters on gas migration during a gas kick in both WBM and OBM. The results are divided into two sections: water-based mud and oil-based mud. The driller method was used in both sections.

\subsection{Oil-Based Mud}

This section investigates the impact of oil-based mud on gas migration during a gas kick and how it would impact the pressure behavior while the gas migrates to the surface. The concept of oil-based mud involves starts with dissolving the gas into the mud. Table 4 shows the result of OBM base-model.

Table 4: Based-Model Results when the Gas Influx Reaches the Surface - OBM

\begin{tabular}{|c|c|c|c|c|}
\hline Base Model & $\begin{array}{c}\text { Choke } \\
\text { Pressure (Psi) }\end{array}$ & BHP (Psi) & $\begin{array}{c}\text { Average gas velocity } \\
\mathrm{ft} / \mathrm{s}\end{array}$ & Time (Min) \\
\hline Oil-Based Mud & 3504 & 7903 & 1.26 & 115.7 \\
\hline
\end{tabular}

\subsubsection{Effect of Wellbore Configuration}

Casing size has a significant impact on gas migration. It affects the gas velocity once the influx enters the wellbore. In this model, three different casing sizes have been used to investigate the impact of this parameter while using oil-based mud. The OBM has a different impact on gas migration due to the ability of the influx to migrate into the mud. By increasing the casing size, it increases the pressures and decreases the amount of the gas dissolved into the mud. $85 / 8$ " has the highest percentage of dissolved gas, while 7" has the lowest percentage of gas dissolved into the mud. The OBM impacts the gas migration differently because the gas in the OBM expands after reaching the bubble point pressure. By comparing the choke pressure and the BHP, the smallest casing and hole size have the highest choke pressure, increasing the BHP as shown in Figure 4.1 

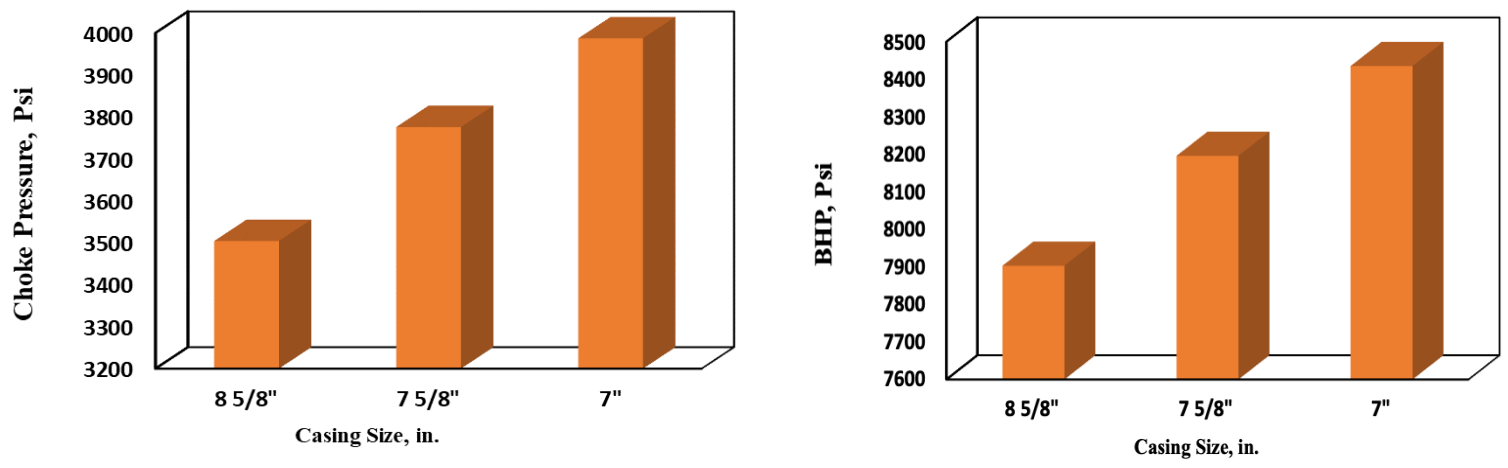

Figure 4. 1: Choke Pressure and BHP when the Gas Influx Reaches the Surface for Different Casing Sizes - OBM

The choke pressure and BHP acted differently in the OBM. As shown in Figure 4.1, the choke pressure was stabilized until the gas influx reached the surface where the expansion occurred as shown in Figure 4.2.

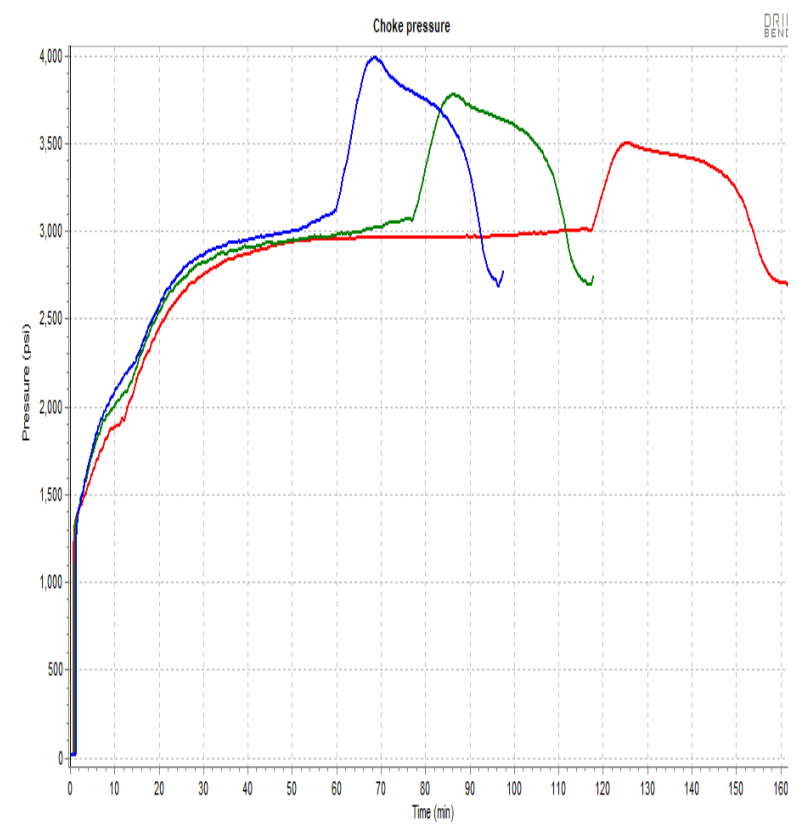

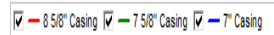

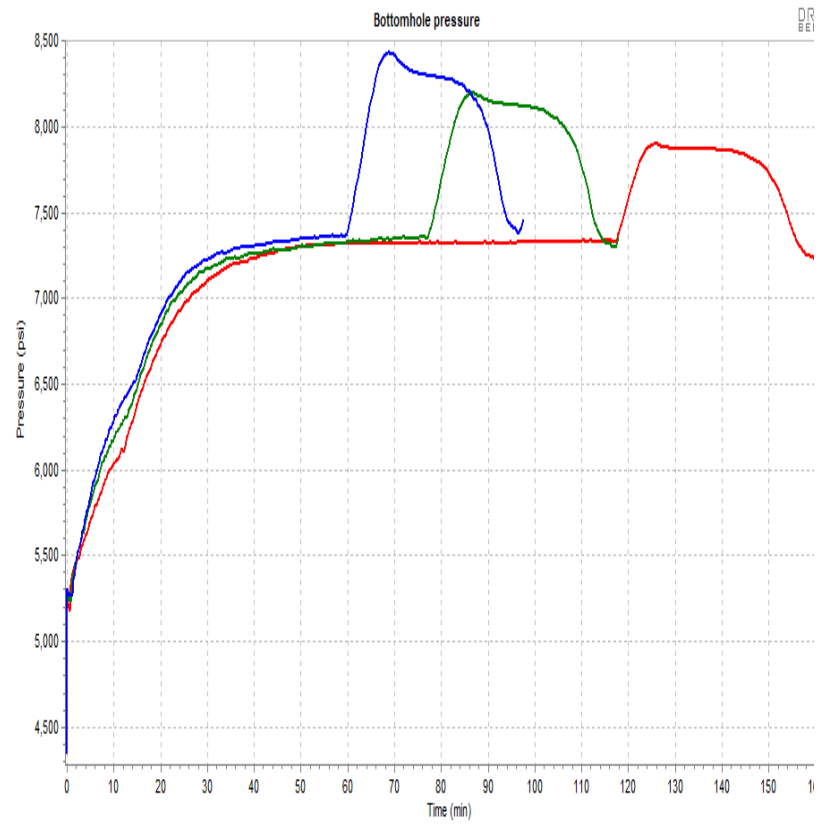

$\bar{\nabla}-85988^{\circ}$ casing $\bar{v}-7588^{8}$ Casing $\bar{v}-7 "$ Casing

Figure 4. 2: Choke Pressure and BHP VS. Time for Different Casing Sizes - OBM

As the choke pressure increases, the BHP is impacted, directly affecting the gas velocity. As shown in Figure 4.3, the smallest casing size has the highest gas velocity compared to the other sizes. 


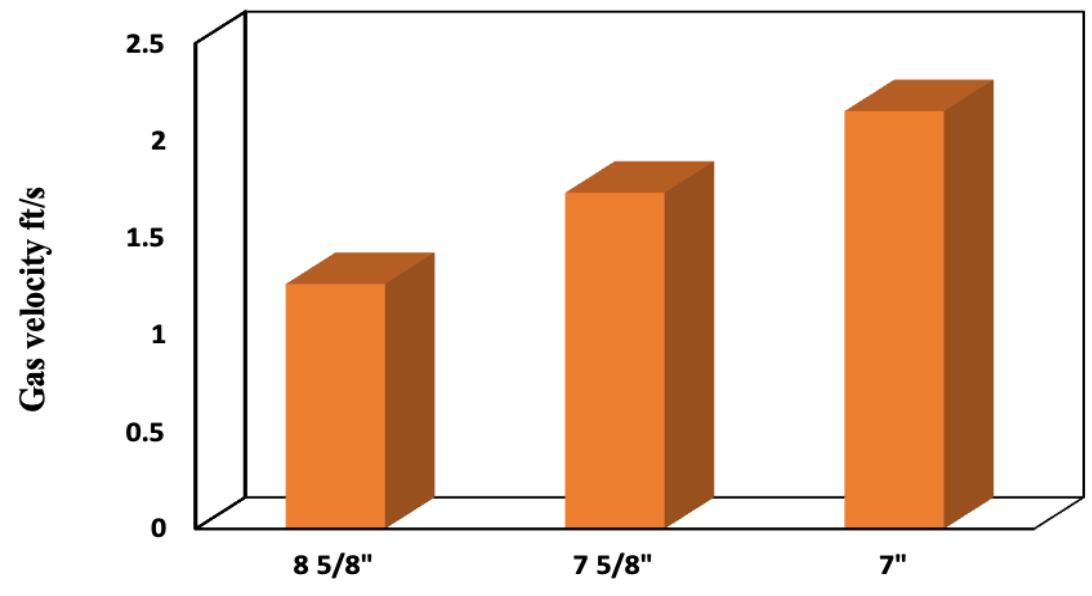

Casing Size, in.

Figure 4. 3: Gas Velocity when the Gas Influx Reaches the Surface for Different Casing Sizes - OBM

Since the gas kick dissolved into the mud, the gas in OBM should take longer until the gas influx reaches the surface. Figure 4.4 shows the gas flow rate and when the gas reaches the surface.

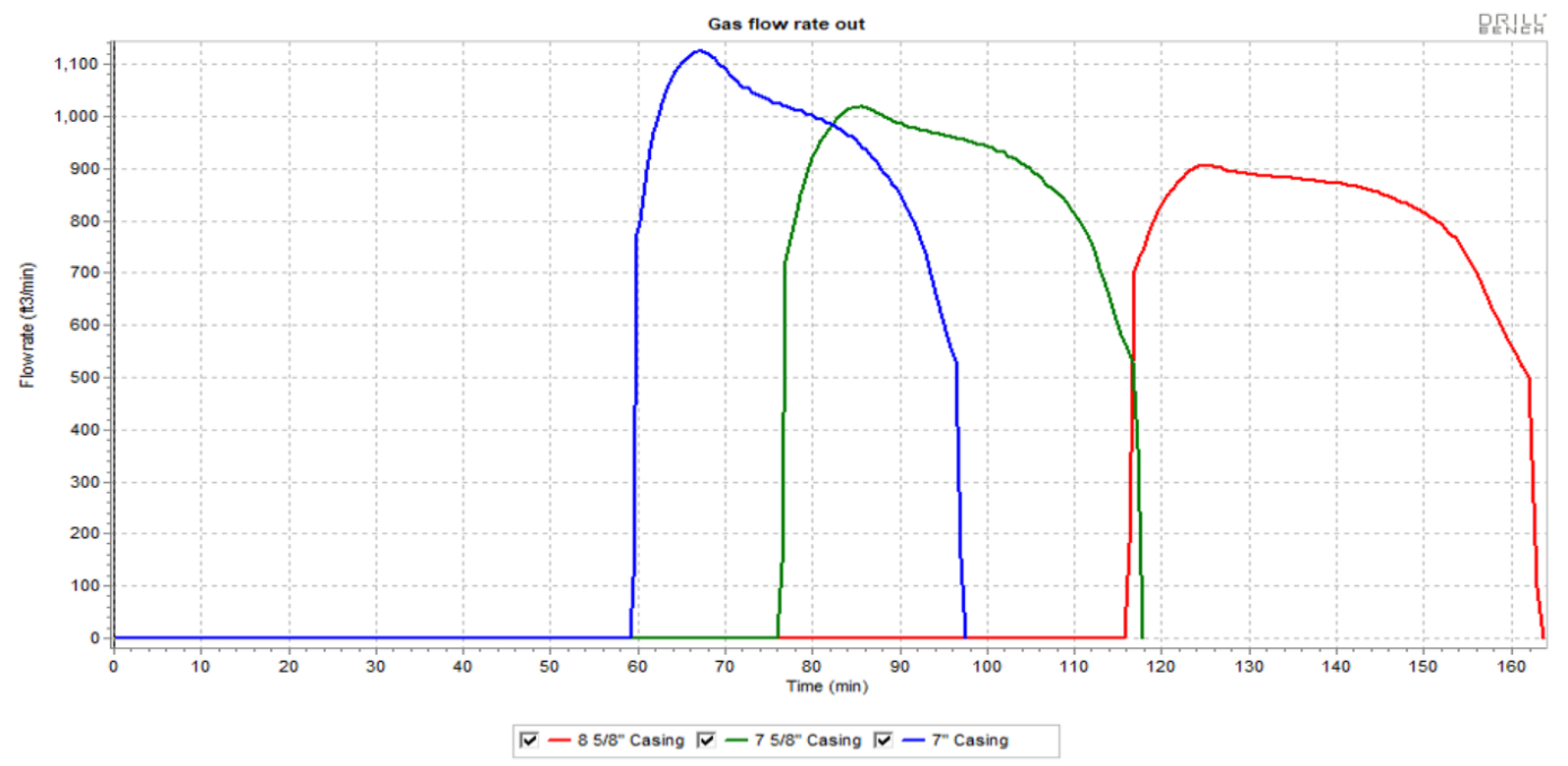

Figure 4. 4: Gas Flow Rate for Different Casing Sizes - OBM

Table 5 shows every run value and how long it takes for each run until the gas influx is ejected from the well. Improvement in Table 5 is based on time until the gas influx reaches the surface. Improvment $=\left(\frac{\left(\text { Time }_{\text {Base-Model }}-\text { Time }_{\text {Run }}\right)}{\text { Time }_{\text {Base-Model }}}\right) * 100$ 
Table 5: Results of Different Casing Sizes when the Gas Influx Reaches the Surface - OBM

\begin{tabular}{|c|c|c|c|c|c|}
\hline \multicolumn{7}{|c|}{ Casing Size } & Improvement \\
\hline Size & $\begin{array}{c}\text { Choke } \\
\text { Pressure (Psi) }\end{array}$ & BHP (Psi) & $\begin{array}{c}\text { Average gas velocity } \\
\mathrm{ft} / \mathrm{s}\end{array}$ & Time (Min) & Base Model \\
\hline $85 / 8 "$ & 3504 & 7903 & 1.26 & 115.7 & $34.3 \%$ \\
\hline $75 / 8 "$ & 3775.6 & 8195.8 & 1.73 & 76 & $49.0 \%$ \\
\hline $7 "$ & 3987 & 8435 & 2.15 & 59 & \\
\hline
\end{tabular}

\subsubsection{Effect of Drill Pipe}

DP has a significant impact on gas migration. Notably, DP and DC have the same effect on gas migration. In this study three different sizes of DP have been studied. This section investigates their impact on gas migration in OBM. The general concept in this part is that once the size of DP increases, it decreases BHA which cause an increase in the choke pressure. This led to an increase in BHP. If the BHP increases, then it affects the gas velocity. Figure 4.5 shows the choke pressure and BHP in different drill pipe sizes.
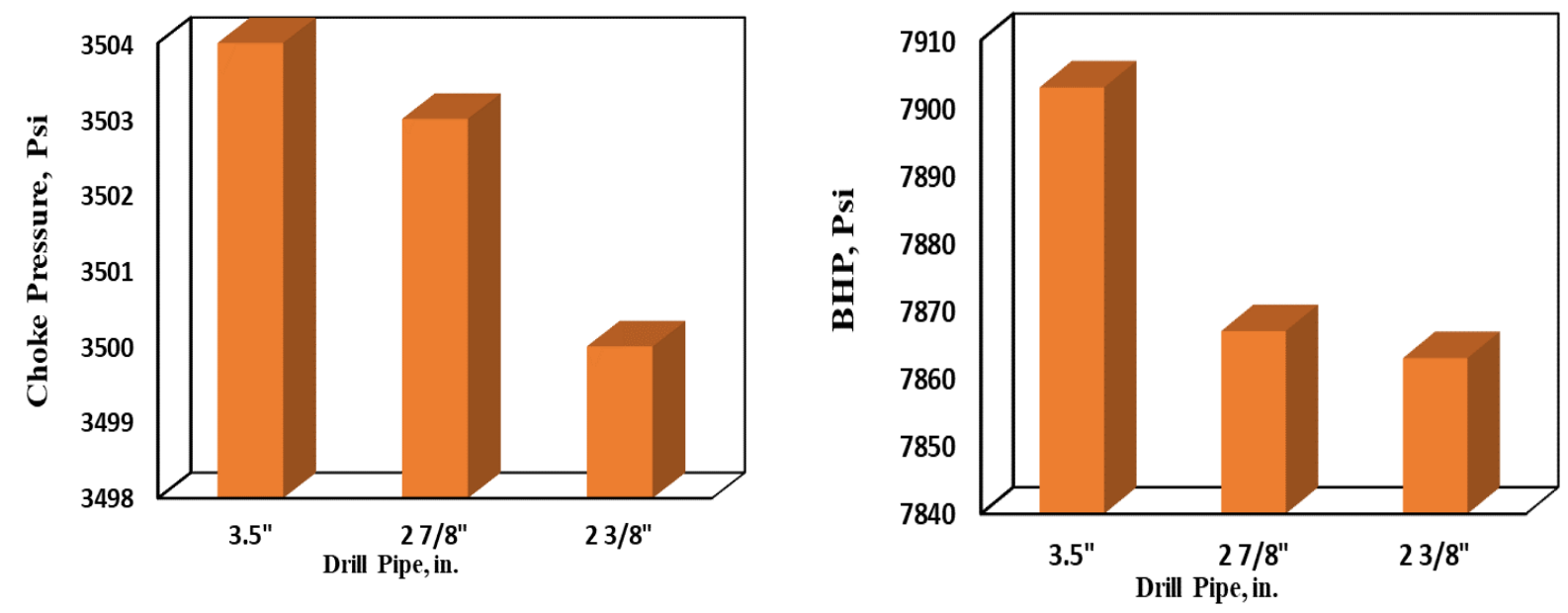

Figure 4. 5: Choke Pressure and BHP when the Gas Influx Reaches the Surface for Different Drill Pipe Sizes - OBM

As it has been discussed, the smaller DP size have the lowest choke pressure and BHP. In Figure 4.5, the $23 / 8$ " DP have the lowest choke pressure. As shown in Figure 4.6, the smallest size of DP has the lowest gas velocity. Figure 4.7 shows the choke, and bottom-hole pressure plots and Table 6 shows the results of drill pipe size for each run and how long it takes for each run until Gas Influx reaches the surface. 


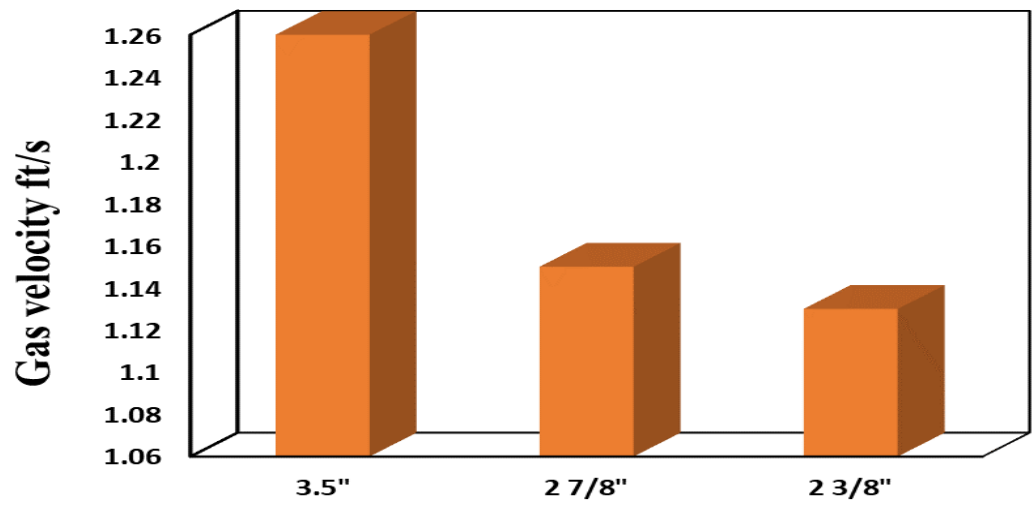

Drill Pipe Size, in.

Figure 4. 6: Gas Velocity when the Gas Influx Reaches the Surface for Different Drill Pipe Sizes - OBM

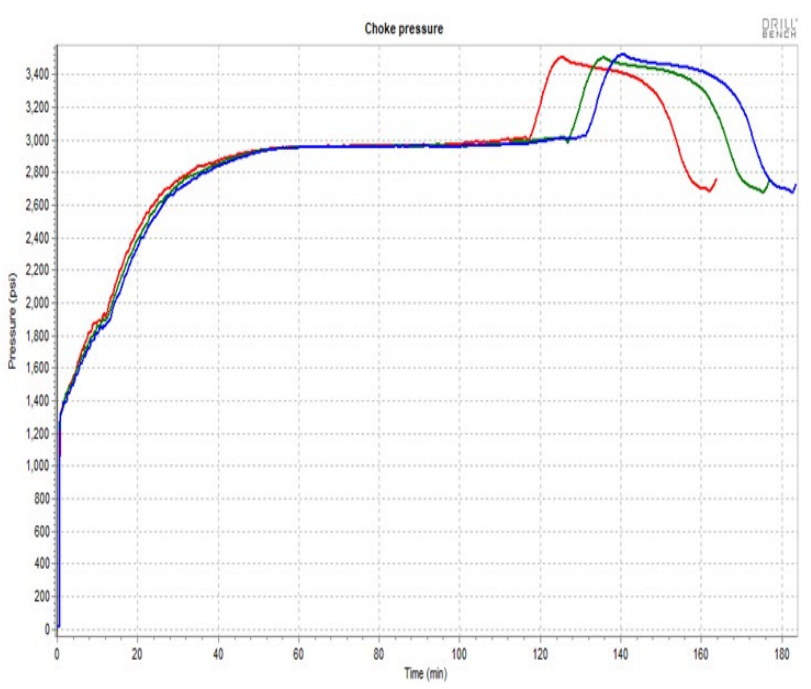

$\bar{\nabla}-35^{\circ} D P \quad \bar{V}-276^{\circ} D P \nabla \nabla-236^{\circ} O P$

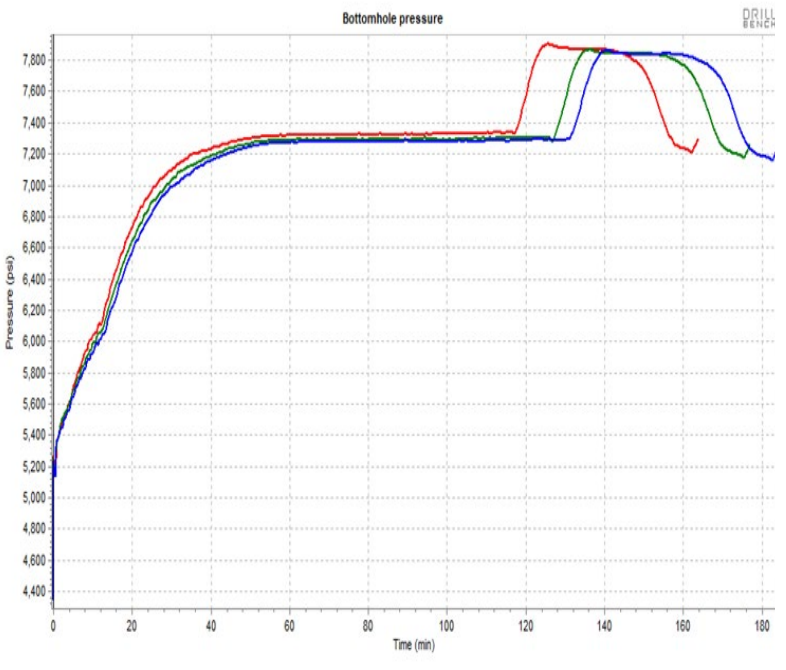

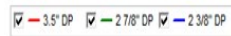

Figure 4. 7: Choke Pressure and BHP VS. Time for Different Drill Pipe Sizes - OBM

Table 6: Results of Different Drill Pipe Sizes when the Gas Influx Reaches the Surface - OBM

\begin{tabular}{|c|c|c|c|c|c|}
\hline \multicolumn{7}{|c|}{ Drill Pipe Size } \\
\hline Size & $\begin{array}{c}\text { Choke Pressure } \\
\text { (Psi) }\end{array}$ & BHP (Psi) & Average gas velocity ft/s & Time (Min) & Improvement \\
\hline $31 / 2 "$ & 3504 & 7903 & 1.26 & 115.7 & Base Model \\
\hline $27 / 8 "$ & 6114 & 7867 & 1.15 & 125 & $-8.0 \%$ \\
\hline $23 / 8 "$ & 6130 & 7863 & 1.13 & 130 & $-12.4 \%$ \\
\hline
\end{tabular}




\subsubsection{Effect of Kick Volume}

The impact of the kick volume has been studied in this model to understand how it would impact the gas migration in OBM fluid. Three different kick sizes have been checked. In the first run, the kick volume was $20 \mathrm{bbl}$, while in the second run, the kick volume was $25 \mathrm{bbl}$. In the last run, the kick volume was $30 \mathrm{bbl}$. Once the kick volume in the $20 \mathrm{bbl}$ entered the wellbore, the free gas volume increased to $33 \%$ then dropped to $3 \%$ mass. In the $25 \mathrm{bbl}$ run, the free gas volume fraction equaled $42 \%$ once the influx entered the wellbore and dissolved in the mud, the free gas dropped to $10.2 \%$ volume fraction. The last run had $30 \mathrm{bbl}$ kick volume, while the free gas mass fraction was equal to $62 \%$ then dropped to $13.4 \%$ mass fraction. By the ratio of the three runs, in the $20 \mathrm{bbl}$ influx, $90 \%$ dissolved in the mud, $76 \%$ in the $25 \mathrm{bbl}$ influx, and the last one is $30 \mathrm{bbl}$ where only $69 \%$ of the influx dissolved in the mud. The larger kick volume had a high choke pressure and high BHP, impacting solubility, which is the main impact on the kick volume. The largest kick volume had less solubility, so the gas influx reached the surface faster. As it shows in Figure 4.8. the largest kick volume had the highest BHP pressure.
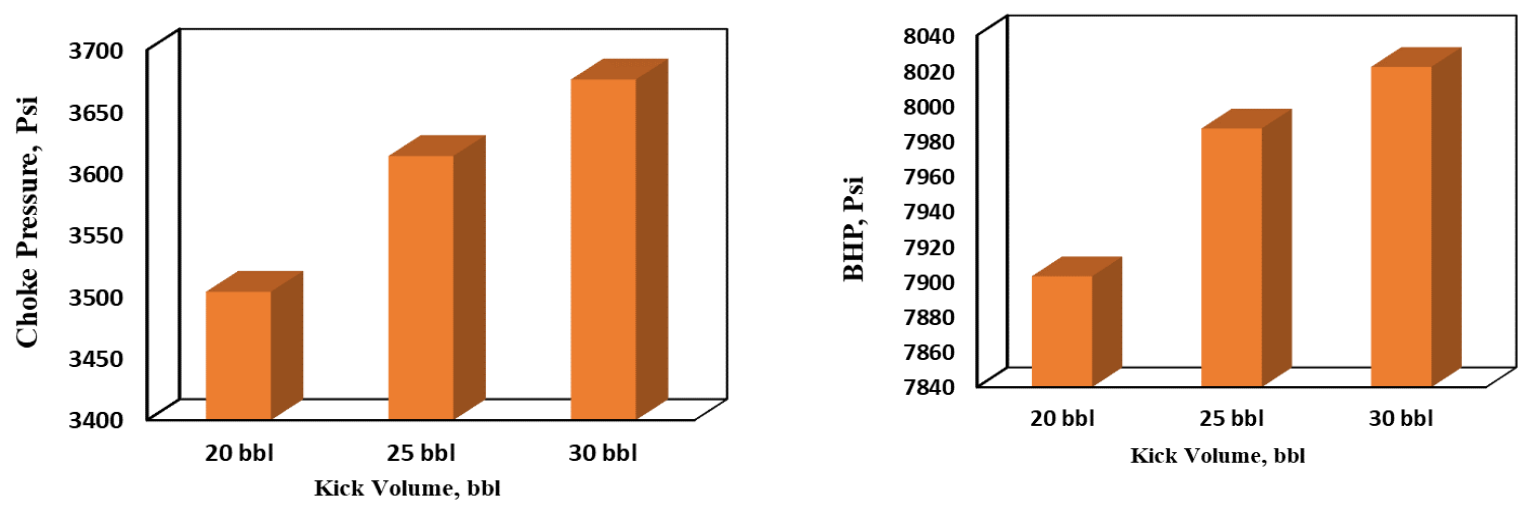

Figure 4. 8: Choke Pressure and BHP when the Gas Influx Reaches the Surface for Different Kick Volumes - OBM

As shown, the larger kick volume had the lowest choke pressure and BHP because the small influx of the amount of gas that dissolved in the mud was higher than the more significant influx, which impacted the pressures. However, the lowest choke pressure and BHP did not impact the gas velocity in this case because the more the gas dissolved in the mud, the slower the velocity was, as shown in Figure 4.9. The gas velocity for $30 \mathrm{bbl}$ was the fastest while the $20 \mathrm{bbl}$ is the lowest. 


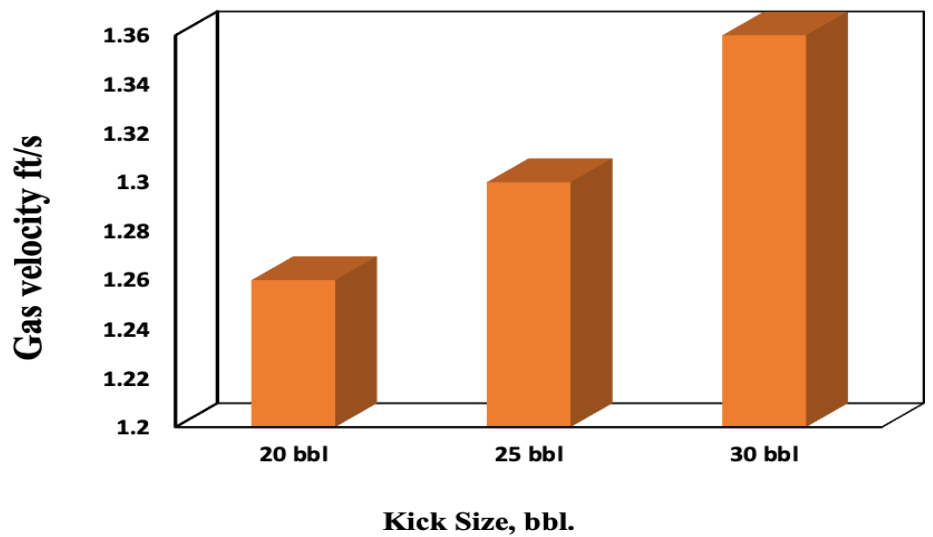

Figure 4. 9: Gas Velocity when the Gas Influx Reaches the Surface for Different Kick Volumes - OBM

Furthermore, Figure 4.11 shows the gas flow rate and each run when the gas started to reach the surface. $30 \mathrm{bbl}$ started reaching the surface first, and then $25 \mathrm{bbl}$ and $20 \mathrm{bbl}$ followed. Furthermore, Figure 4.10 shows the choke pressure and BHP plots. Table 7 shows the results of kick volume for each run and how long it takes for each run until kick reaches the surface

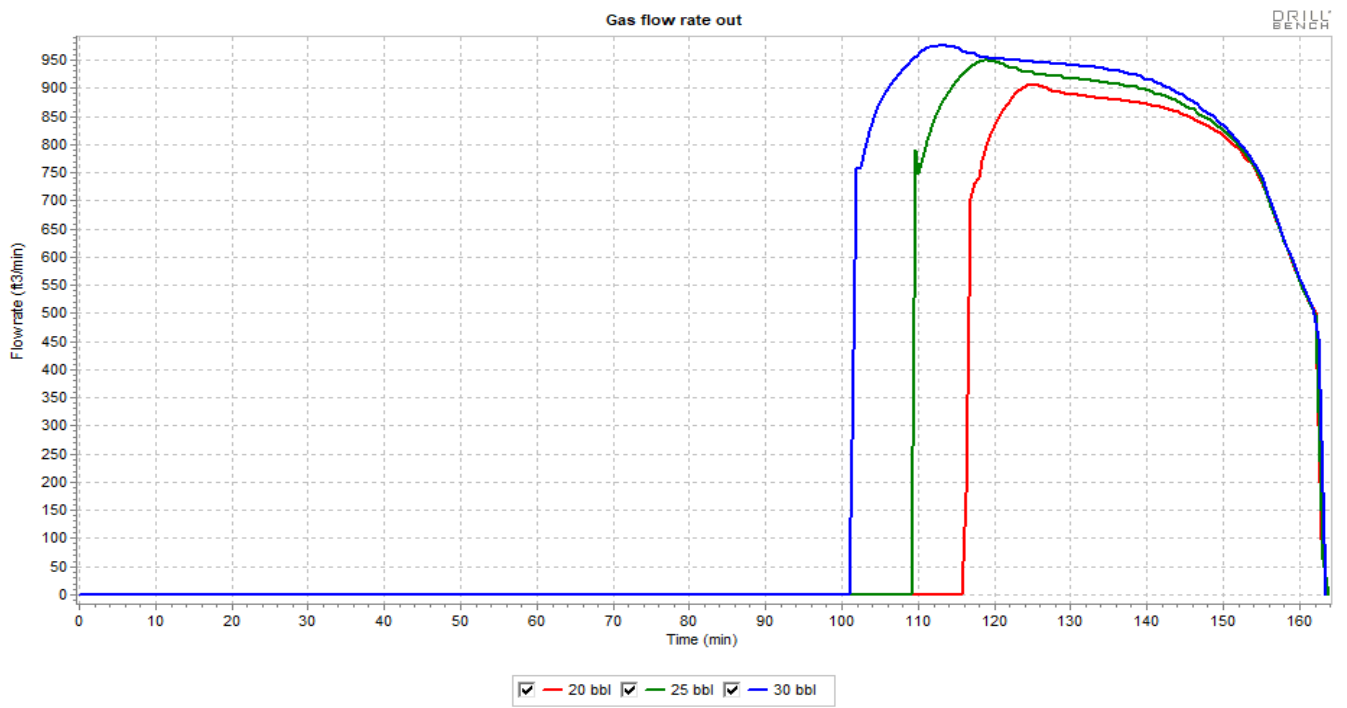

Figure 4. 10: Gas Flow Rate for Different Kick Volumes - OBM 

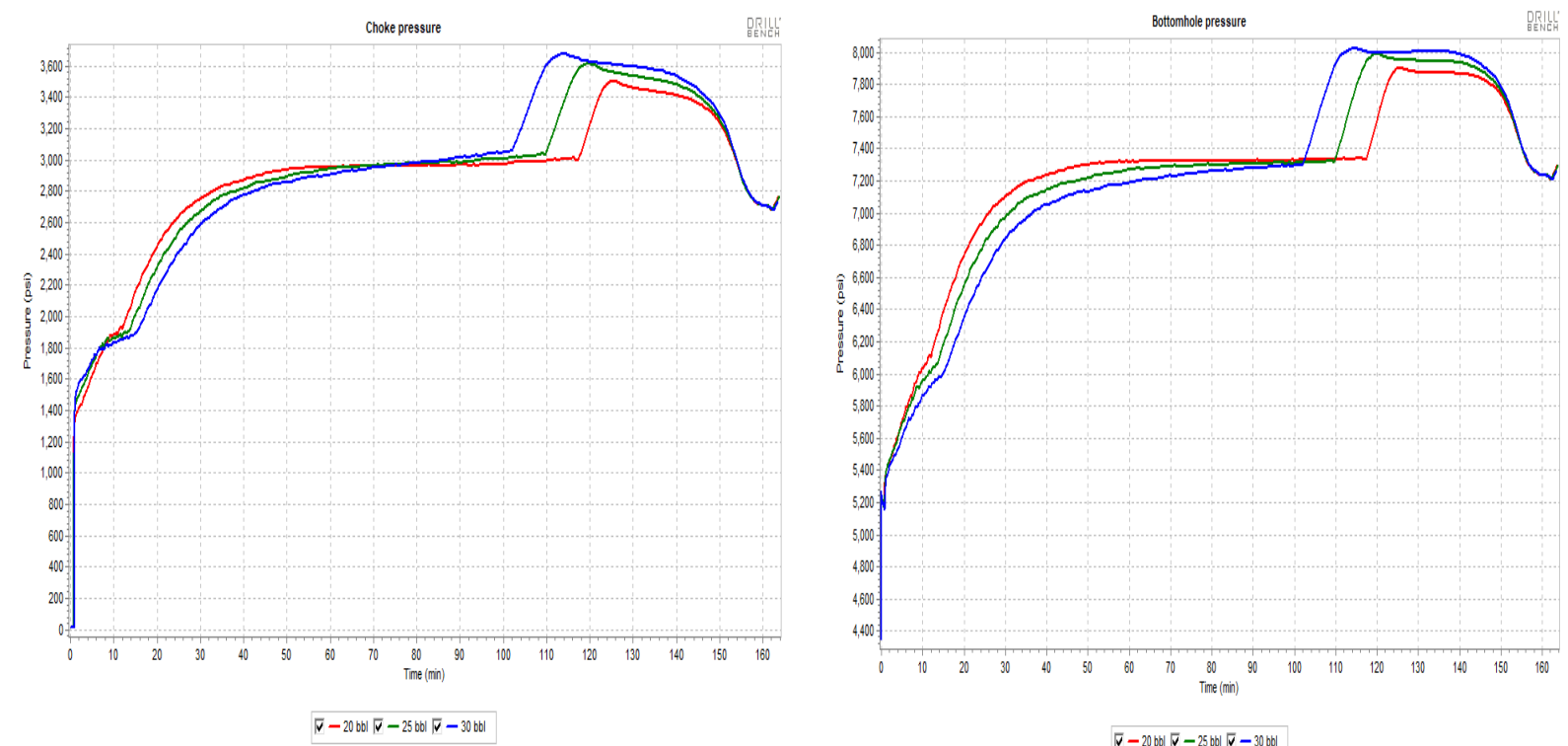

$\bar{\nabla}-20 \mathrm{bb}|\bar{\nabla}-25 \mathrm{bb}| \bar{\nabla}-30 \mathrm{bbl}$

Figure 4. 11: Choke Pressure and BHP VS. Time for Different Kick Volumes - OBM

Table 7: Results of Different Kick Volumes when the Gas Influx Reaches the Surface OBM

\begin{tabular}{|c|c|c|c|c|c|}
\hline \multicolumn{6}{|c|}{ Kick Size } \\
\hline $\begin{array}{c}\text { Size } \\
\text { Bbl. }\end{array}$ & $\begin{array}{c}\text { Choke Pressure } \\
(\text { Psi) }\end{array}$ & $\begin{array}{c}\text { BHP } \\
(\text { Psi) }\end{array}$ & Average gas velocity ft/s & Time (Min) & Improvement \\
\hline 20 & 3504 & 7903 & 1.26 & 115.7 & Base Model \\
\hline 25 & 3614 & 7987 & 1.3 & 109 & $5.8 \%$ \\
\hline 30 & 3676 & 8022 & 1.36 & 100.8 & $12.9 \%$ \\
\hline
\end{tabular}

\subsubsection{Effect of Mud Density}

Mud density is one of the parameters that impacts gas migration. This study explains three different mud densities with three different reservoir pressures since the hydrostatic pressure changes when the mud density is changed. This parameter includes two factors: the mud weight and the reservoir pressure. Hydrostatic pressure $=0.052 *$ Depth $* \mathrm{MW}$; from this equation, it can be determined that the hydrostatic pressure changes as the mud density changes. In addition. a kick is produced when the BHP is less than the pore pressure. This study primarily investigates the impact of each parameter on gas migration during the gas kick, with the reservoir pressure modified to obtain accurate results of the mud density impact. In addition, the study mentions the mud density and reservoir pressure for each run. In contrast, the study revealed a reservoir pressure of $5360 \mathrm{psi}$ for the first run. In the second run the mud density was $11 \mathrm{ppg}$ with reservoir pressure of 5004 psi. In the last run the mud density was 10.33 ppg with reservoir pressure of 4760 psi. 
As shown in Figure 4.12, the choke pressure, and the BHP were the highest when mud density was $12 \mathrm{ppg}$, while the $10.33 \mathrm{ppg}$ has the lowest choke and BHP. The reason for that was the reservoir pressure difference between the three-mud weight.
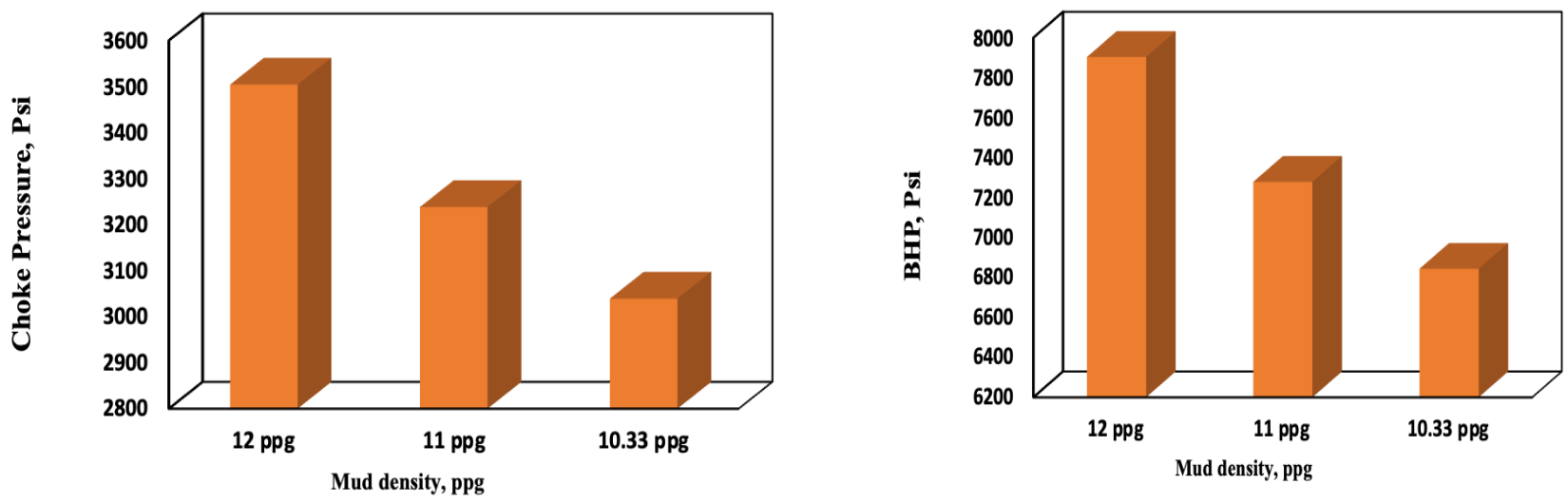

Figure 4. 12: Choke Pressure and BHP when the Gas Influx Reaches the Surface for Different Mud Densities - OBM

From understanding the main concept of the mud weight in the oil-based mud, the gas velocity for the lightest mud should be the fastest while the heaviest should be the slowest. However, the impact of the dissolved gas took place in this case since we were dealing with oilbased mud. In Figure 4.13, the gas velocity for each mud was shown, which means the main concept for the water-based mud and oil-based mud was the same, but the only difference between them was the solubility.

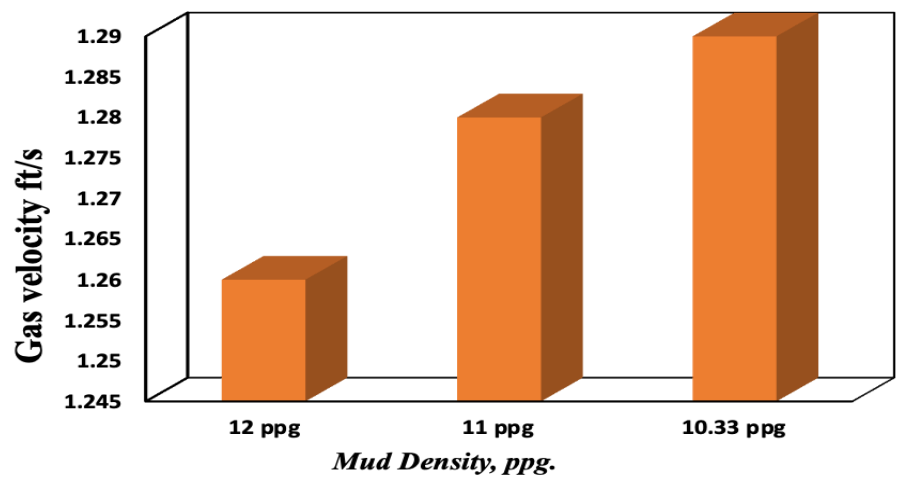

Figure 4. 13: Gas Velocity when the Gas Influx Reaches the Surface for Different Mud Densities - OBM 
As discussed, the lightest mud weight had the highest gas velocity, which means the gas migration was faster while using 10.33 ppg by comparing it with the 12 ppg mud. Figure 4.14 shows the gas flow rate once the influx reached the surface. Figure 4.15 shows the choke pressure and BHP plots, and Table 8 shows the results of mud density for each run and how long it takes for each run until gas influx reaches the surface.

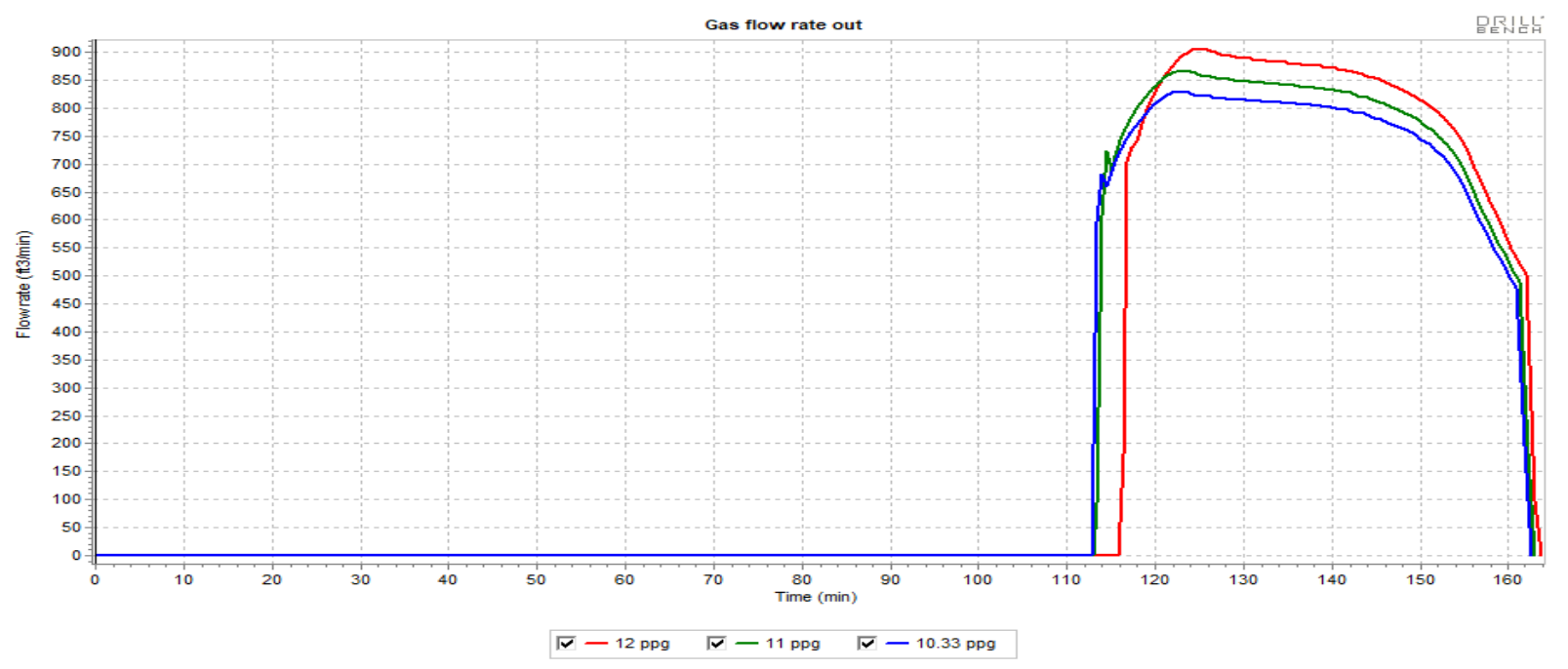

Figure 4. 14: Gas Flow Rate for Different Mud Densities - OBM

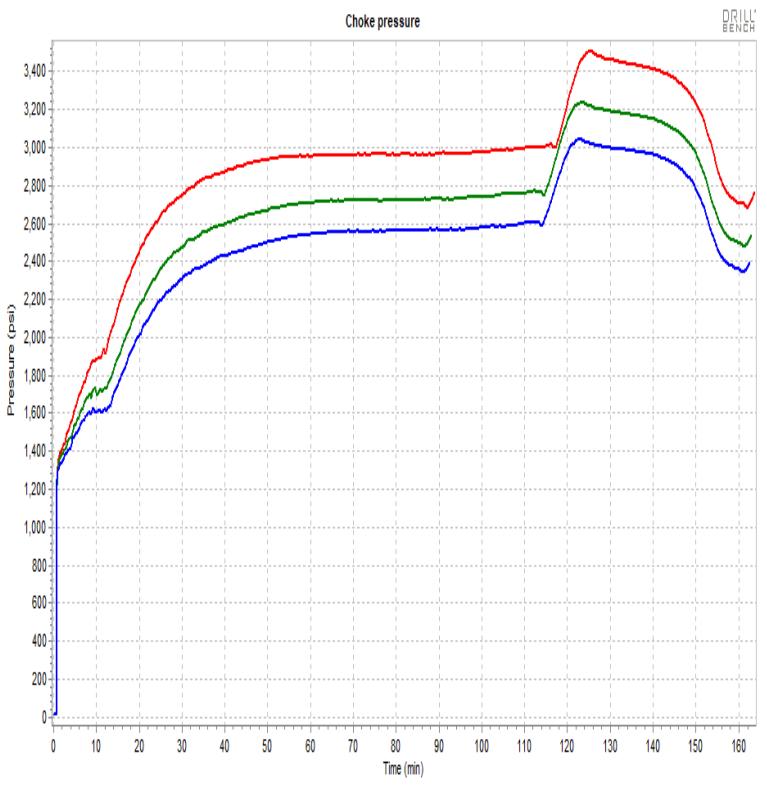

$\bar{\gamma}-12 \mathrm{ppg} \quad \nabla-11 \mathrm{ppg} \quad \bar{\gamma}-10.33 \mathrm{ppg}$

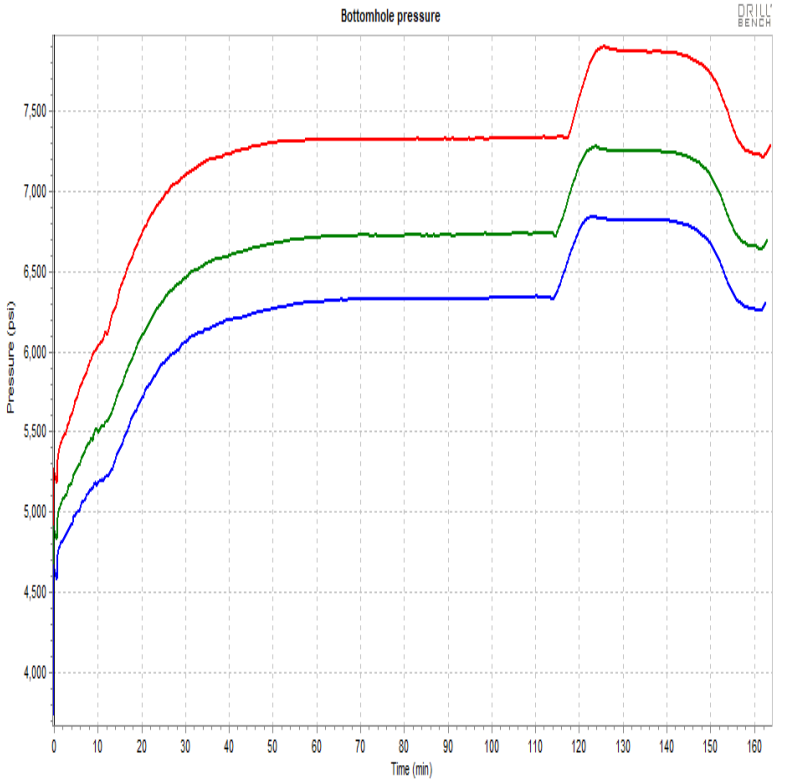

$\bar{\nabla}-12$ popg $\quad \bar{\gamma}-11$ ppg $\quad \bar{\gamma}-10.33$ ppg

Figure 4. 15: Choke Pressure and BHP VS. Time for Different Mud Densities - OBM 
Table 8: Results of Different Mud Densities when the Gas Influx Reaches the Surface - OBM

\begin{tabular}{|c|c|c|c|c|c|}
\hline \multicolumn{7}{|c|}{ Mud density } \\
\hline $\begin{array}{c}\text { Density } \\
\text { ppg }\end{array}$ & $\begin{array}{c}\text { Choke Pressure } \\
\text { (Psi) }\end{array}$ & $\begin{array}{c}\text { BHP } \\
(\text { Psi) }\end{array}$ & Average gas velocity ft/s & Time (Min) & Improvement \\
\hline 12 & 3504 & 7903 & 1.26 & 115.7 & Base Model \\
\hline 11 & 3238 & 7278 & 1.28 & 113 & $2.3 \%$ \\
\hline 10.33 & 3039 & 6843 & 1.29 & 112 & $3.2 \%$ \\
\hline
\end{tabular}

\subsubsection{Effect of Reservoir Temperature}

To better understand the impact of reservoir temperature on gas migration, three different temperatures have been studied in this research. In general, when the temperature increases, the velocity increase because the molecules have more energy, vibrate faster, and allow waves to travel quickly, increasing the gas velocity. However, there is a main factor impact the gas migration while using OBM which is gas solubility. The higher the temperature, the higher the solubility, which means slower velocity. Solubility impacts the gas influx, dissolving into the mud, where high solubility, which has more influx, dissolves in the mud, while the low solubility leads to most of the influx as a free gas. More free gas leads to a faster migration of the gas, which the influx gets out of the well by shortening the time. As shown in Figure 4.16, the choke pressure and BHP were highest at the lowest temperature since the pressure be impacted. Figure 4.17 shows the choke pressure and BHP plots.
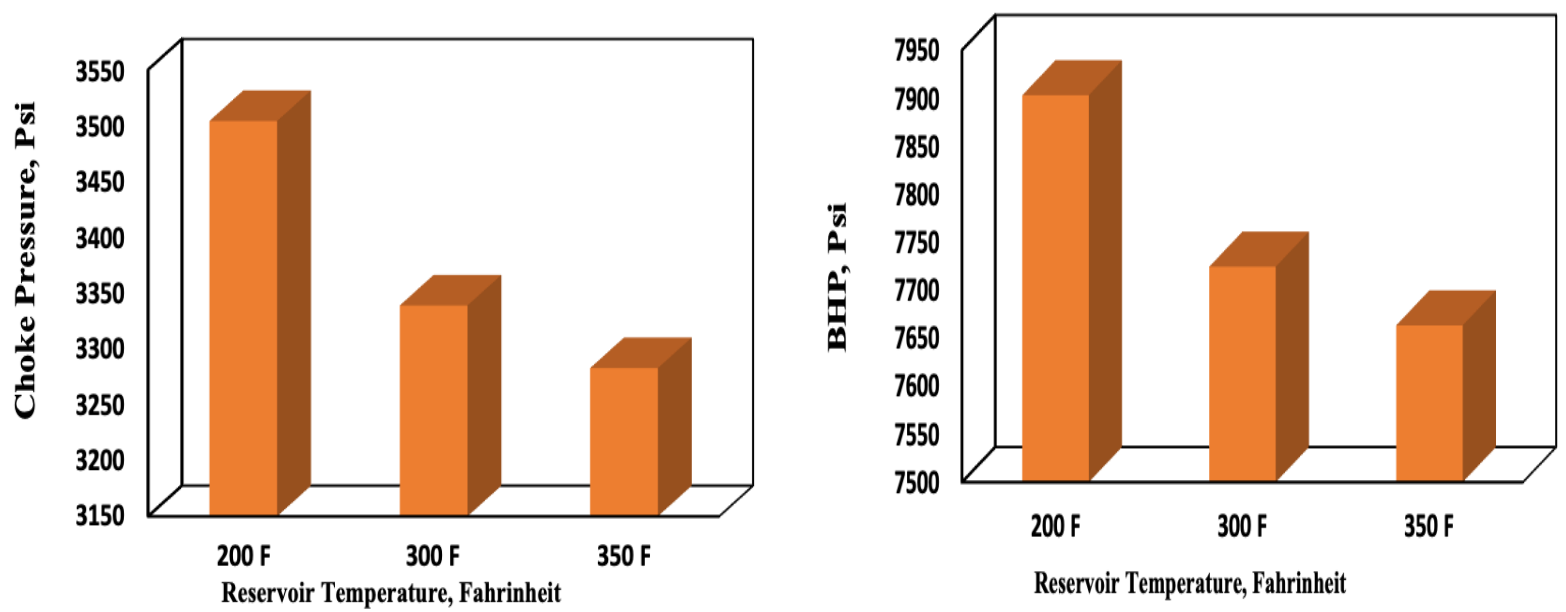

Figure 4. 16: Choke Pressure and BHP when the Gas Influx Reaches the Surface for Different Reservoir Temperatures - OBM 

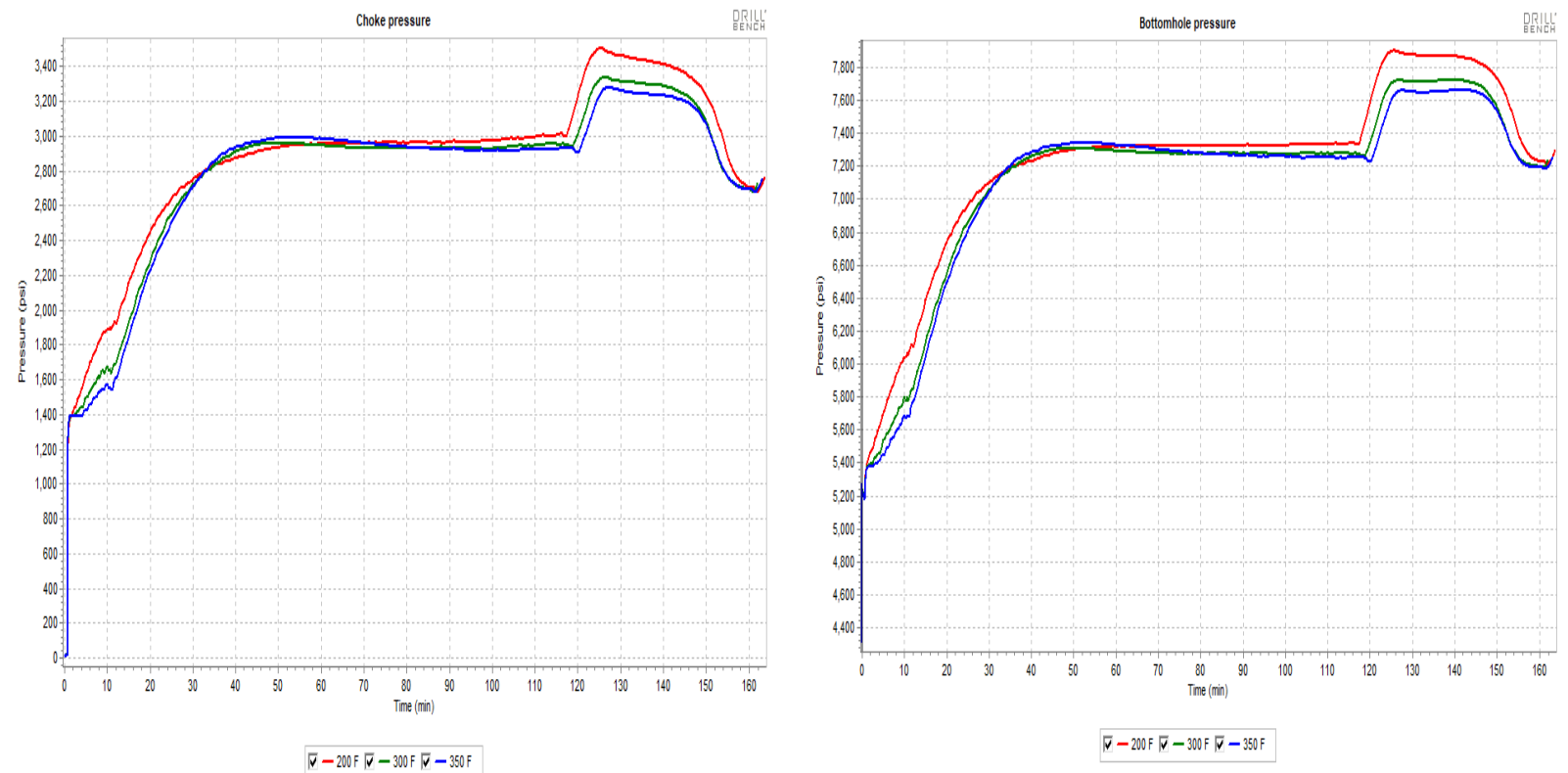

Figure 4. 17 Choke Pressure and BHP VS. Time for Different Reservoir Temperatures - OBM

As always, when the BHP increases, the gas velocity increases. Figure 4.18 shows the gas velocity for each temperature, and in Figure 4.19, the gas flow rate reduced once the influx reached the surface.

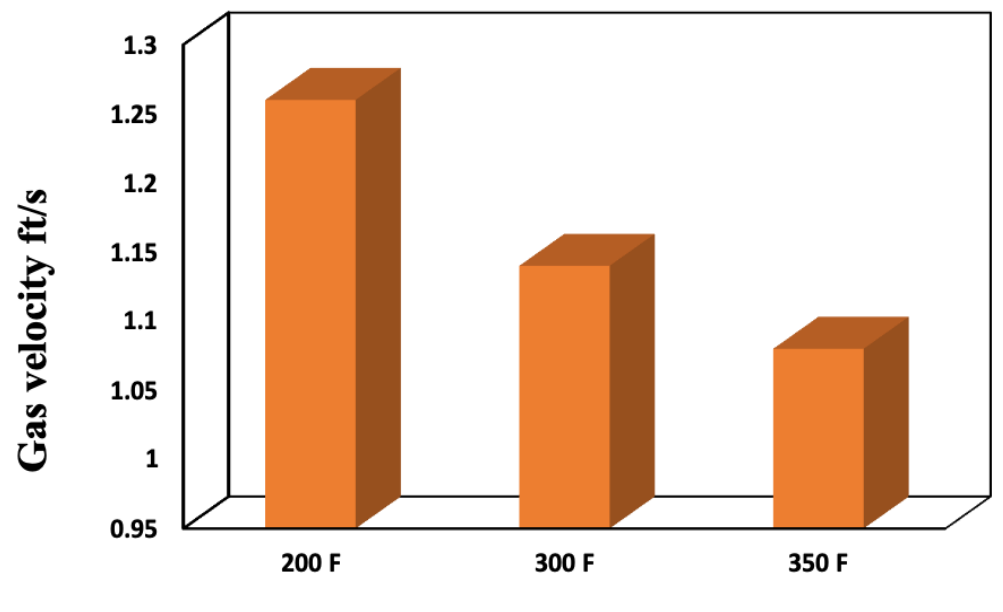

Reservoir Temperature, Fahrenheit

Figure 4. 18: Gas Velocity when the Kick Reaches the Surface for Different Reservoir Temperatures 


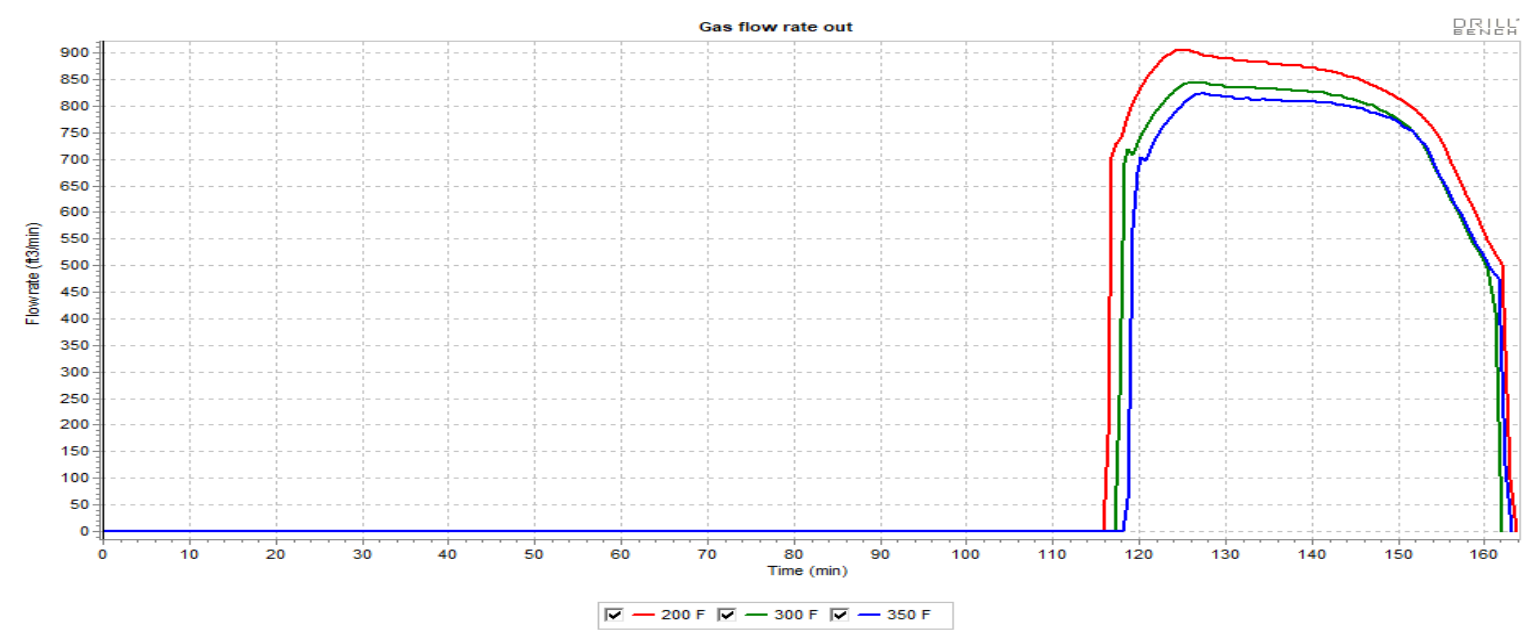

Figure 4. 19: Gas Flow Rate for Different Reservoir Temperatures - OBM

Reservoir temperatures impact the gas migration in OBM by impacting the solubility, which impact the gas velocity, as shown in Table 9. Table 9 shows the results of reservoir temperature for each run and how long it takes for each run until gas influx reaches the surface.

Table 9: Results of Different Reservoir Temperatures when the Gas Influx Reaches the Surface-OBM

\begin{tabular}{|c|c|c|c|c|c|}
\hline \multicolumn{7}{|c|}{ Reservoir Temperature } & Improvement \\
\hline Temperature & $\begin{array}{c}\text { Choke } \\
\text { Pressure } \\
\text { (Psi) }\end{array}$ & $\begin{array}{c}\text { BHP } \\
\text { (Psi) }\end{array}$ & Average gas velocity ft/s & Time (Min) & \\
\hline $250^{\circ} \mathrm{F}$ & 3504 & 7903 & 1.26 & 115.7 & Base Model \\
\hline $300^{\circ} \mathrm{F}$ & 3338.8 & 7724.4 & 1.14 & 117 & $-1.1 \%$ \\
\hline $350^{\circ} \mathrm{F}$ & 3282.7 & 7663.3 & 1.08 & 118 & $-2.0 \%$ \\
\hline
\end{tabular}

\subsubsection{Effect of Oil-Water Ratio}

In this study, four different oil-water ratios were investigated to understand the behavior and the impact of the gas migration. These ratios were 80/20, 70/30,60/40 and 50/50 OWR, where the higher the oil percentage in the mud the higher the solubility. A high solubility led to more gas influx being dissolved into the mud, which took a longer time until the influx reached the surface. Also, the lowest solubility led to an increase in the choke pressure and BHP, which also impacted the gas velocity as shown in Figure 4.20, the choke pressure and BHP for each different OWR. 

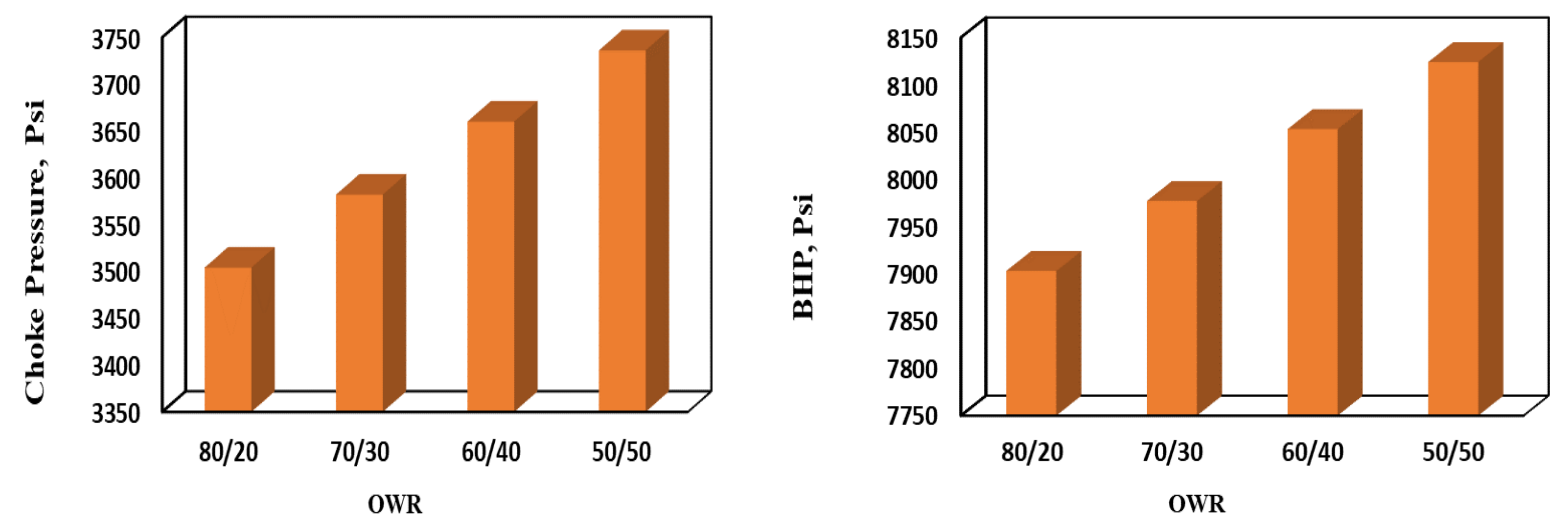

Figure 4. 20: Choke Pressure and BHP when the Gas Influx Reaches the Surface for Different Oil-Water Ratios - OBM

Figure 4.21 shows that when the gas influx reached the surface, the lowest oil percentage reached the surface early comparing it with the higher percentage of oil. Figures 4.22 shows the choke pressure and BHP plots, and Table 10 shows the results of OWR for each run and how long it takes for each run until gas influx reaches the surface. A high oil percentage leads to an increase in the solubility as shown in Figure 4.23.

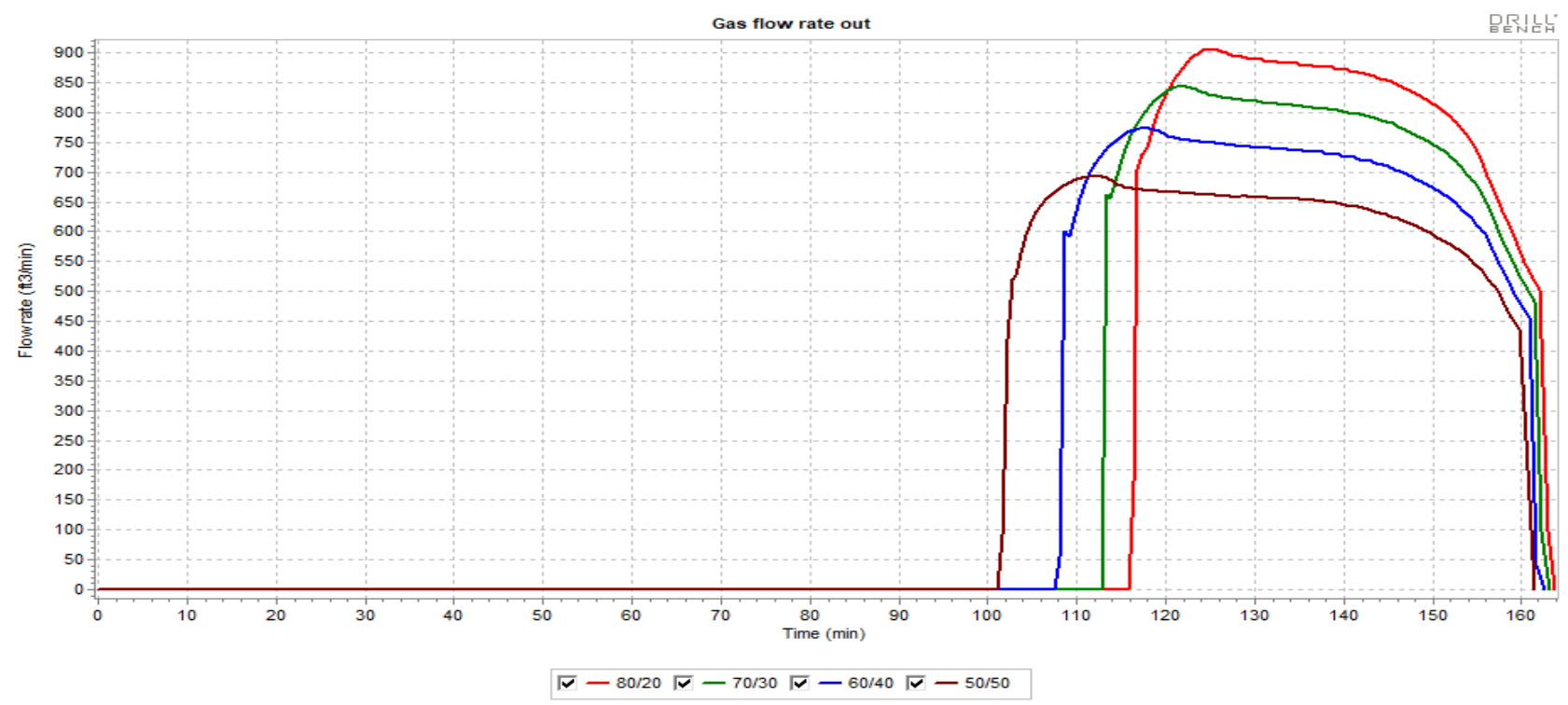

Figure 4. 21: Gas Flow Rate for Different Oil-Water Ratios - OBM 


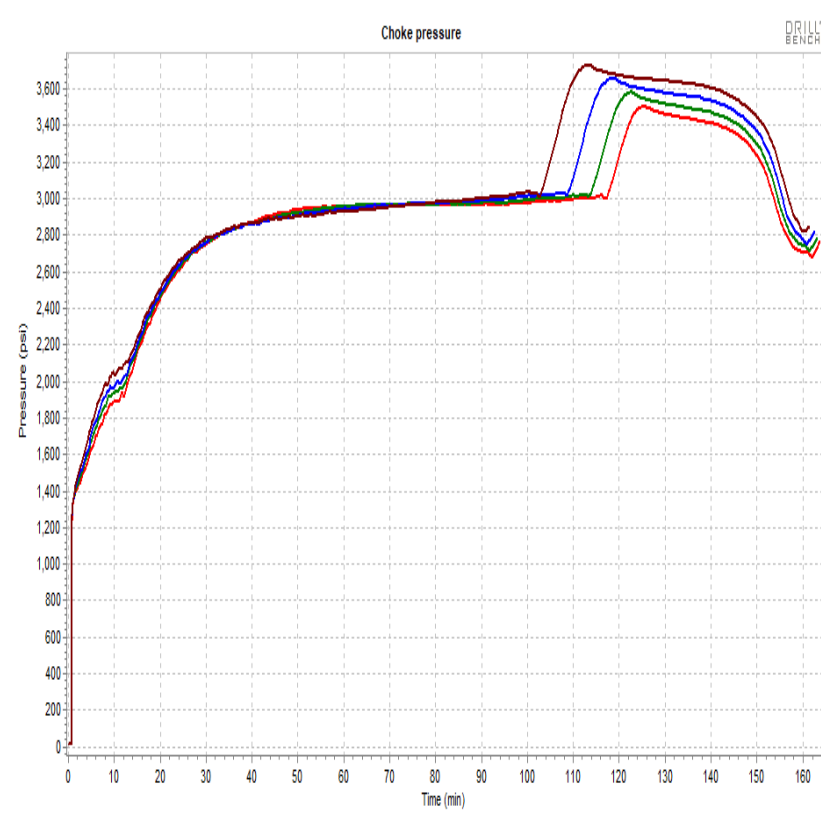

$\sqrt{\gamma}-8020 \sqrt{\nabla}-7030 \sqrt{\gamma}-6040 \sqrt{\gamma}-500150$

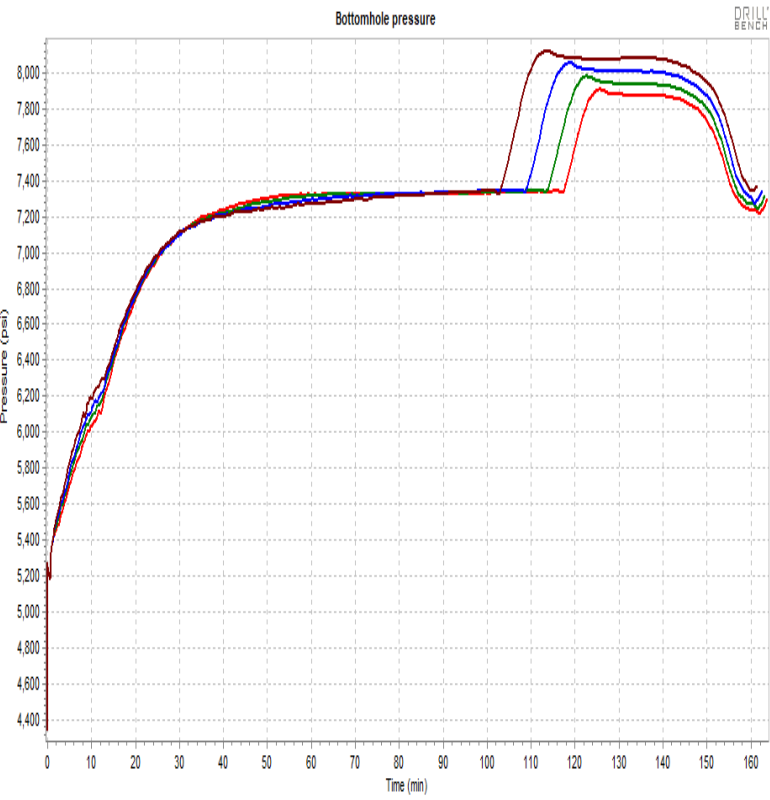

$\bar{\nabla}-80200 \bar{\nabla}-7030 \bar{\nabla}-60140 \bar{\nabla}-50150$

Figure 4. 22: Choke Pressure and BHP VS. Time for Different Oil-Water Ratios - OBM

Table 10: Results of Different Oil-Water Ratios when the Gas Influx Reaches the Surface

\begin{tabular}{|c|c|c|c|c|c|}
\hline \multicolumn{7}{|c|}{ Oil-Water Ratio } \\
\hline OWR & Choke Pressure (Psi) & BHP (Psi) & Average gas velocity ft/s & Time (Min) & Improvement \\
\hline $80 / 20$ & 3504 & 7903 & 1.26 & 115.7 & Base Model \\
\hline $70 / 30$ & 3582 & 7977 & 1.28 & 112.7 & $2.6 \%$ \\
\hline $60 / 40$ & 3660 & 8053 & 1.34 & 107.5 & $4.6 \%$ \\
\hline $50 / 50$ & 3736 & 8124 & 1.355 & 101.1 & $6.0 \%$ \\
\hline
\end{tabular}

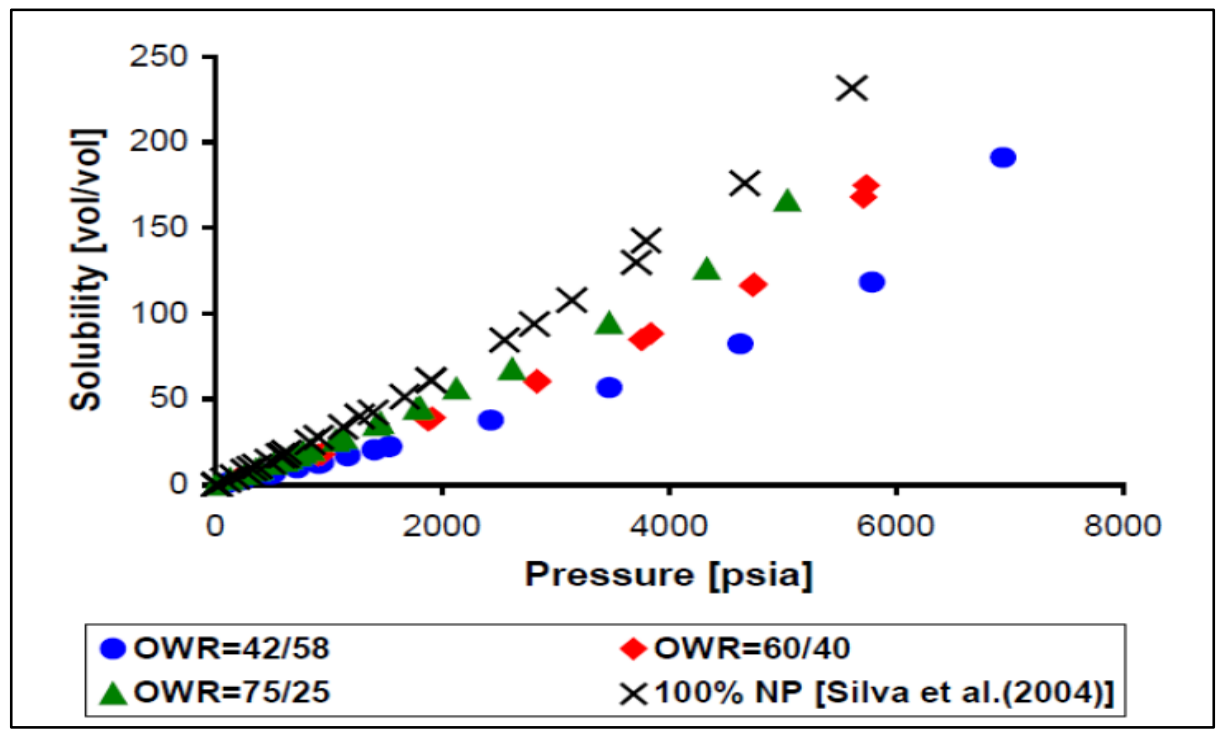

Figure 4. 23: Solubility VS. Pressure (Monteiro. 2005). 


\subsection{Water-Based Mud}

This section in this study focuses on the impact of the water-based mud on the gas migration parameters during the gas kick. The parameters vary because of the water-based mud behavior (choke pressure, BHP, and casing shoe pressure). All the Figures for WBM are shown in appendix A and Table 11 shows the results of WBM base-model.

Table 11: Base-Model Results when the Gas Influx Reaches the Surface - WBM

\begin{tabular}{|c|c|c|c|c|}
\hline Base Model & $\begin{array}{c}\text { Choke Pressure } \\
\text { (Psi) }\end{array}$ & $\begin{array}{c}\text { BHP } \\
\text { (Psi) }\end{array}$ & Average gas velocity ft/s & Time (MIN) \\
\hline Water-Based Mud & 6103 & 10595 & 1.63 & 48.6 \\
\hline
\end{tabular}

\subsubsection{Impact of Wellbore Configuration}

The casing sizes that have been used in this study are similar to casing sizes and hole sizes in the OBM section: 8 5/8", 7 5/8", and 7". The impact of the casing size was studied with three different intermediate casing sizes, including 8 5/8", 7 5/8" and 7". The first run was conducted using the $85 / 8$ " casing, with a 10595-choke pressure, compared to $75 / 8$ " and 7", which had a choke pressure of 10724 Psi and 10991 Psi respectively. Notably, a decrease in casing diameter resulted in an increase in choke pressure as shown in Figure 4.19. Bottom hole pressure (BHP) = Surface Pressure (SP) + Hydrostatic Pressure (HP), when the choke pressure increased (SP), the BHP increased as well. As shown in Figure 4.24, the 8 5/8" had the lowest BHP because the choke pressure in this run was the lowest. Once the casing sizes started to decrease in diameter the pressure increased.
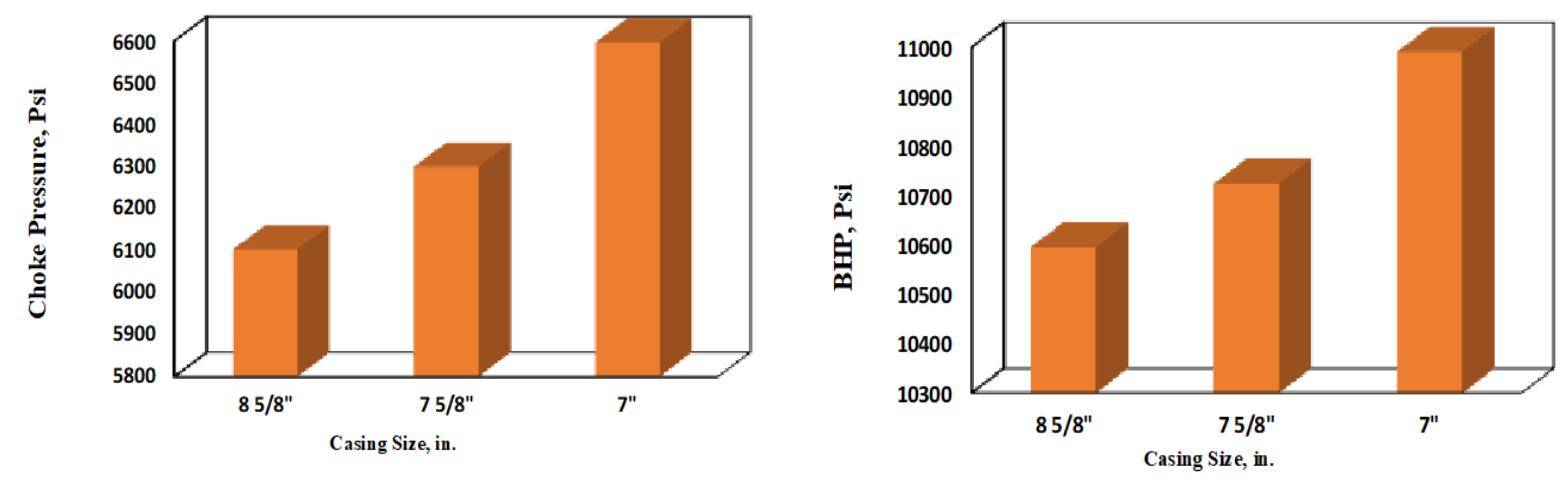

Figure 4. 24: Choke Pressure and BHP Pressure when the Gas Influx Reaches the Surface for Different Casing Sizes - WBM Casing Size 
When the gas kick appears at the well, all the casing sizes are differently adjusted due to the different casing sizes, impacting gas migration. Different sizes lead to varied pressures. As aforementioned, an increase in the choke pressure causes an increase in the bottom-hole pressure.

The Bottom-hole pressure significantly impacted the gas rise velocity. The highest BHP pressure was associated with an increase in gas velocity. As shown in Figure 4.25, the 8 5/8" had the lowest gas velocity, while the 7" had the highest gas velocity. This explains the relationship between the choke size, bottom-hole pressure, and gas velocity. The increase in choke pressure increased the bottom-hole pressure and gas velocity, increasing the time-taken for gas migration. In conclusion, the smallest casing size had the highest gas velocity, as shown in Figure 4.25. This increased the bottom-hole pressure and gas velocity, which decreased the time until the gas existed the well. After comparing the gas velocity in OBM and WBM, the gas velocity in WBM was faster by $58 \%$ than the gas velocity in OBM. Table 12 shows the results of wellbore configuration for each run and how long it takes for each run until the gas influx reaches the surface.

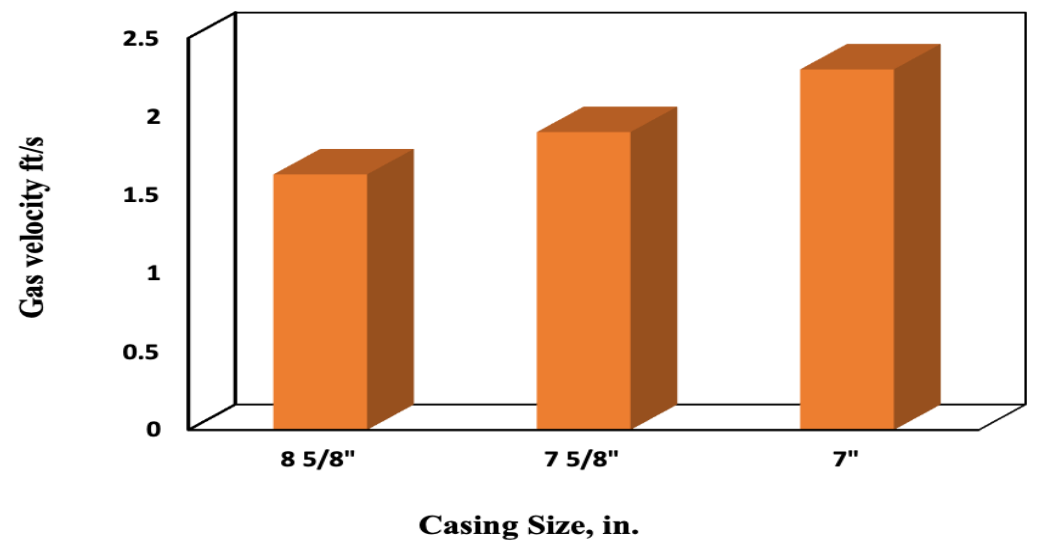

Figure 4. 25: Gas Velocity when the Gas Influx Reaches the Surface for Different Casing Sizes - WBM

Table 12: Results of Casing Size when Gas Influx reaches the surface - WBM

\begin{tabular}{|c|c|c|c|c|c|}
\hline \multicolumn{7}{|c|}{ wellbore configuration } \\
\hline Size & $\begin{array}{c}\text { Choke Pressure } \\
(\text { Psi) }\end{array}$ & $\begin{array}{c}\text { BHP } \\
(\text { Psi) }\end{array}$ & Average gas velocity ft/s & Time (MIN) & Improvement \\
\hline $85 / 8 "$ & 6103 & 10595 & 1.63 & 48.6 & Base Model \\
\hline $75 / 8 "$ & 6300 & 10724 & 1.9 & 35 & $28.0 \%$ \\
\hline $7 "$ & 6596 & 10991 & 2.3 & 32 & $34.2 \%$ \\
\hline
\end{tabular}




\subsubsection{Effects of Drill-Pipe Size}

For a better understanding of the impact of the DP on gas migration, three different DP sizes were studied in this model. The sizes of drill pipe in this study were $31 / 2$ ", $27 / 8$ " and 2 3/8" respectively. The larger the DP size the larger the BHA, leading to an increase in the choke pressure and increasing the BHP, ultimately increasing the gas velocity, demonstrating the impact of DP and DC on gas migration during gas kick. Notably, the larger DP had less time before the gas migrated to the surface. In Figure 4.26, the trend shows the largest DP size had the highest choke pressure, while the smallest DP had the lowest choke pressure. 2 3/8" DP had the lowest choke pressure while $31 / 2$ "had the highest choke. Since the bottom-hole pressure and choke pressure have a positive correlation, the bottom-hole pressure increases as the choke pressure rises which caused an increase in gas velocity as it shown in Figure 4.27.
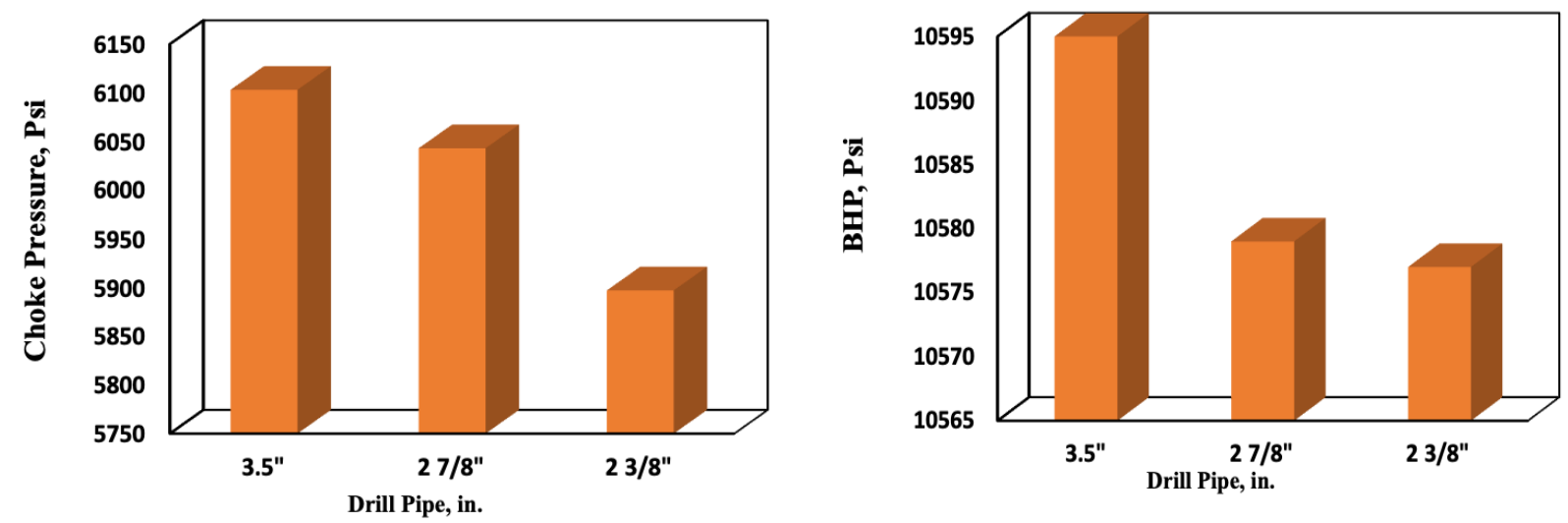

Figure 4. 26: Choke Pressure and BHP when the Gas Influx Reaches the Surface for Different Drill Pipe Sizes - WBM

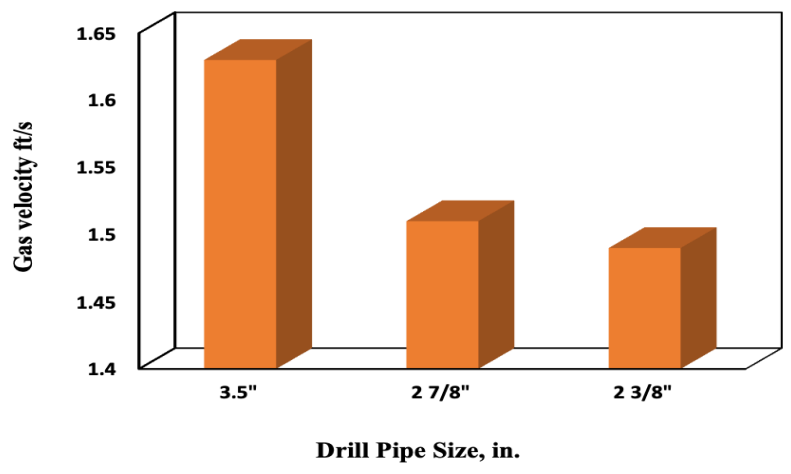

Figure 4. 27: Gas Velocity when the Gas Influx Reaches the Surface for different Drill Pipe Sizes - WBM 
The gas velocity increases when the BHP pressure is high; in this case, the $31 / 2$ " DP had the most elevated BHP pressure, leading to an increase in the gas velocity. By comparing the three different sizes, the larger diameter of DP impacted the choke pressure, affecting the BHP and increasing the gas rise velocity. The highest gas velocity occurred faster until the gas influx reached the surface Table 13 shows the results of drill pipe size for each run and how long it takes for each run until the gas influx reaches the surface.

Table 13: Results of Different Drill Pipe Sizes when Gas Influx reaches the surface - WBM

\begin{tabular}{|c|c|c|c|c|c|}
\hline \multicolumn{6}{|c|}{ Drill Pipe Size } \\
\hline Size & Choke Pressure (Psi) & $\begin{array}{c}\text { BHP } \\
(\text { Psi) }\end{array}$ & Average gas velocity ft/s & $\begin{array}{c}\text { Time } \\
\text { (MIN) }\end{array}$ & Improvement \\
\hline $31 / 2 "$ & 6103 & 10595 & 1.63 & 48.6 & Base Model \\
\hline $27 / 8 "$ & 6114 & 10579 & 1.51 & 50 & $-2.9 \%$ \\
\hline $23 / 8 "$ & 6130 & 10577 & 1.49 & 51.4 & $-5.8 \%$ \\
\hline
\end{tabular}

\subsubsection{Effects of Kick Volume}

The impact of the kick volume causes gas migration to the surface. In this case, three wells with different kick volumes were studied to understand how the kick volume would affect gas migration. The three different values studied in this model include $20 \mathrm{bbl}, 25 \mathrm{bbl}$, and $30 \mathrm{bbl}$. As shown in Figure 4.28, the highest kick volume produced the highest choke pressure. Indeed, an increase in choke pressure resulted in an increase in the BHP.
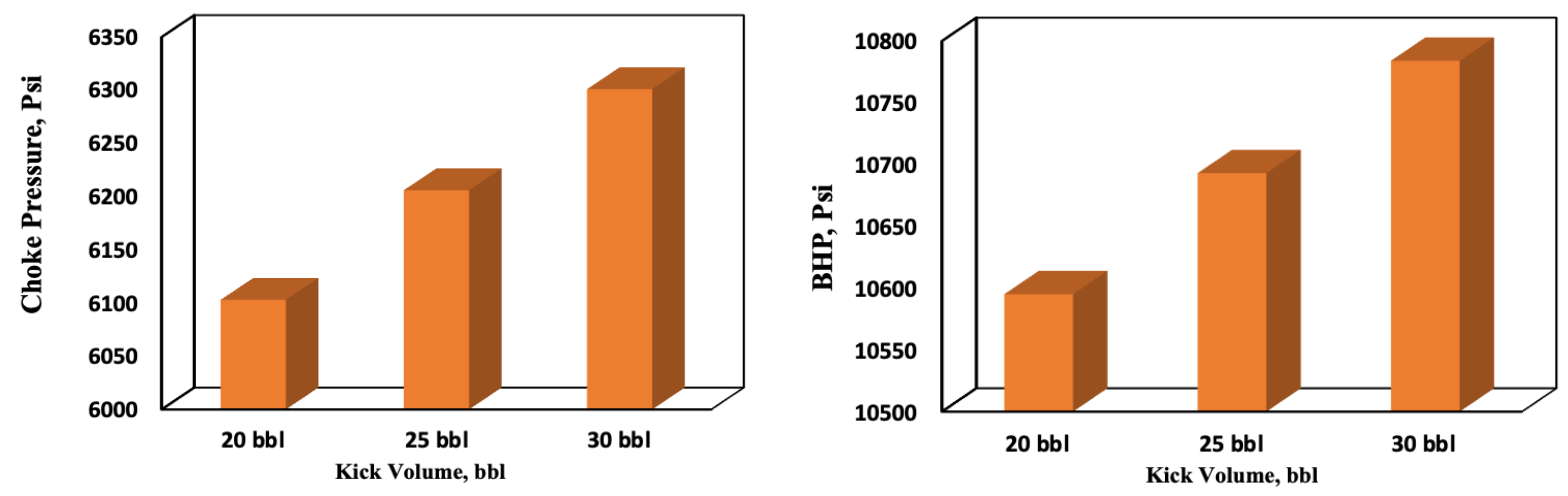

Figure 4. 28: Choke Pressure and BHP when the Gas Influx Reaches the Surface for Different Kick Volumes - WBM

The kick volume affects the choke pressure behavior as a higher kick volume leads to an increase in choke pressure. While comparing the $20 \mathrm{bbl} \mathrm{kick}$ and the $30 \mathrm{bbl}$ volume, as the volume 
increases it leads to an increase in choke pressure and BHP, ultimately affecting the gas velocity. As mentioned, the gas velocity was impacted by the highest BHP, as shown in Figure 4.29. Table 14 shows the results of kick volume for each run and how long it takes for each run until the gas influx reaches the surface.

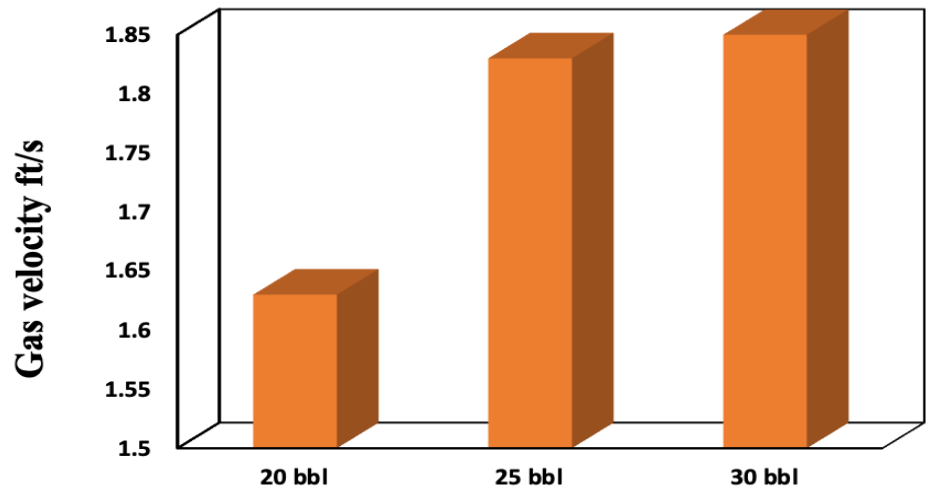

Kick Size, bbl.

Figure 4. 29: Gas Velocity when the Gas Influx Reaches the Surface for Different Kick Volumes - WBM

Table 14: Results of Different Kick Volumes when Gas Influx Reaches the Surface - WBM

\begin{tabular}{|c|c|c|c|c|c|}
\hline \multicolumn{7}{|c|}{ Kick Volume } \\
\hline $\begin{array}{c}\text { Size } \\
\text { Bbl. }\end{array}$ & $\begin{array}{c}\text { Choke Pressure } \\
(\text { Psi) }\end{array}$ & $\begin{array}{c}\text { BHP } \\
(\text { Psi) }\end{array}$ & Average gas velocity ft/s & Time (Min) & Improvement \\
\hline 20 & 6103 & 10595 & 1.63 & 48.6 & Base Model \\
\hline 25 & 6206 & 10693 & 1.83 & 44.7 & $8.0 \%$ \\
\hline 30 & 6301 & 10784 & 1.85 & 40.2 & $17.3 \%$ \\
\hline
\end{tabular}

\subsubsection{Effects of Mud Density}

Mud density had a significant impact on gas migration while using the OBM. To understand the effect on gas migration in WBM, the same mud density and reservoir pressure were used in water-based mud and oil-based mud: 12 ppg with 5360 Psi, 11 ppg with 5004 psi, and 10.33 ppg with 4760 psi. By comparing the three different mud weights with each other, the choke pressure increases by $12 \mathrm{ppg}$. In the $11 \mathrm{ppg}$ and $10.33 \mathrm{ppg}$, one can notice a decrease in the choke pressure, as shown in Figure 4.30. 

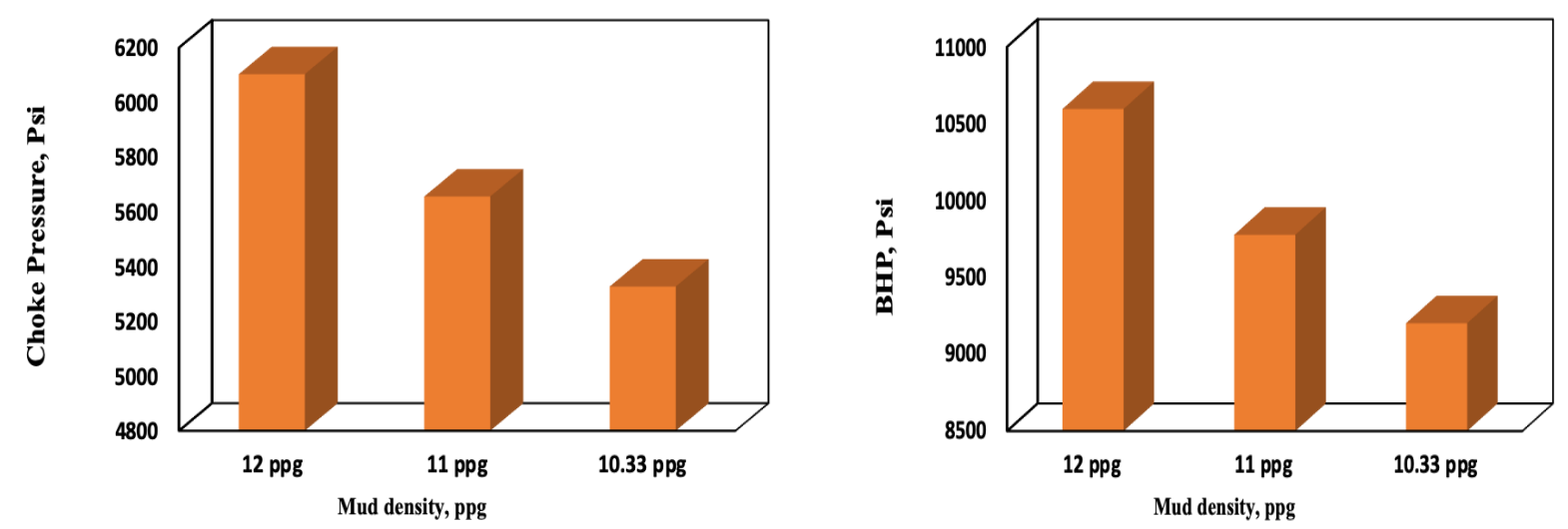

Figure 4. 30: Choke Pressure and BHP when the Gas Influx Reaches the Surface for Different Mud Densities - WBM

The heaviest mud weight has the highest BHP because of the largest reservoir pressure. Since the 12 ppg has the highest reservoir pressure the choke pressure and BHP increased because of the high reservoir temperature.

Each run has an influx as it enters the wellbore, ultimately reaching the surface; however, three different reservoir pressures were experienced. Notably, 12 ppg mud is the heaviest mud, which took the influx more time until it reached the surface. As discussed above, the highest BHP impacted the gas velocity, which caused the gas to migrate faster. However, in this case, the mud density had a significant impact on the gas velocity. Truly, the 12 ppg had the highest choke pressure and BHP; however, it had the slowest time until the gas migrated upward. Also, it can be noted that the heaviest mud migrated slower than the lightest mud. As shown in Figure 4.32, the 10.33 ppg was the fastest until the gas kick reached the surface, while the 12 ppg mud weight was the slowest until the gas started to migrate to the surface, proving that the lightest mud weight migrated faster.

As discussed, mud density has a significant impact on the gas velocity. As shown in Figure 4.31, the lighter mud had the faster mud density while the heavier mud had the slowest velocity. In every parameter, the highest BHP had the quickest gas velocity. However, in this case, it is not because the BHP was increasing in the $12 \mathrm{ppg}$ as a result of the reservoir pressure difference in each case; rather, it could not be the same as the other parameter due to the different mud density, which impacted the hydrostatic pressure. Table 15 shows the results of mud density for each run and how long it takes for each run until the gas influx reaches the surface. 


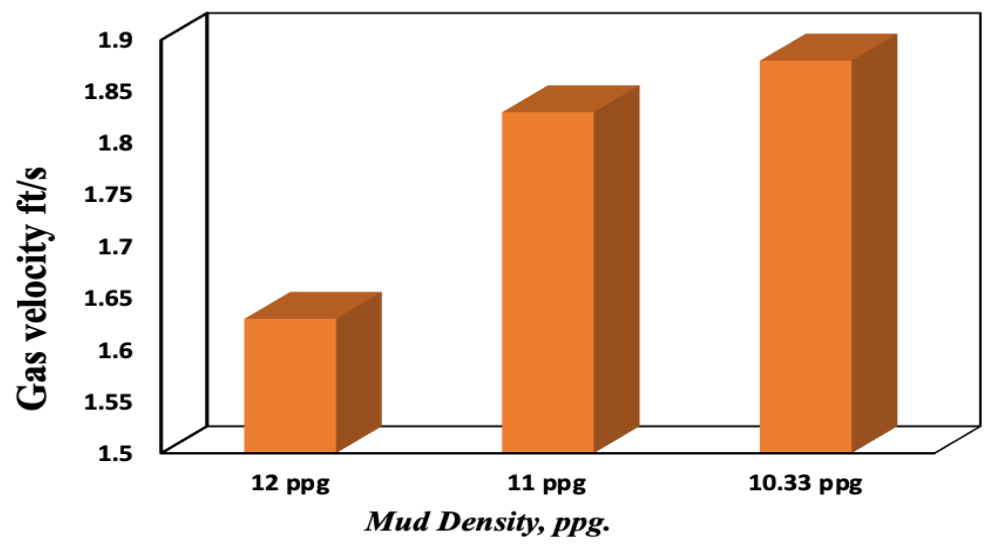

Figure 4. 31: Gas Velocity when the Gas Influx Reaches the Surface for Different Mud Densities -WBM

Table 15: Results of Different Mud Density when the Gas Influx Reaches the Surface - WBM

\begin{tabular}{|c|c|c|c|c|c|}
\hline \multicolumn{7}{|c|}{ Mud density } \\
\hline $\begin{array}{c}\text { Density } \\
\text { ppg }\end{array}$ & $\begin{array}{c}\text { Choke Pressure } \\
\text { (Psi) }\end{array}$ & $\begin{array}{c}\text { BHP } \\
\text { (Psi) }\end{array}$ & Average gas velocity ft/s & Time (Min) & Improvement \\
\hline 12 & 6103 & 10595 & 1.63 & 48.6 & Base Model \\
\hline 11 & 5656 & 9776.8 & 1.83 & 47 & $3.3 \%$ \\
\hline 10.33 & 5327 & 9201 & 1.88 & 46.2 & $4.9 \%$ \\
\hline
\end{tabular}

\subsubsection{Effects of Reservoir Temperature}

As discussed in the OBM section, the highest temperature causes the molecules to move faster, which means the higher the reservoir velocity the faster gas velocity Three runs recorded the behavior of the choke pressure, BHP, and gas velocity to understand these changes while changing the temperature.

From Figure 4.32, the lowest reservoir temperature had a high BHP, while the highest temperature had the lowest BHP. In this case, it can be concluded that the reservoir characteristics impacted the pressures in the wellbore, as it appears in mud density results, by comparing the three runs in a side-by-side plot, it appears that with the highest temperature, the influx reached the surface slower than the lowest reservoir temperature. 

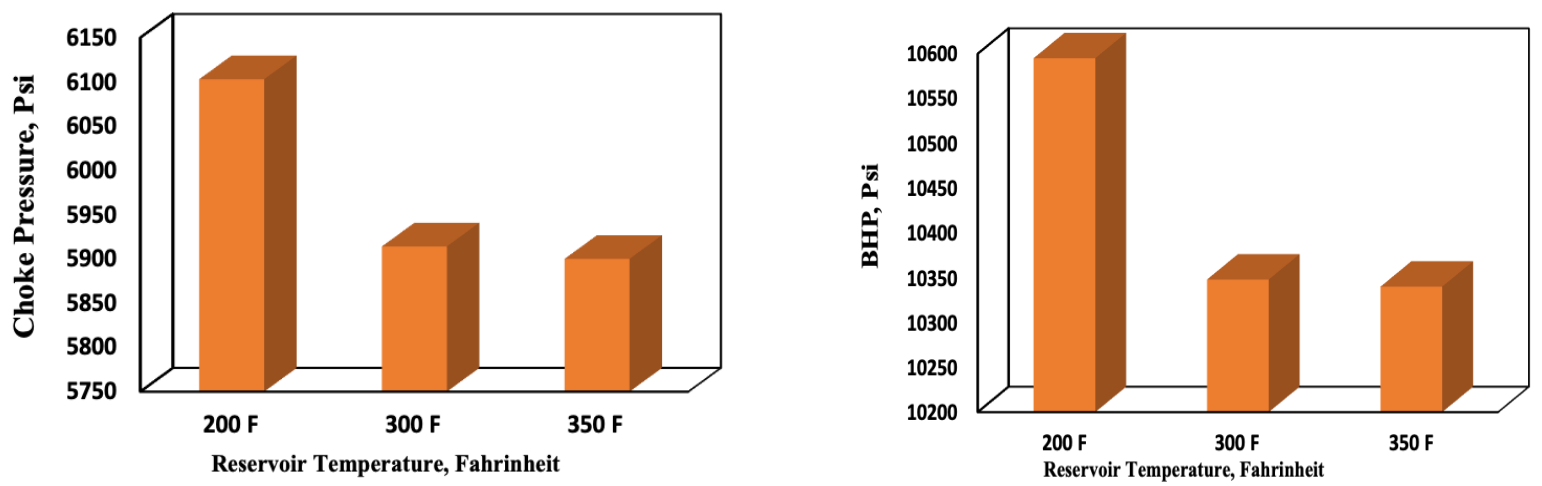

Figure 4. 32: Choke Pressure and BHP when the Gas Influx Reaches the Surface for Different Reservoir Temperatures - WBM

As shown in Figure 4.33, the highest reservoir pressure helps the influx migrate faster with the highest gas velocity. This is due to the high temperature; thus, the more energetic the molecules. The reservoir temperature impacts the solubility the most and while using water-based mud the impact of the reservoir temperature is not same as it is while using oil-based mud. Table 16 shows the results of reservoir temperature for each run and how long it takes for each run until the gas influx reaches the surface.

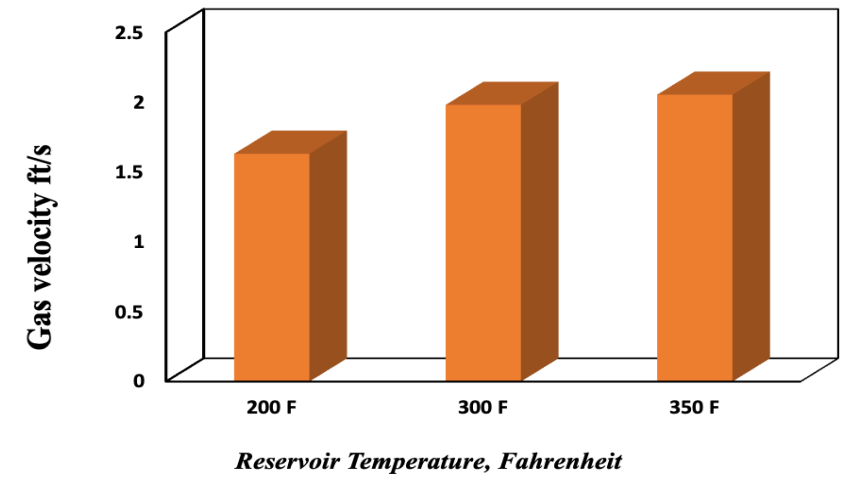

Figure 4. 33: Gas Velocity when the Gas Influx Reaches the Surface for Different Reservoir Temperatures - WBM

Table 16: Results of Different Reservoir Temperature when the Gas Influx Reaches the Surface - WBM

\begin{tabular}{|c|c|c|c|c|c|}
\hline \multicolumn{5}{|c|}{ Reservoir Temperature } \\
\hline Temperature & Choke Pressure (Psi) & BHP (Psi) & $\begin{array}{c}\text { Average gas velocity } \\
\mathrm{ft} / \mathrm{s}\end{array}$ & Time (Min) & Improvement \\
\hline $250^{\circ} \mathrm{F}$ & 6103 & 10595 & 1.63 & 48.6 & Base Model \\
\hline $300^{\circ} \mathrm{F}$ & 5914 & 10348 & 1.98 & 47.8 & $1.6 \%$ \\
\hline $350^{\circ} \mathrm{F}$ & 5922 & 10340 & 2.053 & 46.7 & $3.9 \%$ \\
\hline
\end{tabular}




\subsection{Summary of Result}

In this section, all results from water-based mud and oil-based mud are summarized to clarify the impact of WBM and OBM on gas velocity and time until gas kick migrates to the surface. Section 4.3.1 presents water-based results, while section 4.3.2 presents oil-based mud results.

\subsubsection{Water-Based Mud Summary of Result}

Figure 4.34 shows the gas velocity of all the parameters, whereas Figure 4.35 shows the time-taken until the gas kick reached the surface.

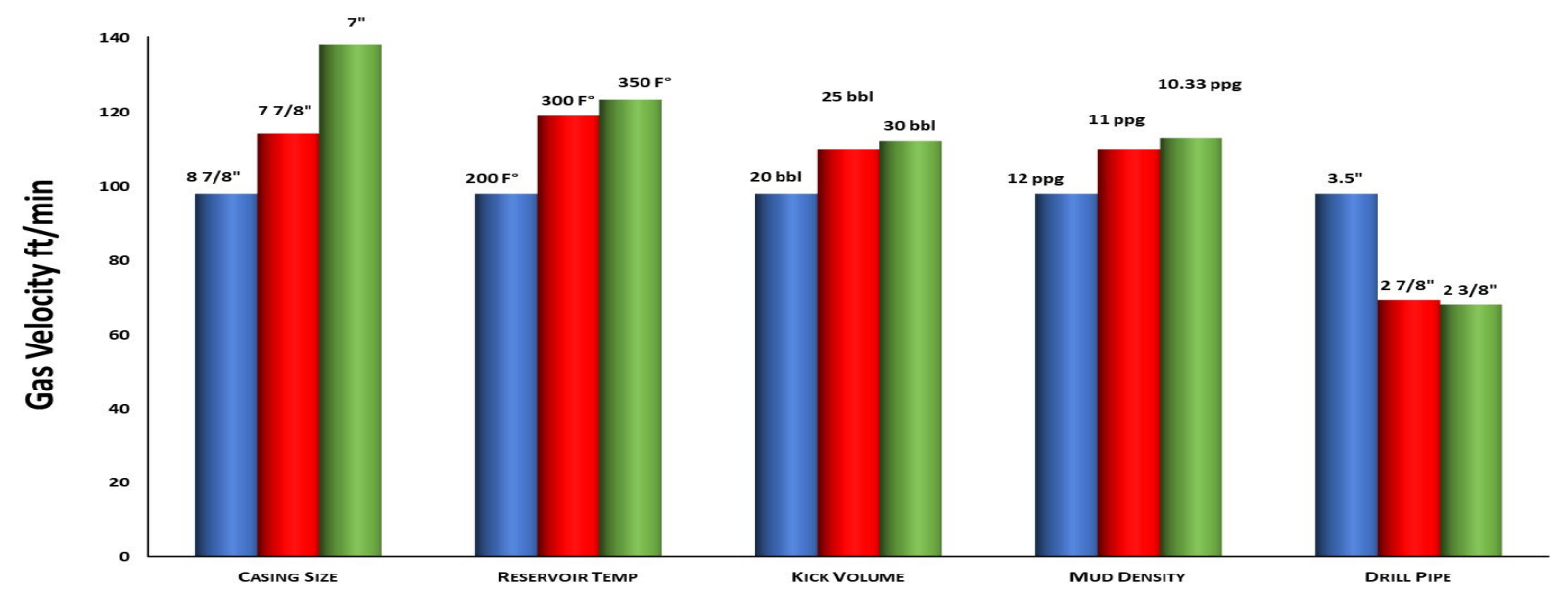

Figure 4. 34: Gas Velocity all Parameters when the Gas Influx Reaches the Surface - WBM

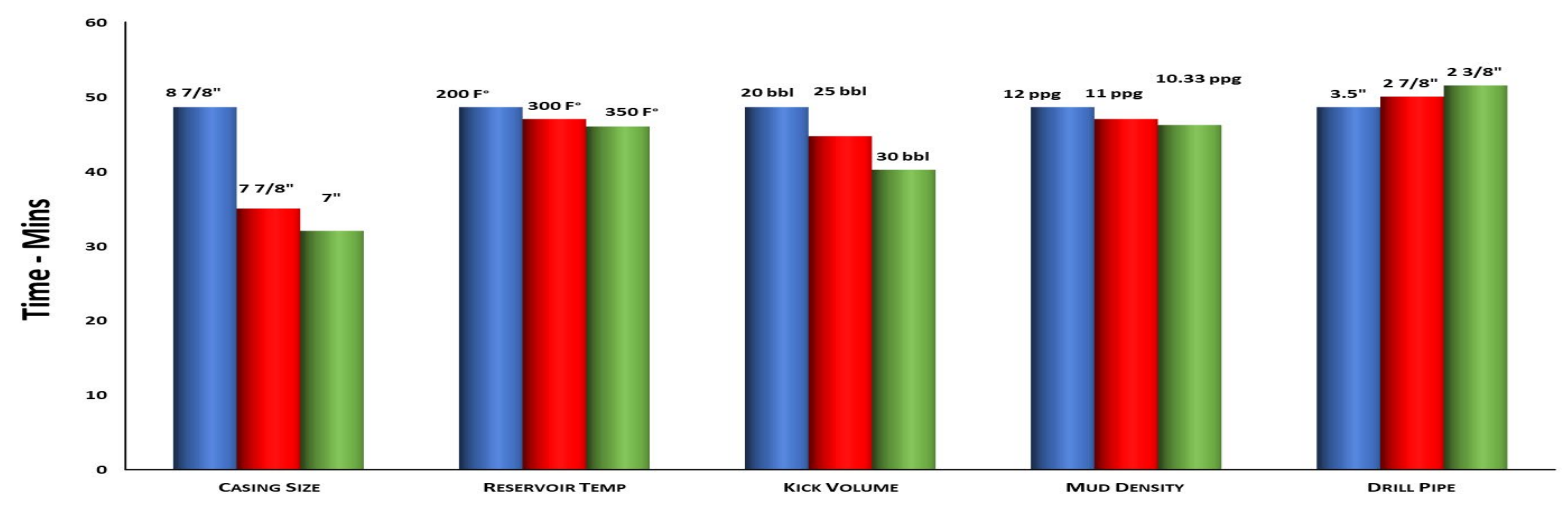

Figure 4. 35: Time of Gas Migrates to the Surface All Parameters - WBM 


\subsubsection{Oil-Based Mud Summary of Result}

Figure 4.36 shows the gas velocity of all the parameters demonstrated, whereas Figure 4.37 shows the time-taken until the gas kick reached the surface

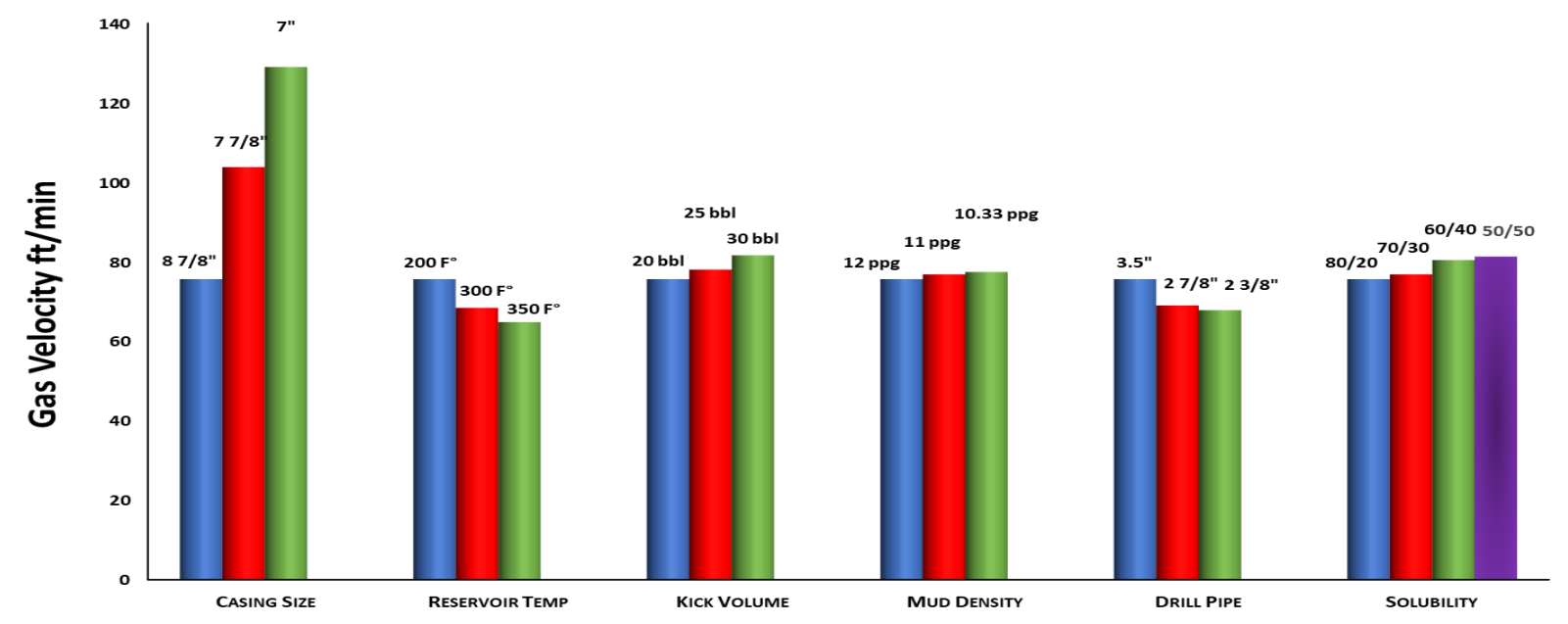

Figure 4. 36: Gas Velocity all Parameters when the Gas Influx Reaches the Surface - OBM

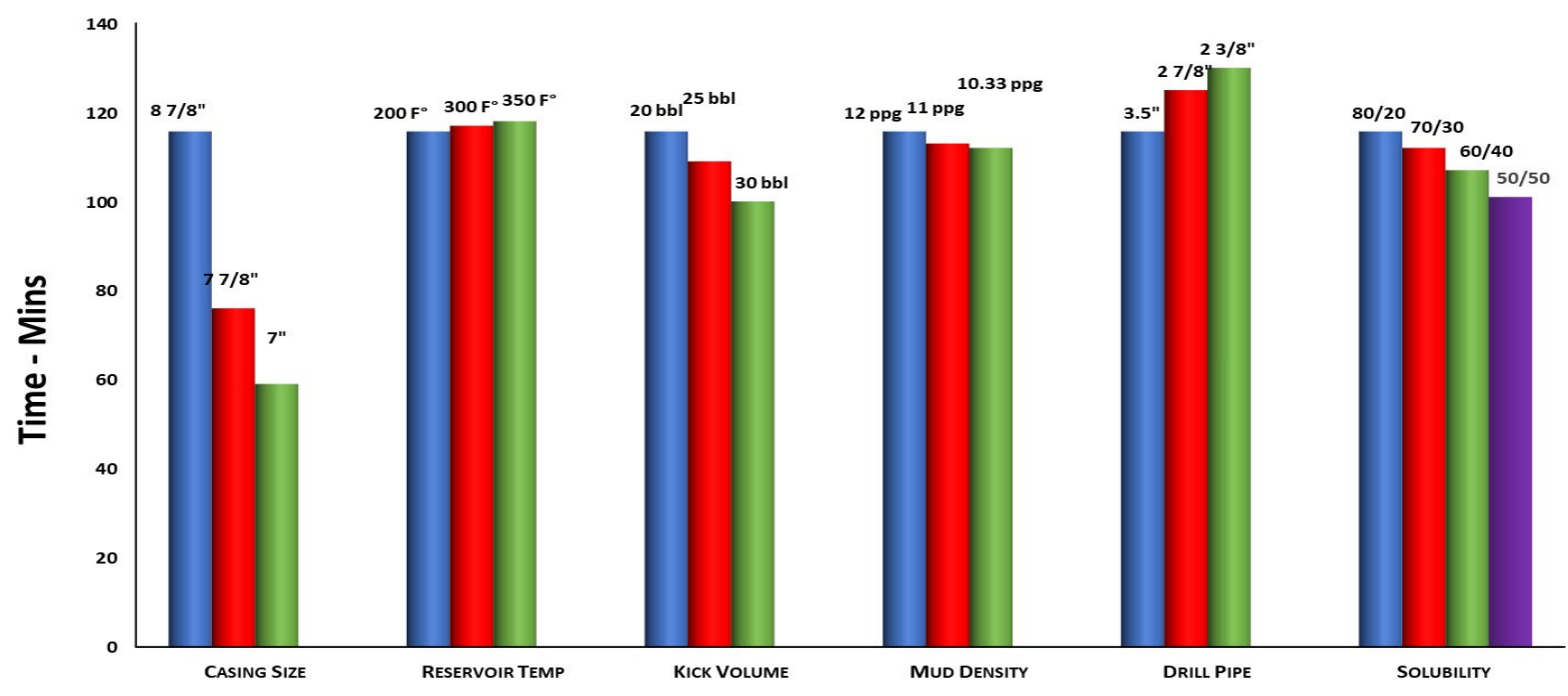

Figure 4. 37: Time of Gas Migrates to the Surface All Parameters - OBM 


\section{CHAPTER 5: CONCLUSION}

A modeling study was implemented to evaluate the impact of critical parameters on gas migration during the gas kick in both water- and oil-based mud. The following conclusions can be drawn from this work:

1. In water-based mud, the Average gas velocity is $97.8 \mathrm{ft} / \mathrm{Min}$, while the Average gas velocity in the oil-based mud is $75.6 \mathrm{ft} / \mathrm{Min}$. Thus, the water-based mud is faster than the oil-based mud by $58 \%$. The gas is discharged from the well within 48.2 Minutes in the water-based mud, while the oil-based mud takes 115.7 Minutes.

2. Drill pipe and drill collar have the same effect, which impacts the gas migration because of the area between the drill pipe and the annulus. If the DP is large, the area of the annulus is small, then the pressure increases and leads to an increase in gas velocity.

3. Mud densities impact the gas migration in two factors in both WBM and OBM; first, when the mud weight is light, the influx moves faster than the heaviest mud weight and impacts the reservoir pressure.

4. A larger kick size occurs faster for the gas to migrate to the surface. This means the more significant the kick volume, the faster gas velocity, then the gas migrates faster in OBM. The larger the kick volume, the lower the percentage of the gas that is dissolved in the mud, which increases the gas velocity in a more significant influx. $30 \mathrm{bbl} \mathrm{kick}$ is the fastest in time until the influx reaches the surface.

5. Reservoir temperatures impact the gas influx once it starts entering the wellbore. The highest reservoir pressure increases the gas velocity, which means the highest temperature is the fastest velocity. In oil-based mud, the low reservoir temperature led to a low solubility, which means less gas is dissolved in the mud, leading to an increase in gas velocity.

6. The parameters ranked from most effective to least effective on gas migration are casing size, kick volume, drill-pipe size, mud density, and reservoir temperature, while in the OBM the parameters are ranked in order as casing size, kick volume, drill-pipe size, casing sizes impact the gas migration once the gas influx enters the 
casing shoe; the gas influx velocity increases if the casing size is small, and if it is big in diameter, the gas velocity decreases. 


\section{References}

Chafin, D. T. (1994). Sources and migration pathways of natural gas in near-surface ground water beneath the Animas River Valley, Colorado, and New Mexico (Vol. 4006). US Geological Survey.

Crook, R., \& Heathman, J. (1998). Predicting potential gas-flow rates to help determine the best cementing practices. Drilling Contractor, 1(1), 40-43. Retrieved 20 December 2020, from http://www.iadc.org/dcpi/dc-novdec98/n-halliburton.pdf.

Fjelde, K. K., Frøyen, J.., and A. A. Ghauri. "A Numerical Study of Gas Kick Migration Velocities and Uncertainty." Paper presented at the SPE Bergen One Day Seminar, Grieghallen, Bergen, Norway, April 2016. doi: https://doi.org/10.2118/180053-MS

Guner, S., Elshehabi, T., \& Bilgesu, H. I. (2017, April). The Effects of Gas Kick Migration on Wellbore Pressure. In AADE National Technical Conference and Exhibition, Houston, Texas, USA (pp. 1112).

Jahanpeyma, Y., \& Jamshidi, S. (2018). Two-phase Simulation of Well Control Methods for Gas Kicks in Case of Water and Oil-based Muds. Journal of Petroleum Science and Technology, 8(4), 34-48.

Lin, X., Zeng, J., Wang, J., \& Huang, M. (2020). Natural Gas Reservoir Characteristics and Non-Darcy Flow in Low-Permeability Sandstone Reservoir of Sulige Gas Field, Ordos Basin. Energies, 13(7), 1774.

Manikonda, Kaushik, Hasan, Abu Rashid, Kaldirim, Omer, Schubert, Jerome J., and Mohammad Azizur Rahman. "Understanding Gas Kick Behavior in Water and Oil-Based Drilling Fluids." Paper presented at the SPE Kuwait Oil \& Gas Show and Conference, Mishref, Kuwait, October 2019

Monteiro, E. 2005. Study of Methane Solubility in Organic Emulsions Applied to Drilling Fluid Formulation and Well Control. Presented at the SPE Annual Technical Conference and Exhibition.

Nastev, M., Therrien, R., Lefebvre, R., \& Gelinas, P. (2001). Gas production and migration in landfills and geological materials. Journal of contaminant hydrology, 52(1-4), 187-211.

Penoyer, P. (2013). Stray Gas Migration Issues in Well Design and Construction; Considerations in Avoiding Methane Impacts to Drinking Water Aquifers and/or Air Emissions. Oral presentation at the Environmentally Friendly Drilling Workshop on Wellbore Integrity, Cannonsburg, PA. Water Resources Division, Natural Resources Stewardship and Science Directorate of the National Park Service, Fort Collins Colorado. 
Pour, M. M., \& Moghadasi, J. (2007, January). New cement formulation that solves gas migration problems in Iranian south pars field condition. In SPE Middle East Oil and Gas Show and Conference. Society of Petroleum Engineers.

Raheel Zubairy. (2014). "Gas Kick Mechanistic Model." Texas A\&M University

Tissot, B. P., \& Welte, D. H. (1978). An Introduction to Migration and Accumulation of Oil and Gas. In Petroleum Formation and Occurrence (pp. 257-259). Springer, Berlin, Heidelberg.

Yin, H., Si, M., Li, Q., Zhang, J., \& Dai, L. (2019). Kick Risk Forecasting and Evaluating During Drilling Based on Autoregressive Integrated Moving Average Model. Energies, 12(18), 3540.

Zhou, Q., Zhao, H., Li, S., He, Y., \& Zhang, H. (2017). An improved gas kick detection method based on continuous Doppler ultrasonic wave in deep water drilling. Advances in Mechanical Engineering, 9(8), 1687814017715424. 
APPENDIX A:

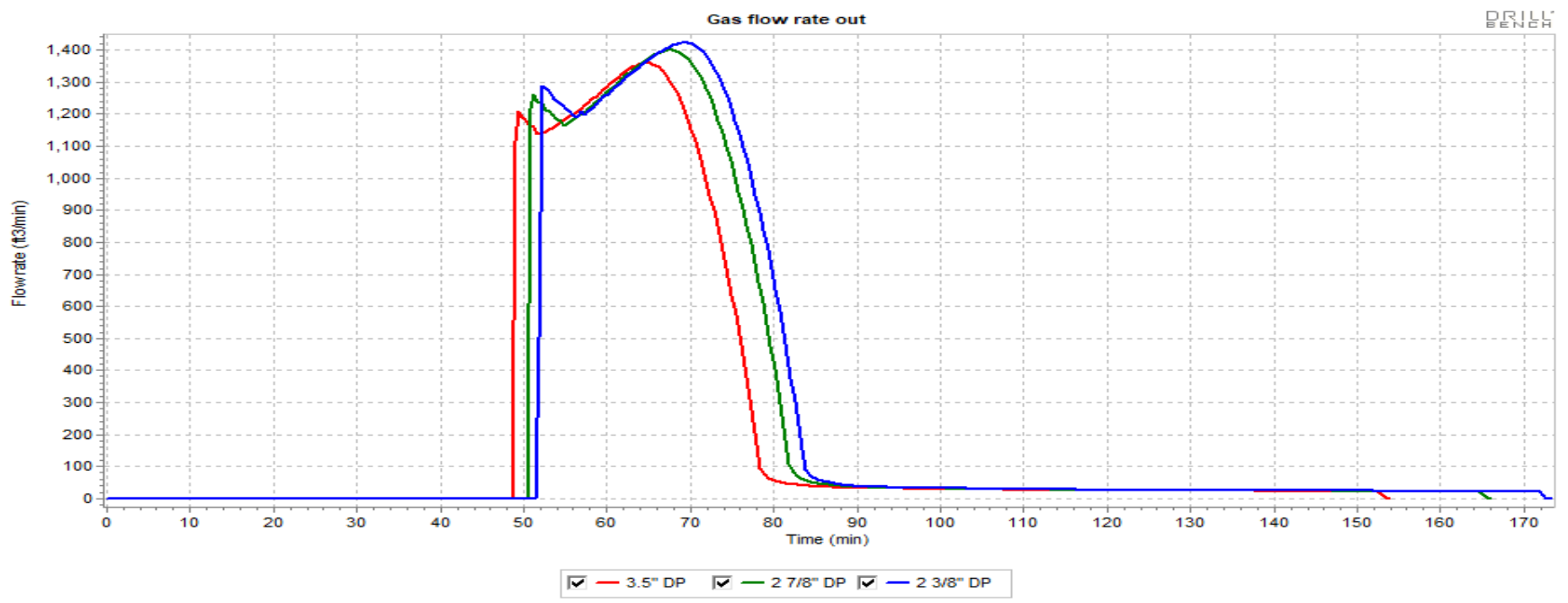

Figure A 1: Gas flow rate for Different Drill Pipe Sizes - WBM

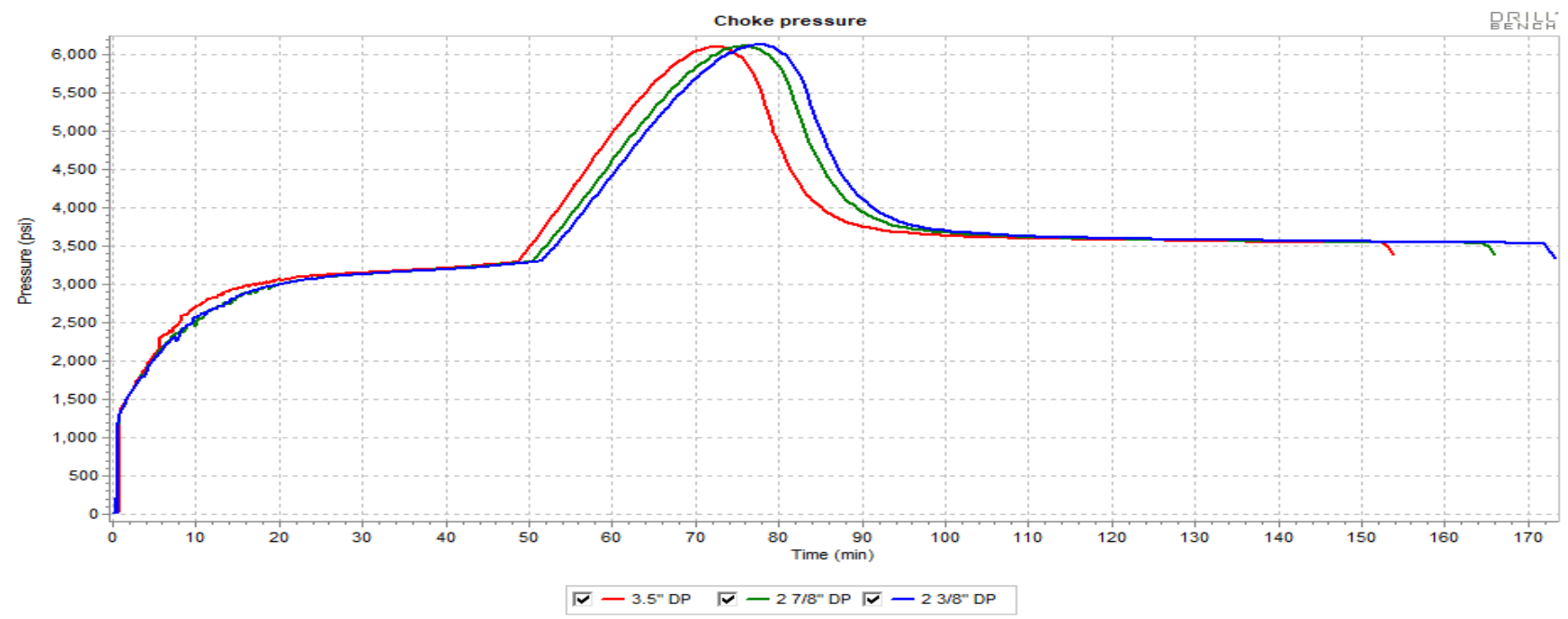

Figure A 2: Choke Pressure VS. Time for Different Drill Pipe Sizes - WBM

45 


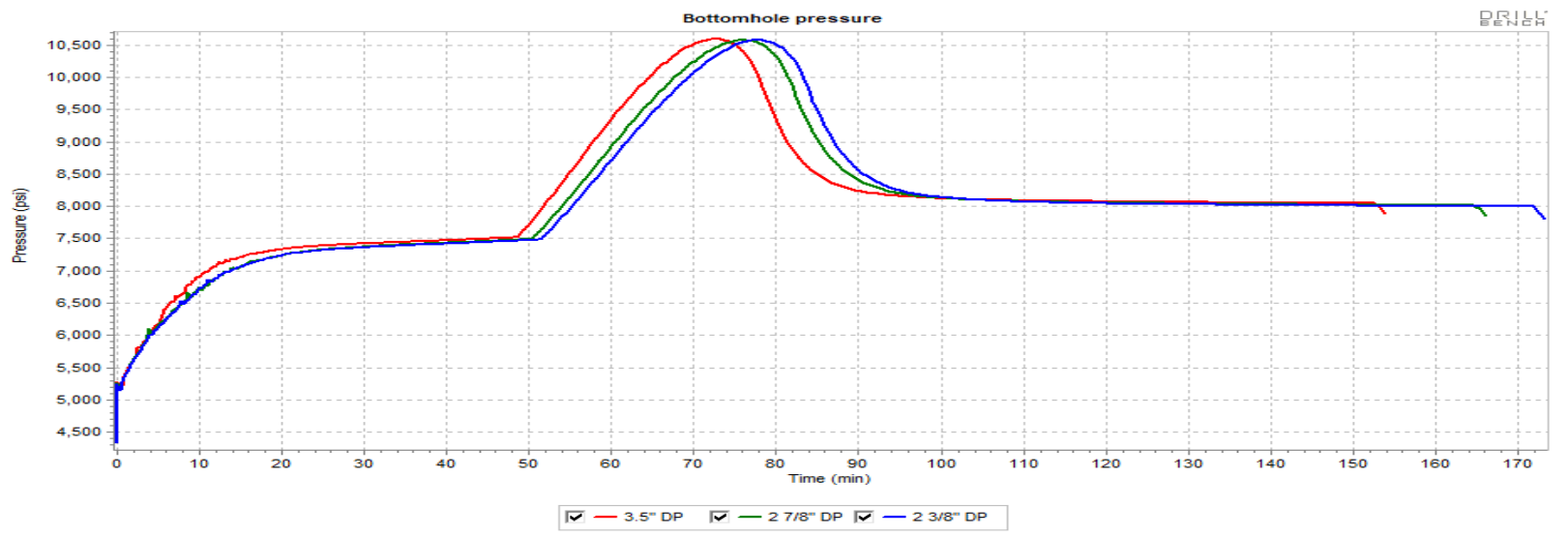

Figure A 3: BHP VS. Time for Different Drill Pipe Sizes - WBM
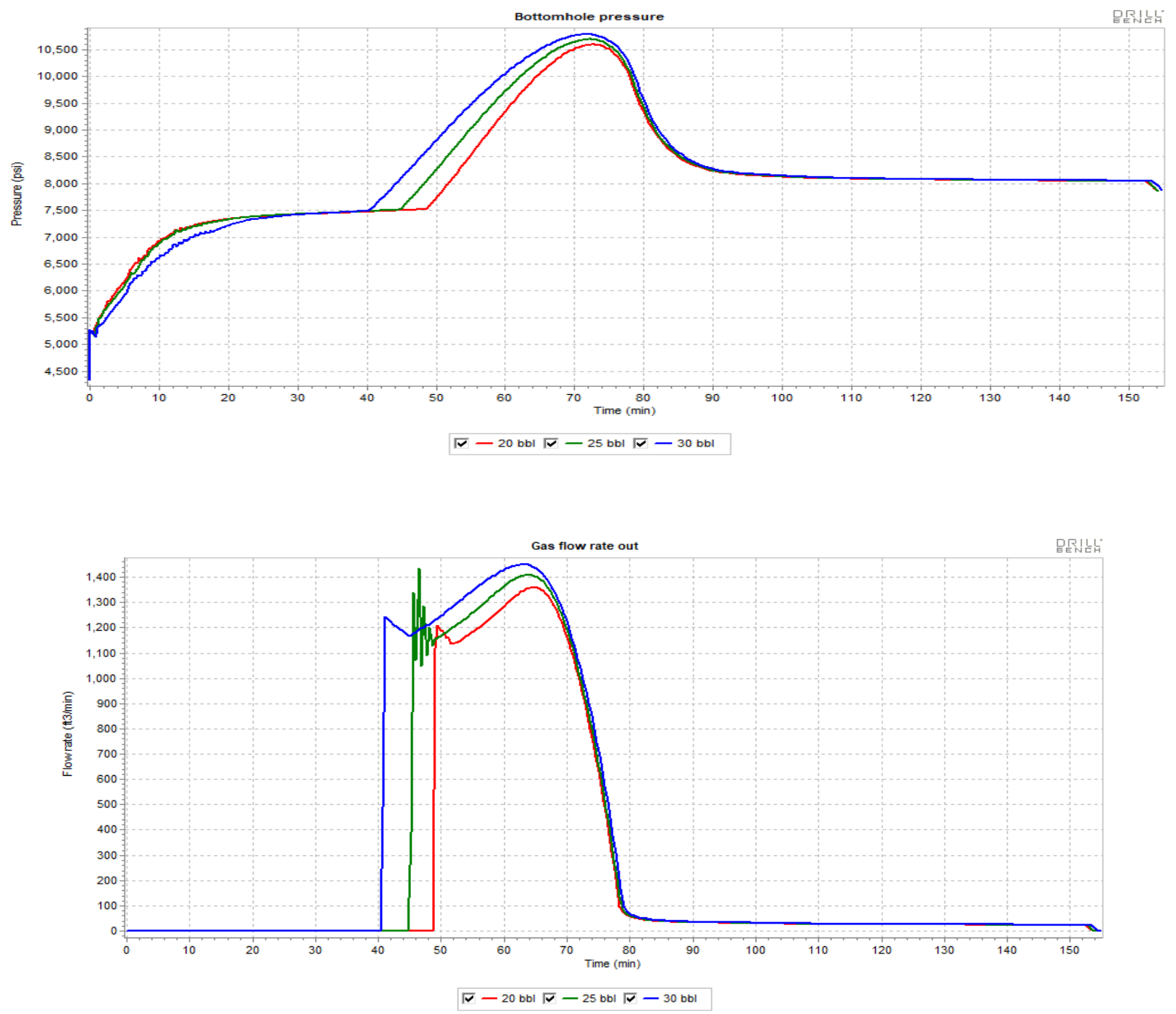

Figure A 5: Gas Flow Rate for Different Kick Volumes - WBM

46 


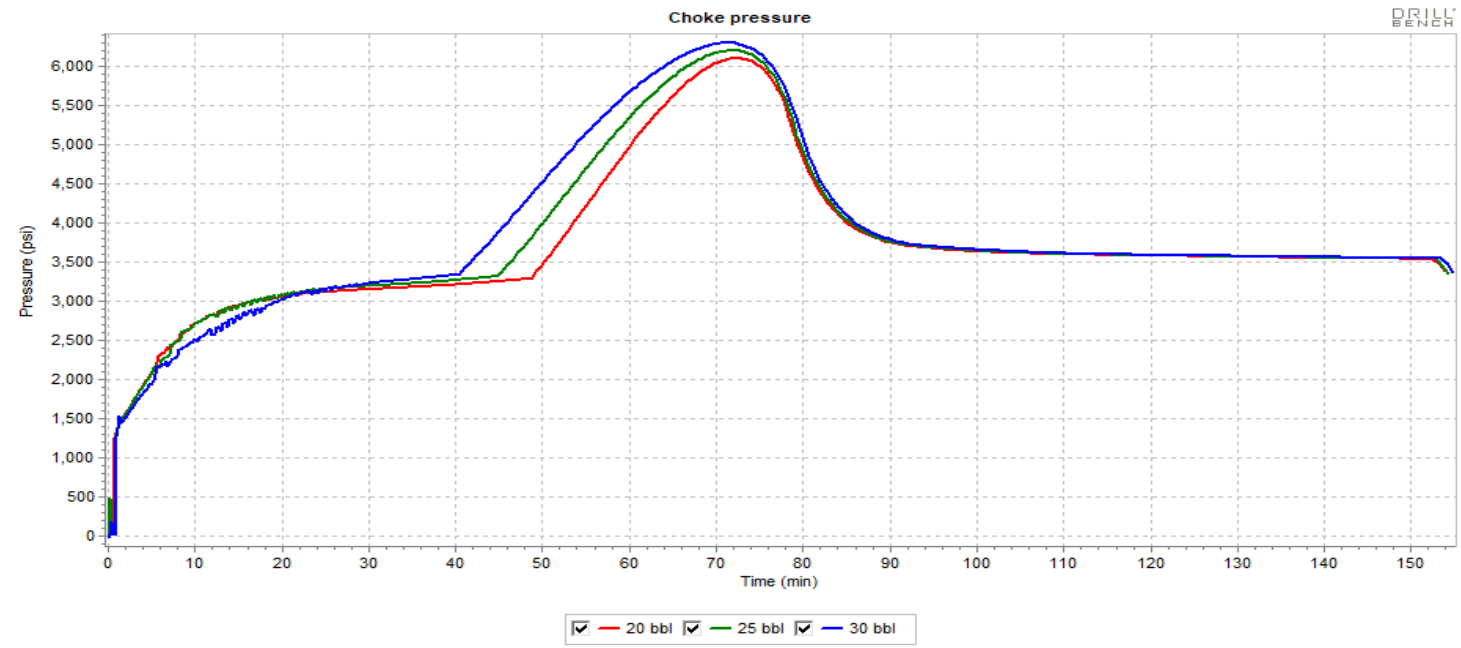

Figure A 6: Choke Pressure VS. Time for Different Kick Volumes - WBM

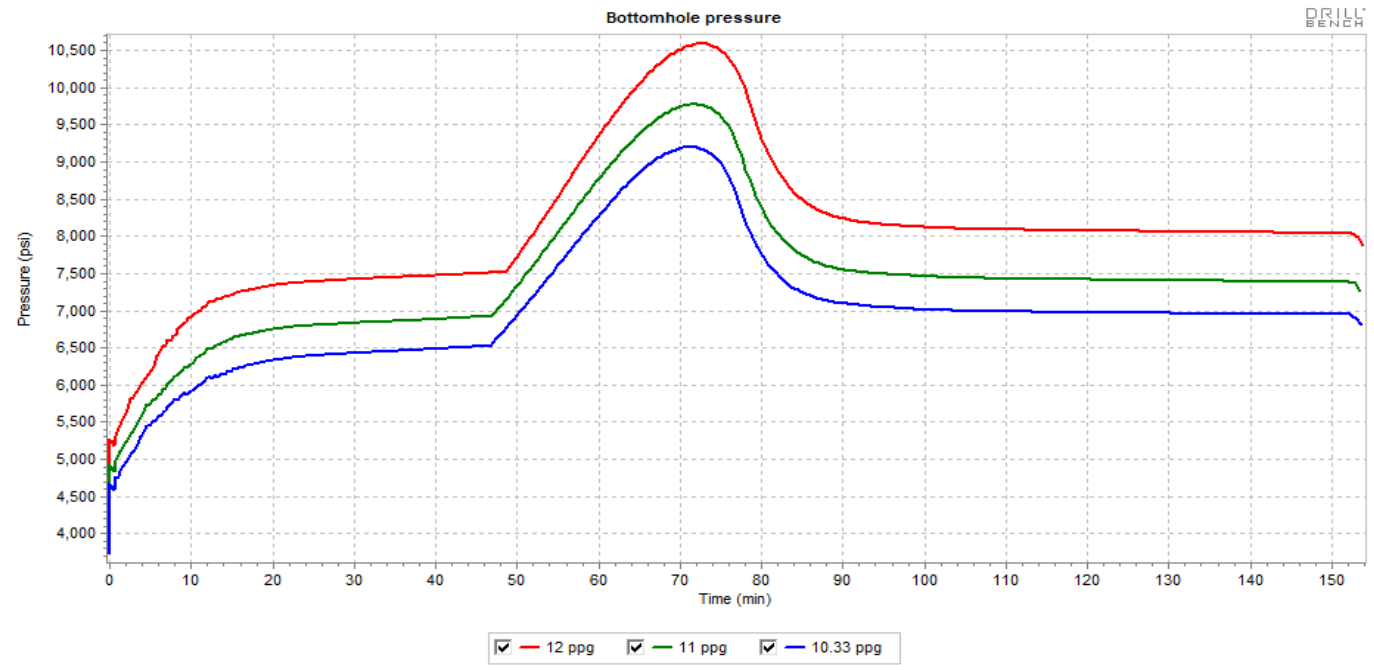

Figure A 7: BHP VS. Time for Different Mud Densities - WBM 


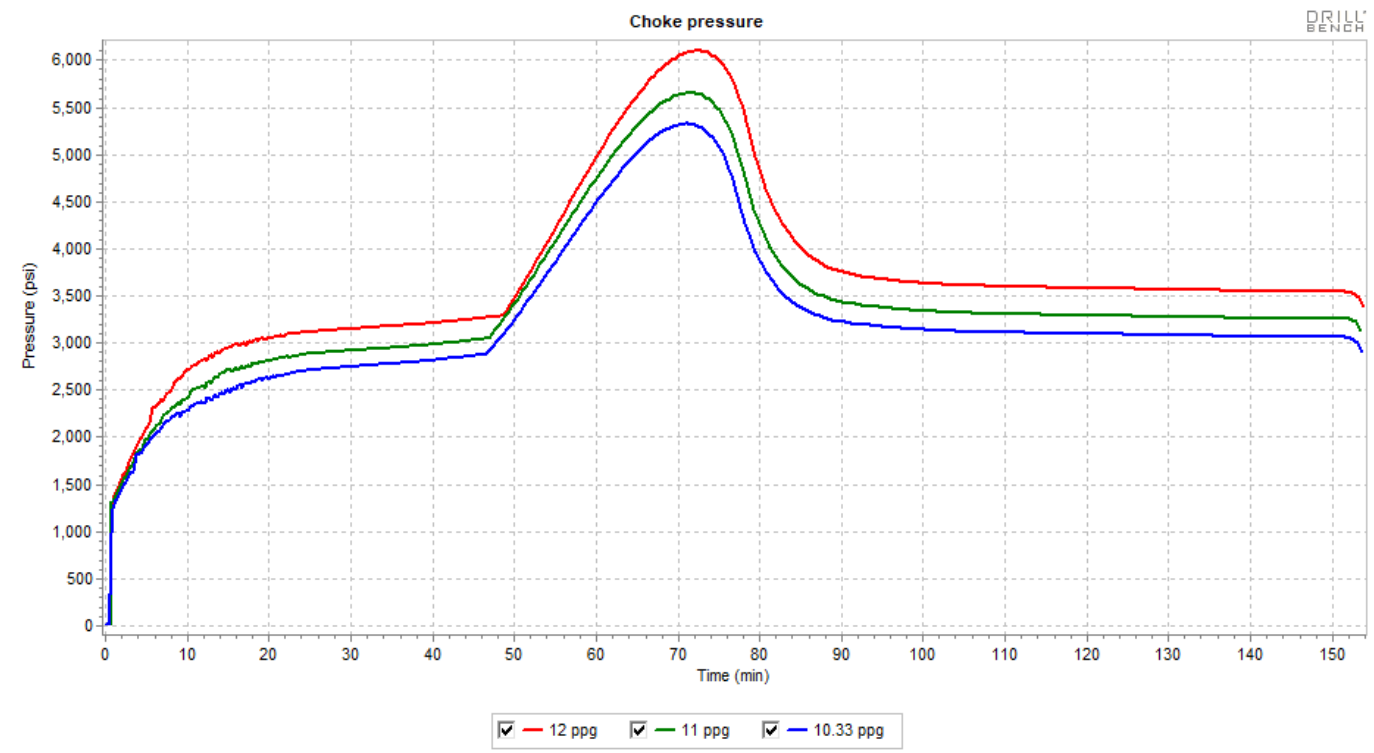

Figure A 8: Choke Pressure VS. Time for Different Mud densities - WBM

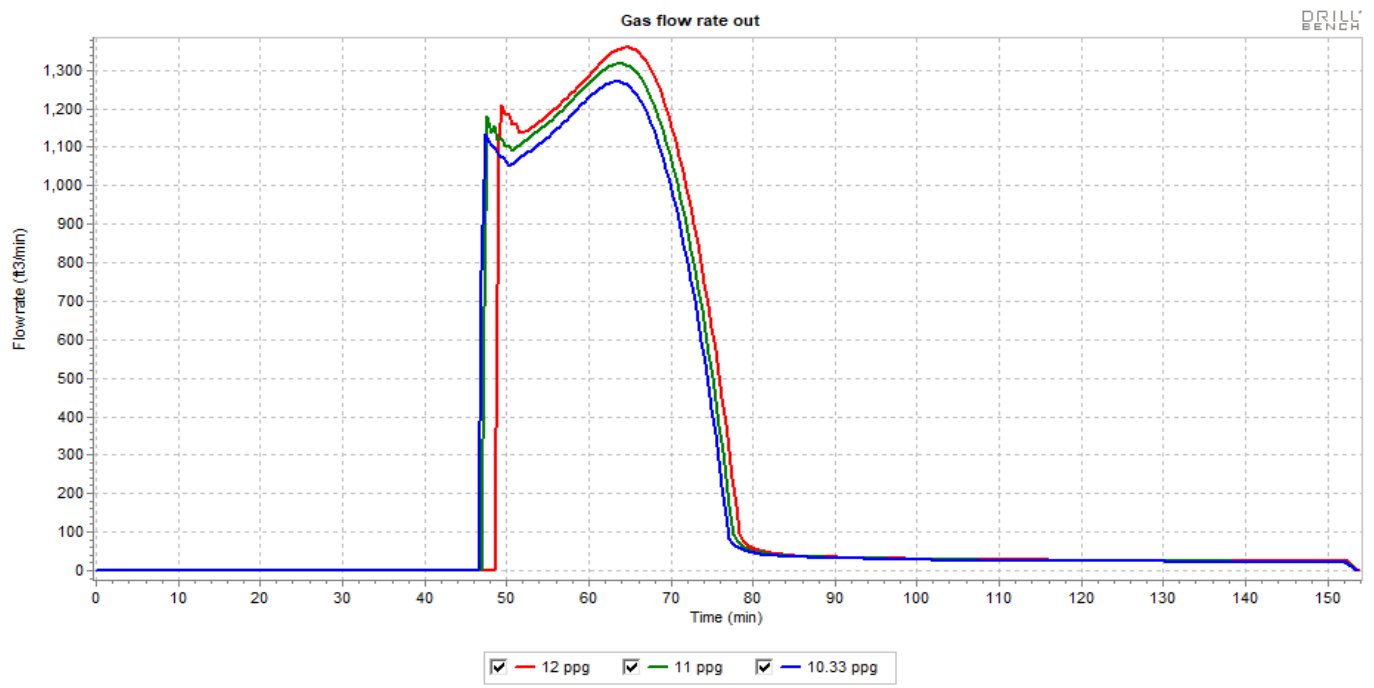

Figure A 9: Gas Flow Rate for Different Mud Densities WBM 


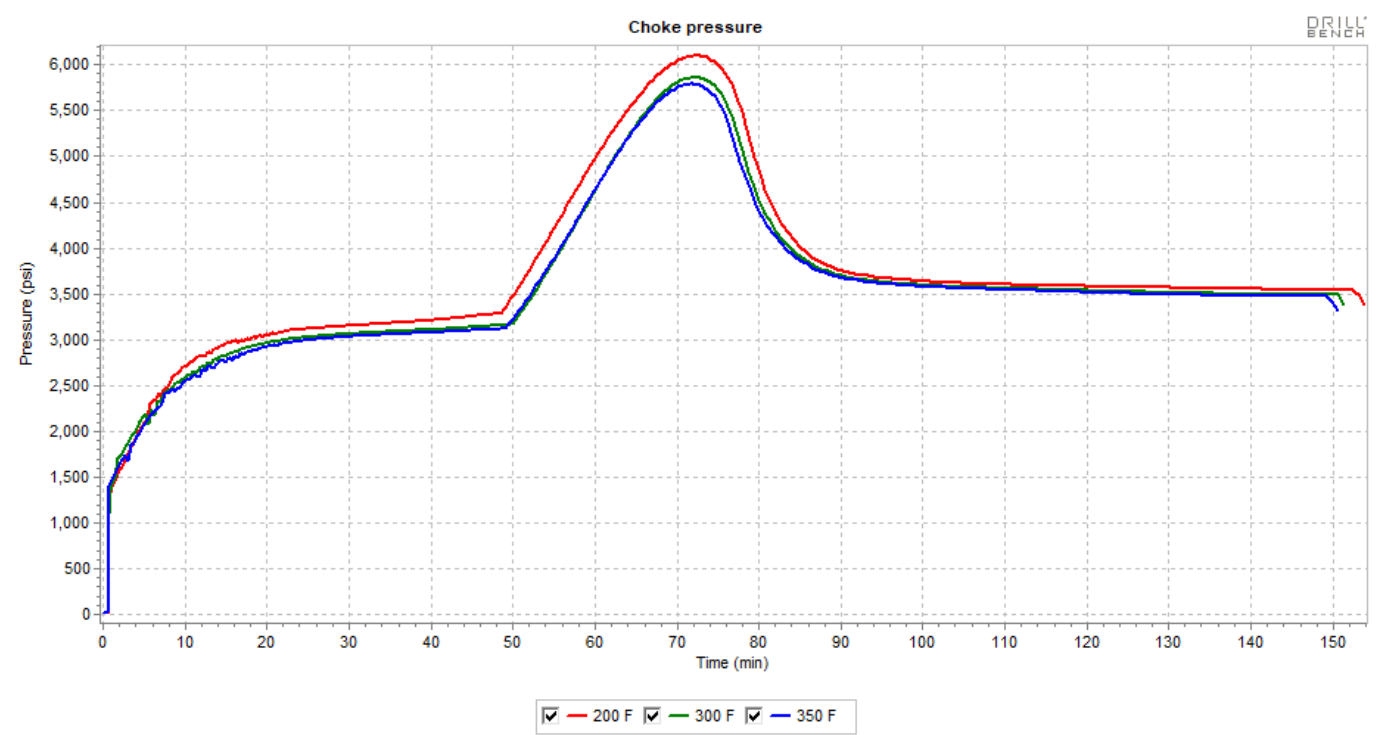

Figure A 10: Choke Pressure VS. Time for Different Reservoir Temperatures - WBM

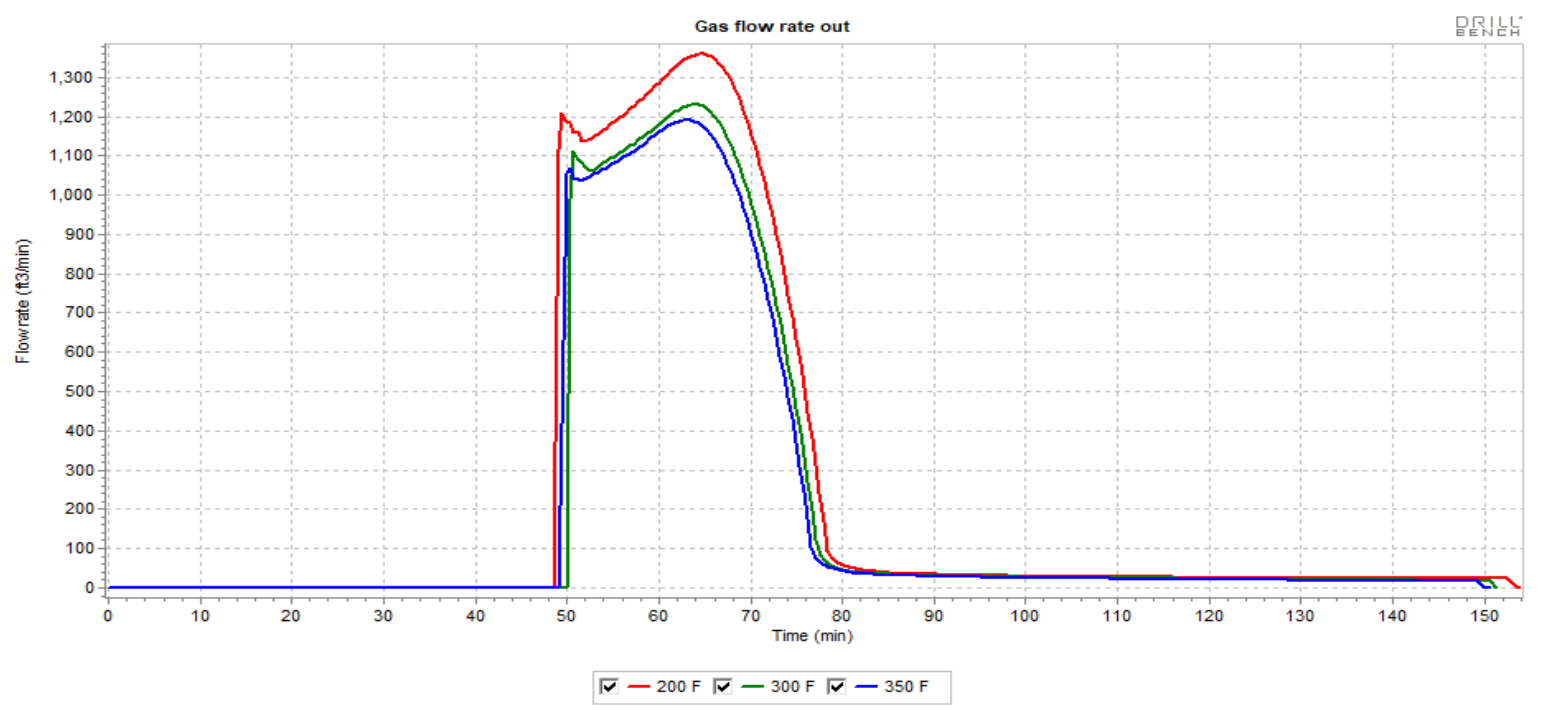

Figure A 11: Gas Flow Rate for Different Reservoir Temperatures - WBM 


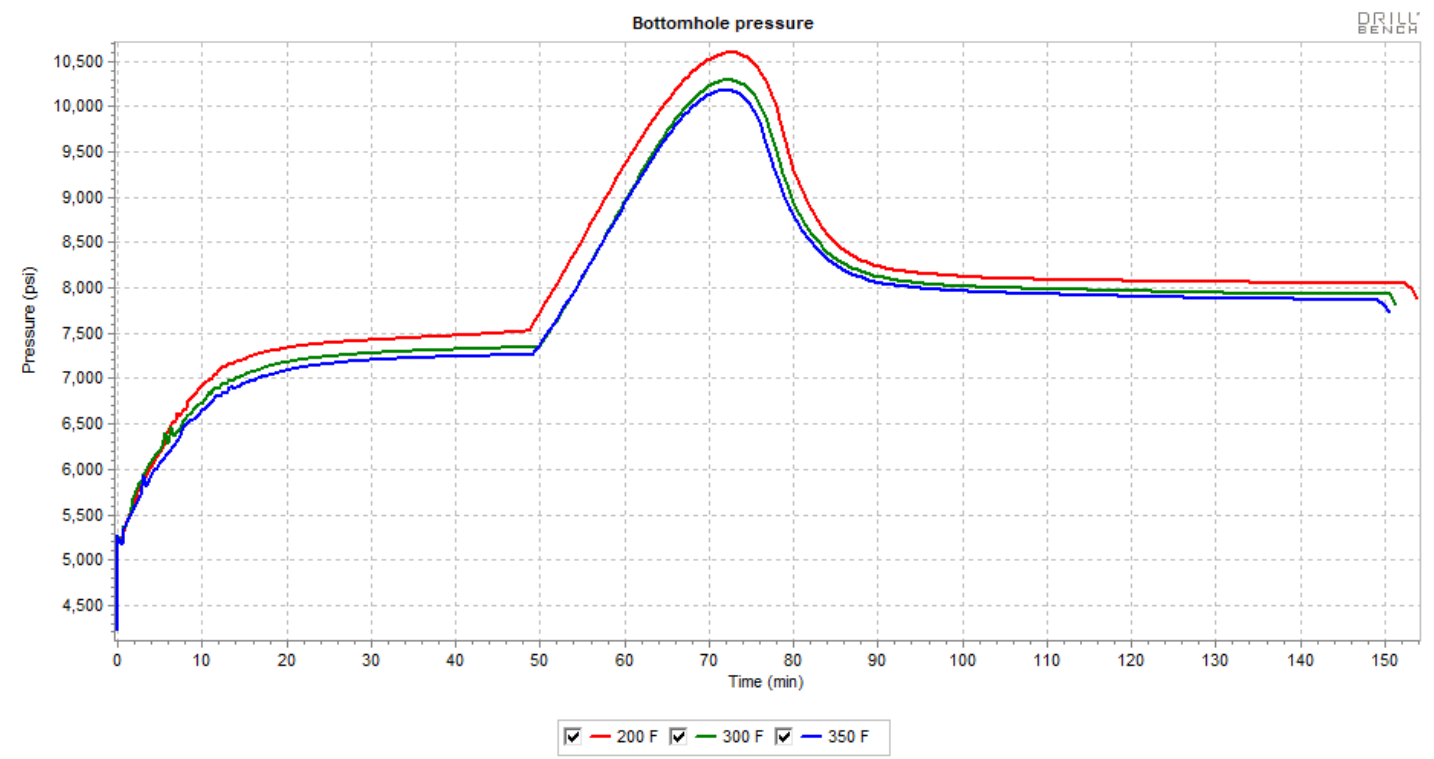

Figure A 12: BHP VS. Time for Different Reservoir Temperatures - WBM 


\section{APPENDIX B:}

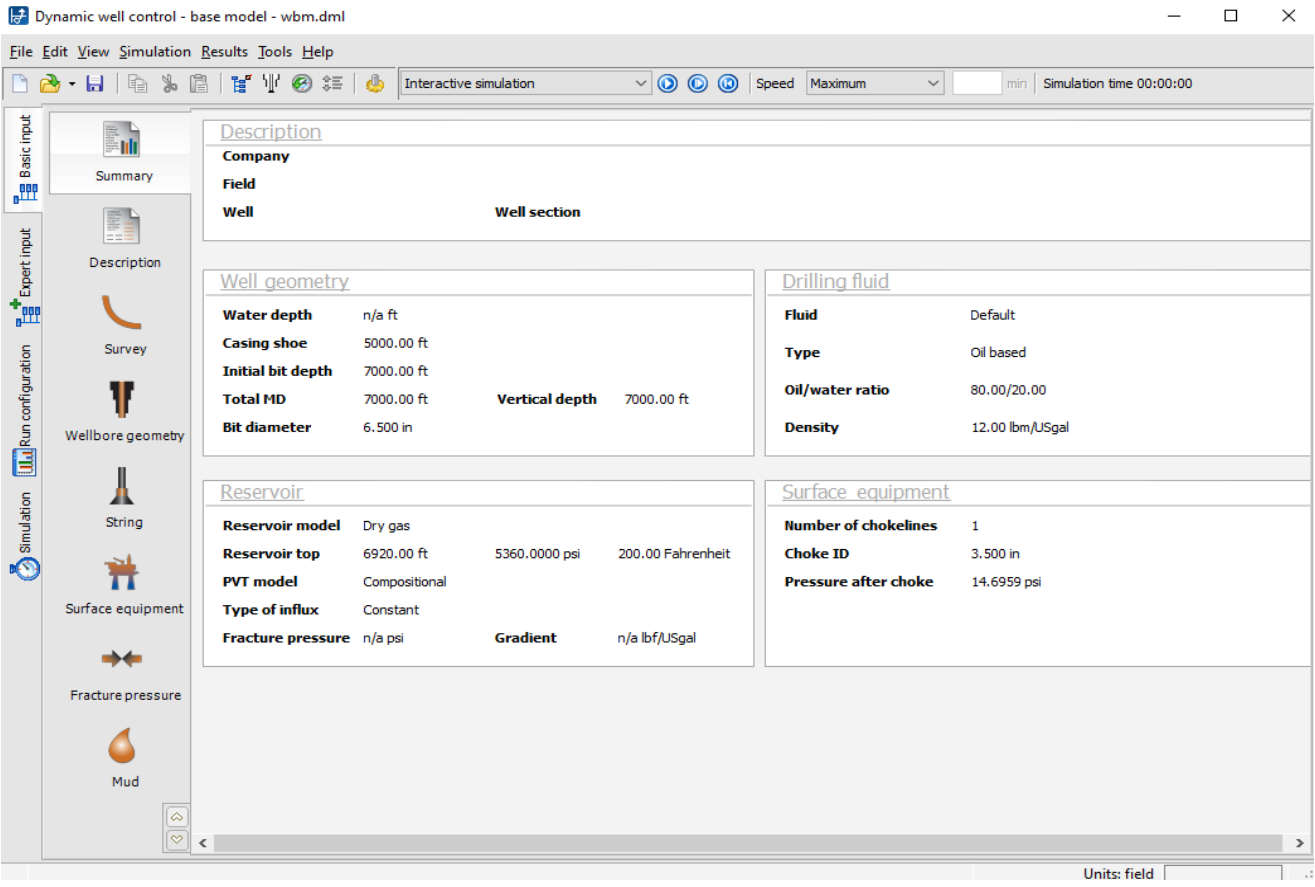

Figure B 1: Summary Page

Dynamic well control - base model - wbm.dml

File É dit View Simulation Results Iools Help

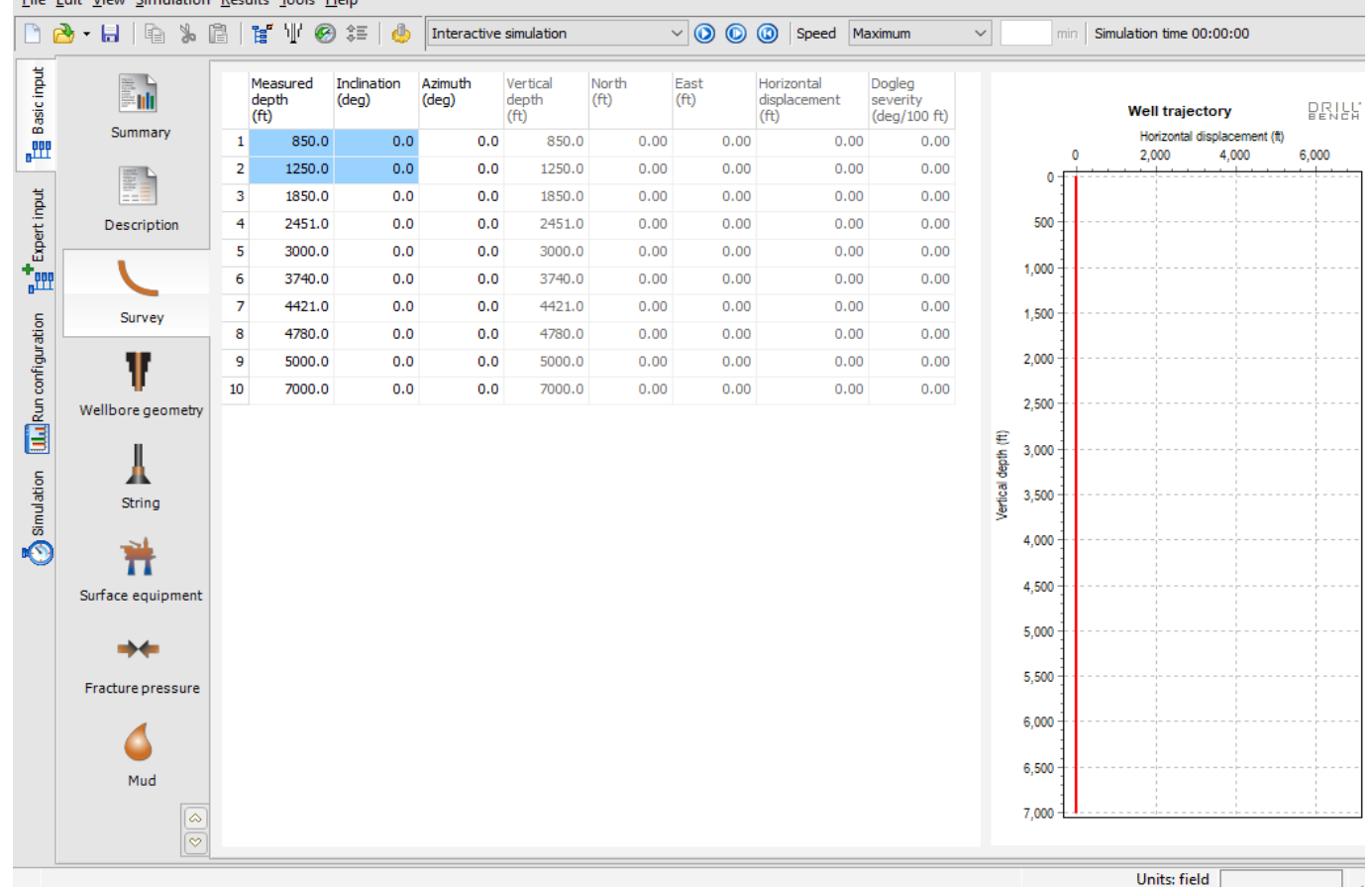

Figure B 2: Survey Page 


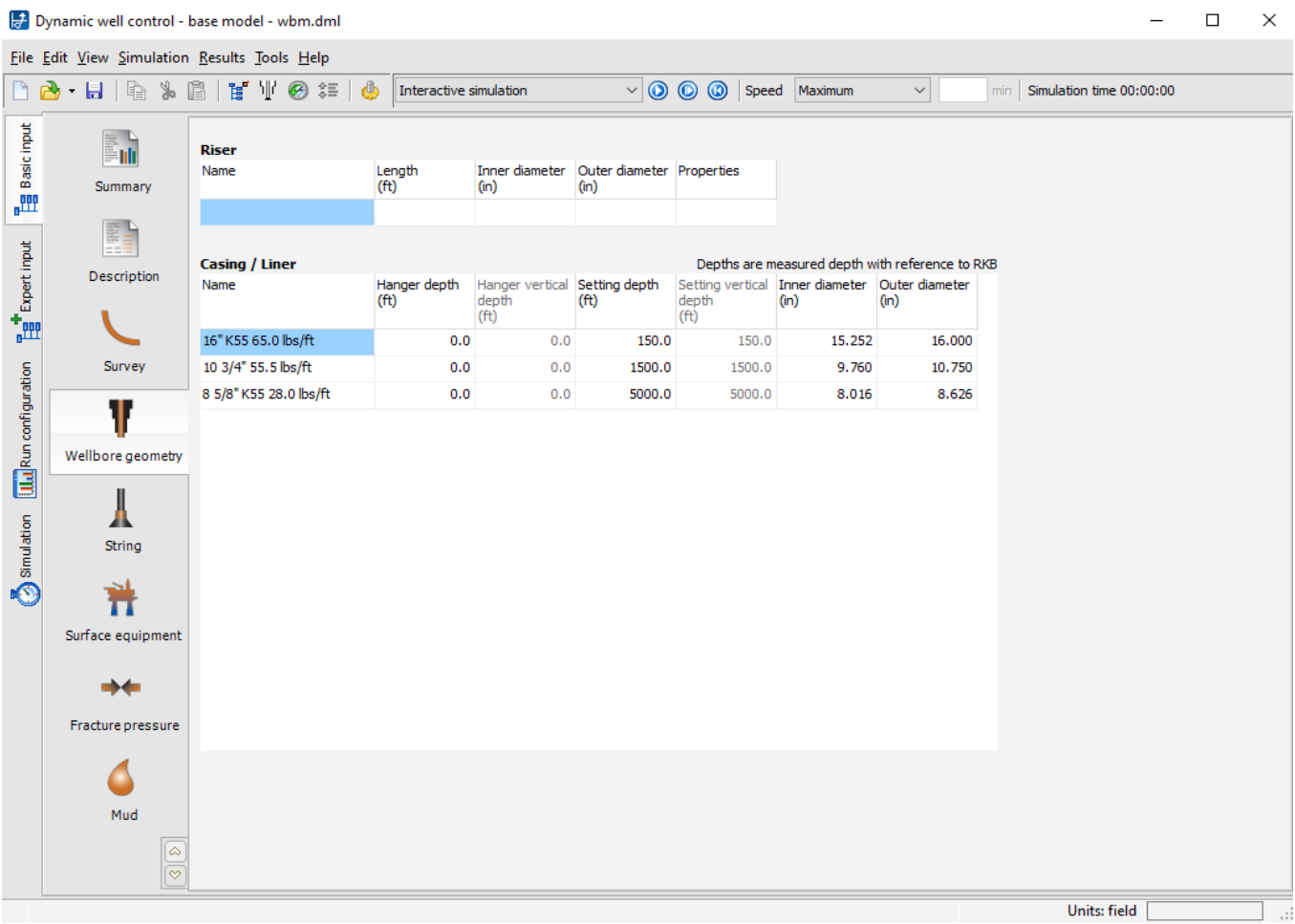

Figure B 3: Wellbore Geometry

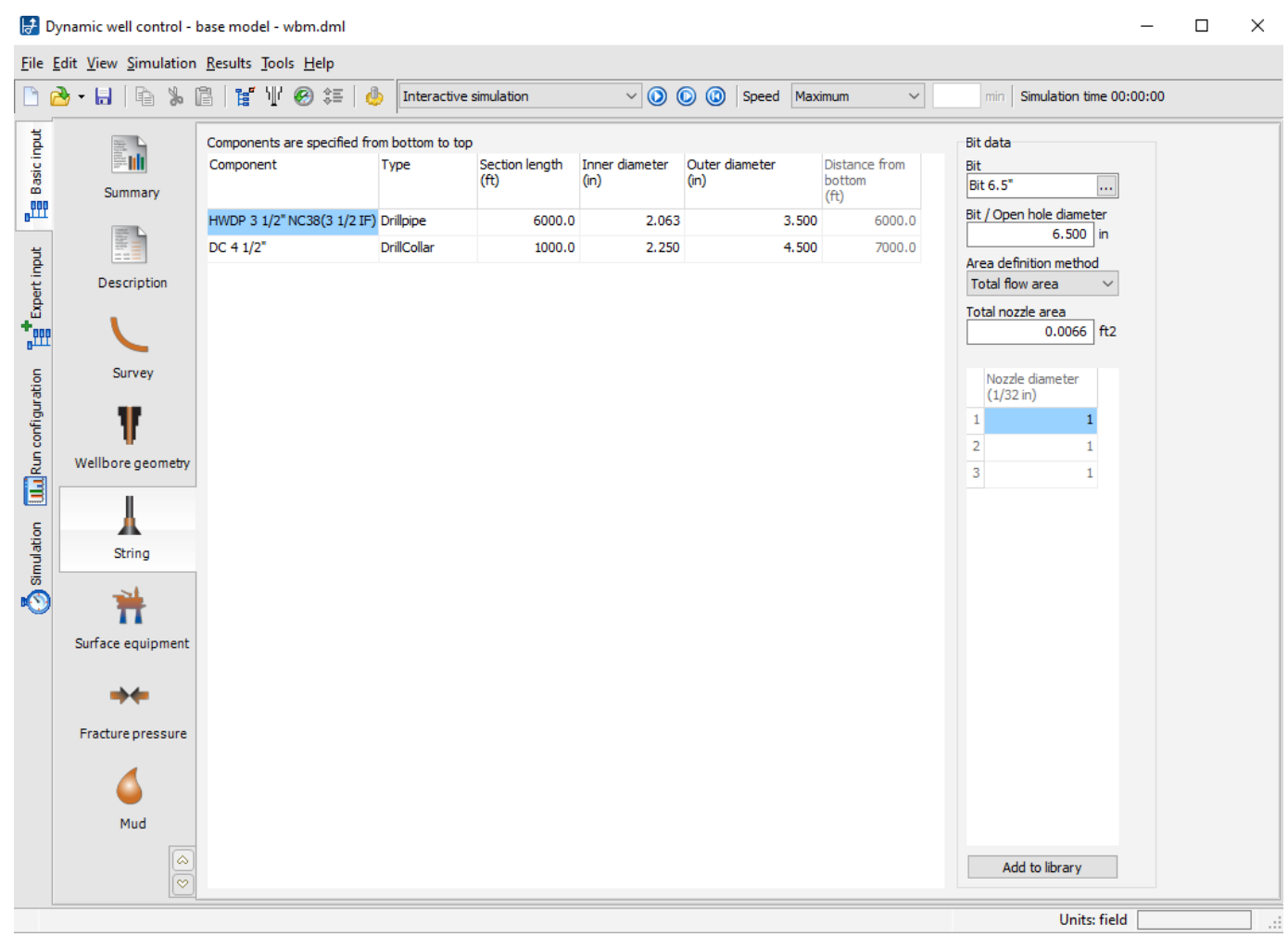

Figure B 4: String 


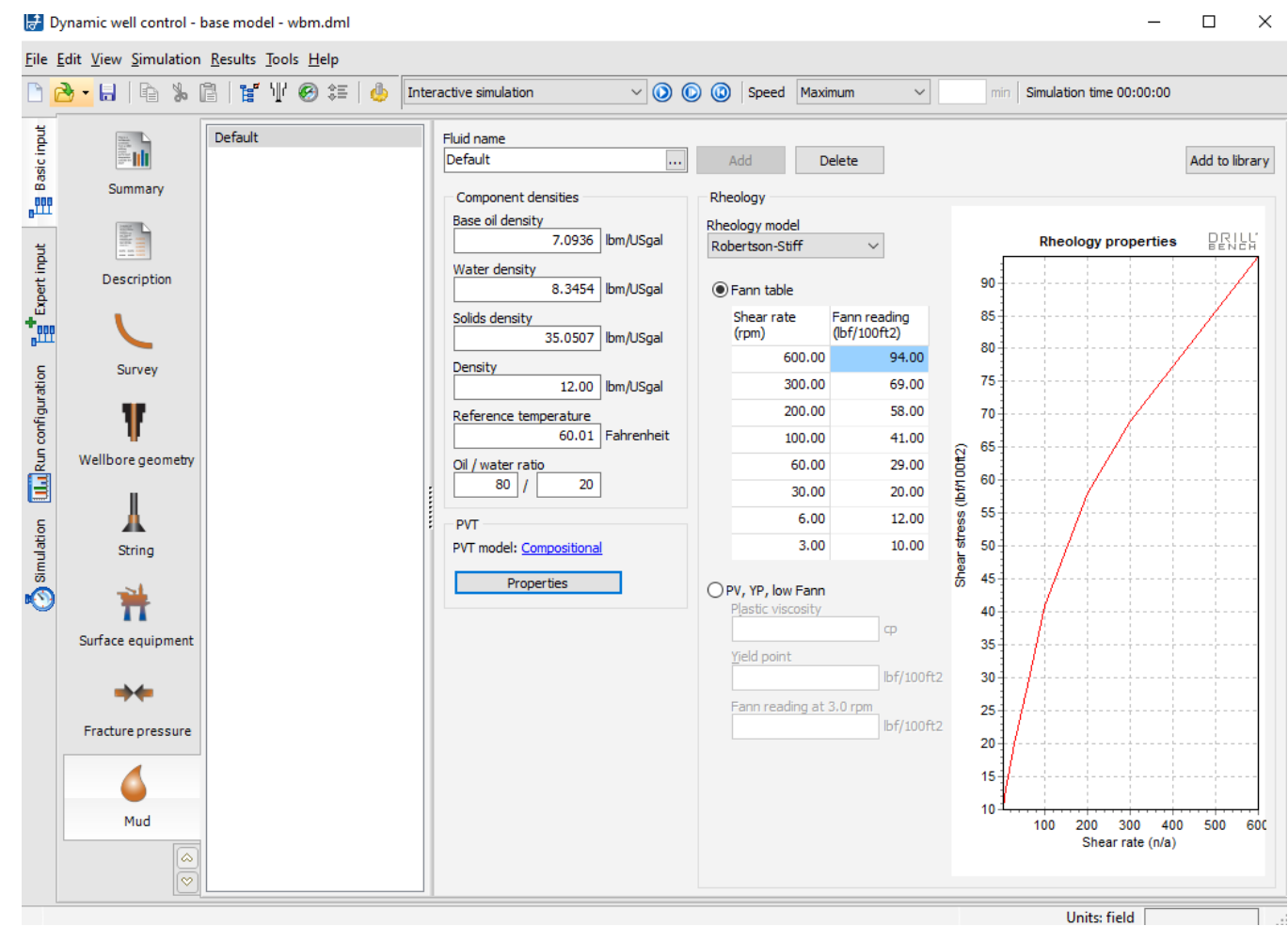

Figure B 5: Mud Inputs

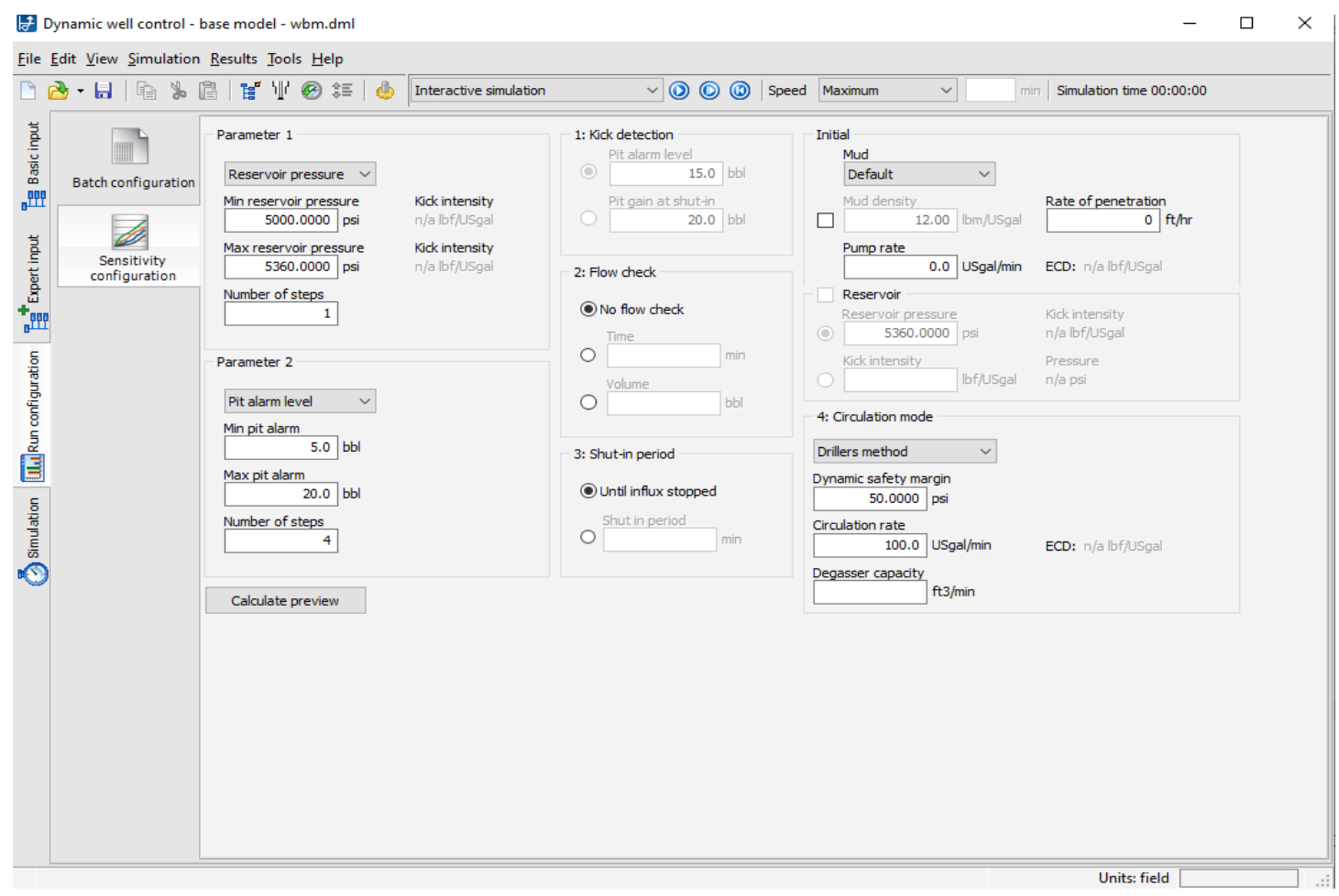

Figure B 6: Calculate Preview 
[न] Uynamic well control - base model - wbm.amı

File É dit View Simulation Results Tools Help

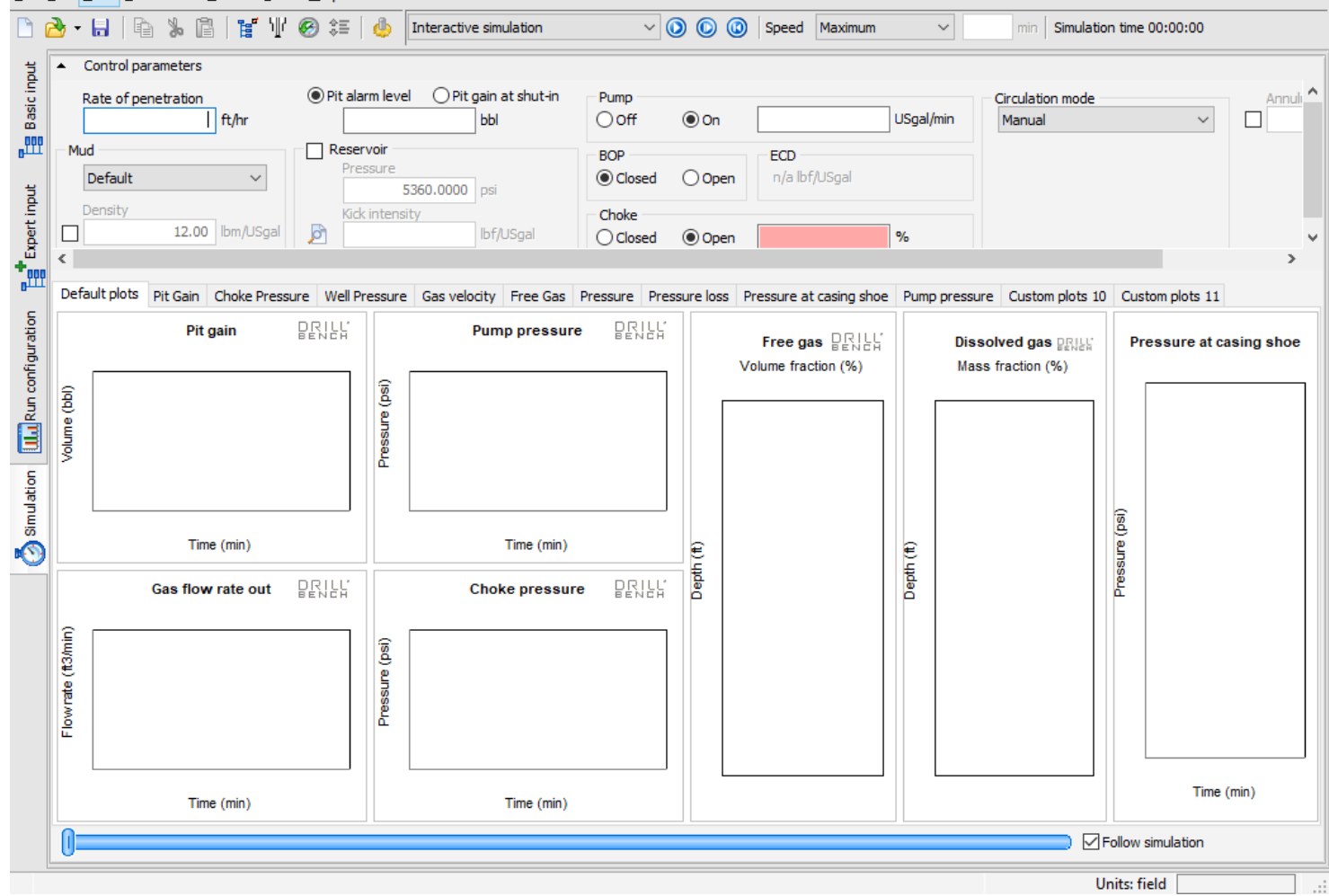

Figure B 7: Result Page 